\title{
Characterization and Identification of Super-Effective Thermal Fire Extinguishing Agents-First Annual Report
}

William M. Pitts ${ }^{1}$, Jiann C. Yang ${ }^{1}$, Marcia L. Huber ${ }^{2}$, and Linda G. Blevins ${ }^{1}$

1Building and Fire Research Laboratory

Gaithersburg, Maryland 20899

${ }^{2}$ Chemical Sciences and Technology Laboratory

Boulder, CO 80303

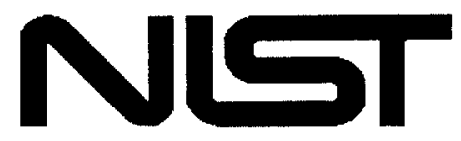

United States Department of Commerce

Technology Administration

National Institute of Standards and Technology

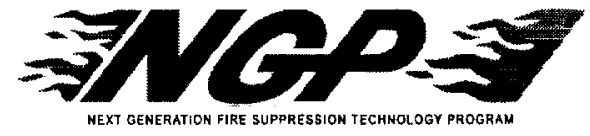




\section{TABLE OF CONTENTS}

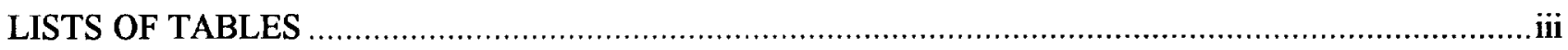

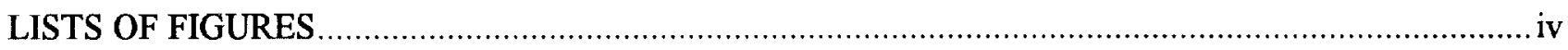

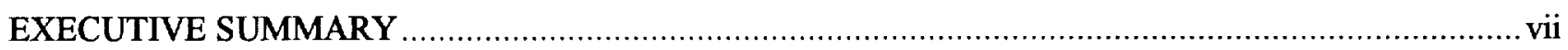

I. INTRODUCTION

II. SCREENING OF THERMOPHYSICAL PROPERTIES DATABASES FOR SUPER EFFECTIVE

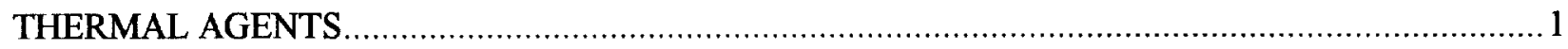

III. DETAILED CHEMICAL KINETIC MODELING OF EXTINGUISHMENT BEHAVIOR FOR THERMAL AGENTS IN METHANE/AIR DIFFUSION FLAMES …....................................... 6

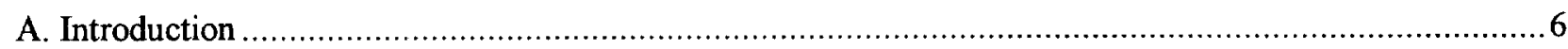

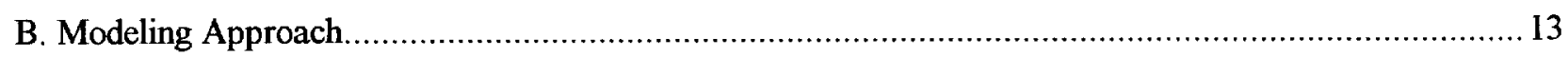

C. Effects of Nitrogen Addition on Diffusion Flame Extinction and Extinguishment..........................21

D. Effects of Argon Addition on Extinction and Extinguishment of Methane Diffusion Flames Burning in

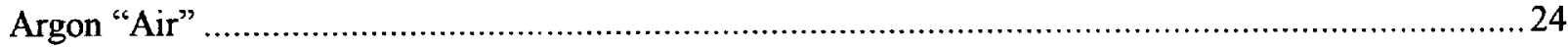

E. Calculated Extinguishing Concentrations for Several Gaseous Thermal Agents ................................22

F. Effects of Dilution and Heat Extraction Location Relative to the Flame Front on Extinction and

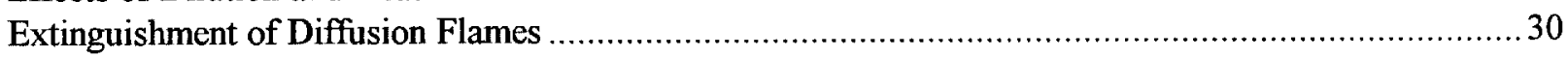

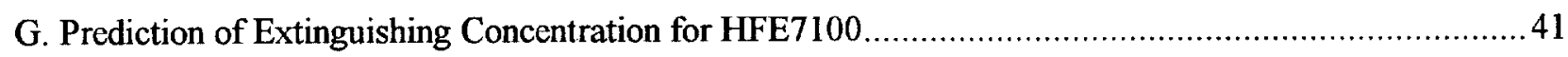

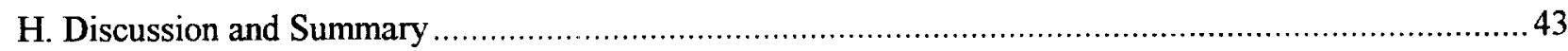

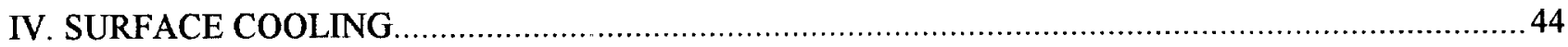

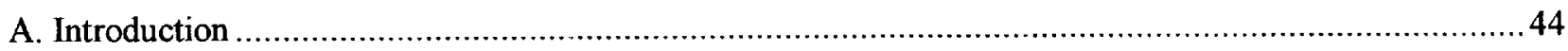

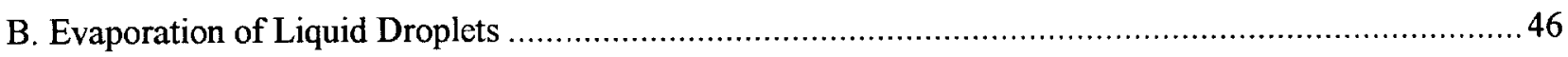

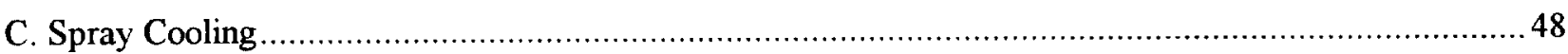

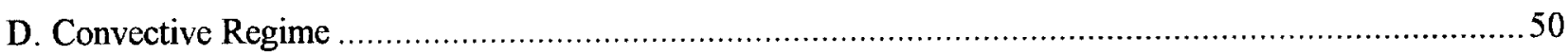

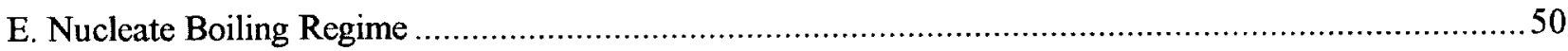

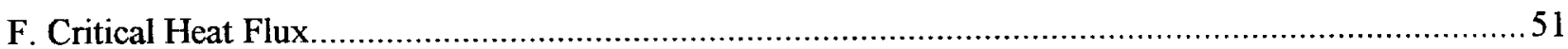




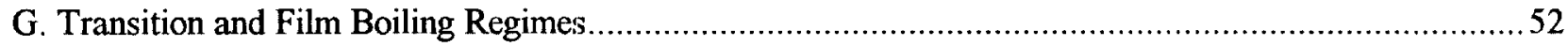

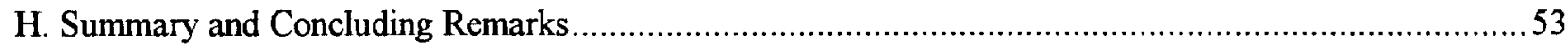

V. RECOMMENDATIONS FOR ADDITIONAL STUDY ............................................................ 54

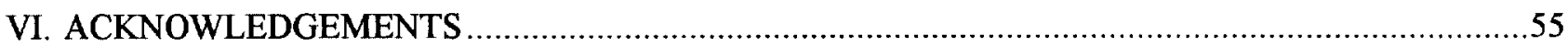

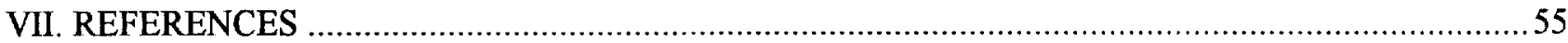




\section{LIST OF TABLES}

Table 1. Family Types in the DIPPR Database

.2

Table 2. Results of Search for Compounds with High Heat of Vaporization at the Normal Boiling Point ........4

Table 3. References for Property Data (Critical Point, Normal Boiling Point, Heat of Vaporization, Liquid Heat Capacity)

Table 4. Results of Search for Compounds with High Liquid Phase Heat Capacities at the Normal Boiling Point

Table 5. Results of Search for Compounds with High $\Delta H^{\text {Total }}$ (Molar Basis) ......................................... 7

Table 6. Results of Search for Compounds with High $\Delta H^{\text {Total }}$ (Mass Basis) .........................................8

Table 7. Some Parameters Used in Most Oppdif Calculations ..................................................... 16

Table 8. Various Measures of Strain Rate Calculated for the Methane/Air Diffusion Flame at Extinction ....20

Table 9. Extinguishing Concentrations (Mole Fraction) of Thermal Agents .........................................22 


\section{LIST OF FIGURES}

Figure 1. Maximum flame temperature plotted as a function of the equal fuel and air velocity magnitudes for a methane/air opposed flow diffusion flame.

Figure 2. Calculated strain rates, $a$, are plotted as a function of distance from the fuel exit for low exit velocity magnitudes ( $25 \mathrm{~cm} / \mathrm{s}$ for fuel and air) and for a condition very close to extinction (320.1 $\mathrm{cm} / \mathrm{s})$.

Figure 3. The maximum flame temperature is plotted against a characteristic local strain rate, $\left|a_{o}\right|$, defined to be equal to the highest absolute value of strain rate on the air side observed outside of the boundary layer associated with the flame.

Figure 4 Mixture fraction is plotted as a function of distance from the fuel exit for low exit velocity magnitudes $(25 \mathrm{~cm} / \mathrm{s}$ for fuel and air) and for a condition very close to extinction $(320.1 \mathrm{~cm} / \mathrm{s})$

Figure 5. Calculated scalar dissipation rates, $\chi$, are plotted as a function of distance from the fuel exit for low exit velocity magnitudes ( $25 \mathrm{~cm} / \mathrm{s}$ for fuel and air) and for a condition very close to extinction $(320.1 \mathrm{~cm} / \mathrm{s})$.

Figure 6. Values of maximum flame tempcraturc for opposed-flow methane/air diffusion flames are plotted as a function of $\chi_{s}$ which is varied by changing the velocities of the fuel and air. Extinction is calculated to occur for $\chi_{\mathrm{s}}=20.7 \mathrm{~s}^{-1}$

Figure 7. Maximum calculated flame temperatures are plotted against methane and oxidizer exit velocity magnitudes for a series of methane/air opposed flow diffusion flames diluted with nitrogen. Symbols correspond to the percentage of added nitrogen.

Figure 8. Ratios for the indicated measures of conditions at flame extinction are plotted as a function of the percentage of nitrogen added to the air for methane/air flames.

Figure 9. Maximum calculated flame temperatures are plotted against methane and oxidizer flow velocity magnitudes for a series of methane/argon "air" opposed flow diffusion flames diluted with argon. Symbols correspond to the percentage of added argon.

Figure 10. Maximum calculated flame temperatures are plotted against methanc and oxidizcr flow velocity magnitudes for a series of methane/air opposed flow diffusion flames diluted with argon. Symbols correspond to the percentage of added argon.

Figure 11. Maximum calculated flame temperatures are plotted against methane and oxidizer flow velocity magnitudes for a series of methane/air opposed flow diffusion flames diluted with helium.

Symbols correspond to the percentage of added helium.

Figure 12. Maximum calculated flame temperatures are plotted against methane and oxidizer flow velocity magnitudes for a series of methane/air opposed flow diffusion flames diluted with carbon dioxide. Symbols correspond to the percentage of added carbon dioxide. 
Figure 13. Maximum calculated flame temperatures are plotted against methane and oxidizer flow velocity magnitudes for a series of methane/air opposed flow diffusion flames diluted with water vapor. Symbols correspond to the percentage of added water vapor.

Figure 14. Values of maximum flame temperature at extinction are plotted as a function of the corresponding fuel and oxidizer velocity magnitudes for a range of concentrations of various thermal agents.

Figure 15. Values of maximum flame temperature at extinction are plottcd as a function of the corresponding global strain rates, $a_{g}$, for a range of concentrations of various thermal agents.....

Figure 16. Values of maximum flame temperature at extinction are plotted against the corresponding characteristic local strain rates, $\left|a_{o}\right|$, defined as the highest absolute value of strain rate observed outside of the boundary layer on the oxidizer side of the flame, for a range of concentrations of various thermal agents.

Figure 17. Maximum flame temperatures at extinction for $\mathrm{N}_{2}, \mathrm{Ar}, \mathrm{He}$, and $\mathrm{CO}_{2}$ as a function of the corresponding fuel and oxidizer velocity magnitudes are fit by two piecewise fourth order polynomials (solid line).

Figure 18. The maximum temperature at extinction for counterflow methane flames is plotted as a function of the percentage of a thermal agent added to air divided by the amount calculated to be required for flame extinguishment.

Figure 19. Maximum calculated flame temperatures are plotted against methane and oxidizer flow exit velocity magnitudes for a series of methane/air opposed flow diffusion flames diluted with a surrogate agent similar to argon, but with $C_{p}=0$. Symbols correspond to the percentage of surrogate agent added.

Figure 20. Values of maximum flame temperature at extinction are plotted as a function of fuel and oxidizer extinction velocity magnitudes for a range of concentrations of argon and a similar surrogate agent having $C_{p}=0$. The solid line is the result of the regression fits shown in Figure 17 .

Figure 21. Temperature is plotted as a function of distance from the fuel exit for methane flames burning in air and air mixed with $60 \%$ of a diluent having similar properties to Ar, but with zero heat capacity. Fuel and air exit velocity magnitudes are $25 \mathrm{~cm} / \mathrm{s}$ for both flames.

Figure 22. Calculated methane and oxygen mole fractions are shown on a semi-log plot as a function of distance from the fuel exit for methane flames burning in air (open symbols) and air mixed with $60 \%$ of a diluent having similar properties to Ar, but with zero heat capacity. Fuel and air exit velocity magnitudes are $25 \mathrm{~cm} / \mathrm{s}$ for both flames.

Figure 23. Calculated flame temperature is plotted as a function of distance from the fuel exit for methane/air diffusion flames where the oxidizer is diluted with $5 \%$ of either argon or the hypothetical agent $\mathrm{X}$ which reacts to form $Y$ with $E_{a}=25.1 \mathrm{~kJ} / \mathrm{mole}$ and $\Delta H_{X-Y}=96.1 \mathrm{~kJ} / \mathrm{mole}$. Methane and oxidizer exit velocity magnitudes are $25 \mathrm{~cm} / \mathrm{s}$.

Figure 24. The mole fractions of $\mathrm{X}$ and $\mathrm{Y}$ are plotted as a function of distance from the fuel exit for a methane flame burning in air with $5 \%$ added $\mathrm{X}$. X reacts to form Y with $E_{a}=25.1 \mathrm{~kJ} / \mathrm{mole}$ and 
$\Delta H_{X-Y}=96.1 \mathrm{~kJ} /$ mole. The spatial variation of temperature is also shown as the solid line.

Methane and oxidizer exit velocity magnitudes are $25 \mathrm{~cm} / \mathrm{s}$.

Figure 25. The mole fractions of $X$ and $Y$ are plotted as a function of distance from the fuel exit for a methane flame burning in air with $5 \%$ added $X$. X reacts to form $Y$ with $E_{a}=58.6 \mathrm{~kJ} / \mathrm{mole}$ and $\Delta H_{X-Y}=96.1 \mathrm{~kJ} / \mathrm{mole}$. The spatial variation of temperature is also shown as the solid line. Methane and oxidizer exit velocity magnitudes are $25 \mathrm{~cm} / \mathrm{s}$.

Figure 26. The mole fractions of $\mathrm{X}$ and $\mathrm{Y}$ are plotted as a function of distance from the fuel exit for a methane flame burning in air with $5 \%$ added $\mathrm{X}$. $\mathrm{X}$ reacts to form $\mathrm{Y}$ with $E_{a}=83.7 \mathrm{~kJ} / \mathrm{mole}$ and $\Delta H_{X \rightarrow Y}=96.1 \mathrm{~kJ} / \mathrm{mole}$. The spatial variation of temperature is also shown as the solid line. Methane and oxidizer exit velocity magnitudes are $25 \mathrm{~cm} / \mathrm{s}$.

Figure 27. Values of maximum flame temperature for methane flames burning in air diluted with $5 \% \mathrm{X}$ are plotted as a function of the energy of activation for the conversion of $\mathrm{X}$ to $\mathrm{Y}$. Methane and oxidizer exit velocity magnitudes are $25 \mathrm{~cm} / \mathrm{s}$.

Figure 28. Maximum calculated flame temperatures are plotted against methane and oxidizer exit velocity magnitudes for a series of methane/air opposed flow diffusion flames diluted with agent $\mathrm{X}$ which reacts to form $\mathrm{Y}$ with $\mathrm{E}_{\mathrm{a}}=41.8 \mathrm{~kJ} / \mathrm{mole}$ and $\Delta H_{X-Y}=96.1 \mathrm{~kJ} / \mathrm{mole}$. Symbols correspond to the pcrcentage of added $X$.

Figure 29. Maximum calculated flame temperatures are plotted against methane and oxidizer exit flow velocity magnitudes for a series of methane/air opposed flow diffusion flames diluted with argon and agent $X\left(E_{a}=41.8 \mathrm{~kJ} / \mathrm{mole}\right.$ and $\left.\Delta H_{X-Y}=96.1 \mathrm{~kJ} / \mathrm{mole}\right)$.

Figure 30. Maximum calculated flame temperatures are plotted against methane and oxidizer exit flow velocity magnitudes for a series of methane/air opposed flow diffusion flames diluted with agent $\mathrm{X}$ which reacts to form $\mathrm{Y}$ with $E_{a}=41.8 \mathrm{~kJ} / \mathrm{mole}$ and $\Delta H_{X-Y}=192.1 \mathrm{~kJ} / \mathrm{mole}$. Symbols correspond to the percentage of added $\mathrm{X}$.

Figure 31. Values of maximum flame temperature at extinction are plotted as a function of fuel and oxidizer exit velocity magnitudes for air diluted with a range of concentrations of argon and surrogate agent $\mathrm{X}$ having $\Delta H_{X-Y}=96.1 \mathrm{~kJ} / \mathrm{mole}$ or $192.1 \mathrm{~kJ} / \mathrm{mole}$. The solid line is the result of the regression fits shown in Figure 17.

Figure 32. Maximum calculated flame temperatures are plotted against methane and oxidizer exit velocity magnitudes for a series of methane/air opposed flow diffusion flames diluted with $\mathrm{C}_{4} \mathrm{~F}_{9} \mathrm{OCH}_{3}$. Symbols correspond to the percentage of added $\mathrm{C}_{4} \mathrm{~F}_{9} \mathrm{OCH}_{3}$.

Figure 33. Droplet evaporation time as a function of initial droplet diameter.

Figure 34. An illustration of a typical boiling curve associated with quenching of a hot surface 49

Figure 35. Calculated boiling curve in the convective regime. 51

Figure 36. Calculated boiling curve in the transition and film boiling regimes. 53 


\section{EXECUTIVE SUMMARY}

The use of halons for fire fighting is being phased out due to their deleterious effects on stratospheric ozone. This report summarizes the first-year findings of a three-year study designed to characterize and identify super-effective thermal firc-fighting agents as possible replacements for these widely used compounds. Three distinct aspects related to the effectiveness of potential thermal agents have been considered. First, existing thermodynamic databases maintained by NIST have been searched in order to identify chemical compounds which are predicted to extract large amounts of heat from a combustion zone. Second, detailed chemical kinetic modeling has been used to characterize the effects of thermal agents on an idealized flame system, namely, a methane/air counterflow diffusion flame. Third, empirical heat transfer correlations for spray cooling of a surface have been used to estimate the efficiencies of surface cooling by thermal agents.

The database search used two primary sources-the Design Institute for Physical Properties database containing 1458 compounds from 83 family types and a smaller database, REFPROP, containing 43 compounds which is tailored to refrigerant applications. Additional substances were included which are not well represented in these databases. Compounds having 1) high heats of vaporization, 2) liquid-phase heat capacities, and 3) total heat absorption due to phase changes (if applicable), heating of a liquid (if applicable), and the heating of the gas phase to combustion temperatures were identified. The results are reported in tables of compounds ordered in terms of their ability to extract heat.

Detailed chemical kinetic modeling of opposed flow methane diffusion flames burning in air and air diluted with thermal agents has been used to obtain insights into the effectiveness of thermal agents and their mechanisms of flame extinction. Values of fuel and air velocities which induce flame extinction were determined as a function of agent concentration. Comparison of the calculated results for burning in two types of oxidizer, air diluted with added nitrogen and a synthetic "air" having nitrogen replaced by argon and diluted with additional argon, with corresponding experimental measurements of the concentrations necessary to extinguish a counterflow diffusion flame showed that extinguishment occurs when the maximum calculated flame temperature drops to approximately $1550 \mathrm{~K}$ for fuel and oxidizer velocities of a few tens of $\mathrm{cm} / \mathrm{s}$. Using this result, extinguishing calculations were then estimated for carbon dioxide, argon, helium, and water. Published experimental extinguishment concentrations for these thermal agents are unavailable for methane flames, but a strong correlation was found with agent extinguishing concentrations determined in cup burner tests using liquid heptane as fuel. A series of calculations were performed for one of compounds identified as likely to be particularly cffective at extracting heat during the database search, methoxy-nonafluorobutane. An extinguishing concentration of $5.5 \%$ was predicted, which is close to unpublished experimental cup burner values of $6.1 \%$

An advantage of detailed kinetic modeling studies is that surrogate agents having properties which are not physically realizable can be used to investigate specific details concerning extinguishment. A surrogate agent was specified which reacted over different temperature ranges to extract a predetermined amount of heat. The calculations showed that the effectiveness of this agent was independent of the location of heat extraction relative to the flame zone. In a second series of calculations a surrogate agent was used to isolate the role of dilution on extinguishment. When the agent, which was incapable of extracting heat, was added to the air, much higher concentrations were required to extinguish the flame than when heat was extracted. Details of the calculations revealed that extinguishment ultimately occurred due to oxygen passing through the flame zone.

Calculations of droplet evaporation times using the classical $\mathrm{d}^{2}$-law for the five fluids (water, lactic acid, $\mathrm{C}_{3} \mathrm{~F}_{5} \mathrm{H}_{3} \mathrm{O}$, HFE7100, and $\mathrm{R} 338$ mccq) identified as having the highest latent heat of vaporization (per unit mass) by the database searches were performed as part of the surface cooling studies. Empirical heat transfer 
correlations from the spray surface quenching literature were used to assess the surface cooling characteristics of these fluids for various heat transfer regimes. Based on these calculations, water and lactic acid appear to be more effective than the other three fluids for surface cooling applications.

Recommendations are included for additional studies during the second year of the project. 


\section{INTRODUCTION}

The usc of halons for firc fighting is being phased out due to their deleterious effects on stratospheric ozone. This report summarizes the first-year findings of a three-year study designed to characterize and identify super-effective thermal fire-fighting agents as possible replacements for these effective compounds. "Thermal" agents refer to compounds which act simply by extracting heat from a flame zone and lowering the temperature to a point where combustion can no longer be sustained. These types of agents should be contrasted with "chemical" agents which generate active chemical species (e.g., the bromine atoms generated by halons) which interfere with the radical chain branching mechanisms required to sustain combustion.

There are a number of endothermic physical processes which can extract heat from a gaseous flame zone, thus lowering the temperature and ultimately leading to flame extinguishment. These include simple heating (i.e., heat capacity) of an agent, phase changes such as vaporization of a liquid or sublimation of a solid, endothermic molecular decomposition (note that this process is classed as a physical process as long as the initial agent and its products do not participate in the combustion chemistry), and simple dilution which can modify flame temperatures by spreading the heat release over larger volumes and by slowing three-body reactions by lowering species collision rates. The flame temperature is also expected to be a function of the thermal diffusivity of an agent.

Another potentially effective way for thermal agents to extinguish a flame fueled by liquids or solids is to interact with the fuel surface to lower the temperature to a point where the fuel generation rate is insufficient to maintain combustion. This mechanism for fire extinguishment has not been extensively studied, and the physical properties which determine the effectiveness of an agent operating in this mode are not known.

During the first year of the investigation three distinct aspects related to the effectiveness of potential thermal agents have been considered. First, existing thermodynamic data bases maintained by NIST have been searched in order to identify chemical compounds which are predicted to extract large amounts of heat as the

temperature is raised. Second, detailed chemical kinetic modeling has been used to characterize the effects of thermal agents on an idealized flame system, namely, a methane/air counterflow diffusion flame. Third, empirical heat transfer correlations for spray cooling of a surface have been used to estimate the efficiencies of surface cooling by thermal agents which are expected to be very efficient at extracting heat from combustion regions.

The following three sections summarize the findings of each of these approaches. The results are then used as the basis for recommending that the investigation be carried into a second year in order to further validate the current findings and to provide initial laboratory testing of several potentially effective thermal agents.

\section{SCREENING OF THERMOPHYSICAL PROPERTIES DATABASES FOR SUPER EFFECTIVE THERMAL AGENTS}

The objective of this sub-task was to search thermophysical property databases and identify substances that may be suitable candidates for fire extinguishing agents based on their thermophysical properties. We identified two thermophysical propcrty databases to search. The first was the DIPPR (Design Institute for Physical Properties) Database, version 9.02 [1] which contained 1458 substances from 83 family types. The families are listed in Table 1. The second database, REFPROP, Version 5, [2] is a much smaller database 


\section{Table 1. Family Types in the DIPPR Database}

1 n-Alkanes
2 Methylalkanes
3 Dimethylalkanes
4 Other alkanes
5 Cycloalkanes
6 Alkylcyclopentanes
7 Alkylcyclohexanes
8 Multi-ring cycloalkanes
9 1-alkynes
10 , $3,4-a l k e n e s$
11 Methylalkenes
12 Ethyl \& higher alkenes
13 Cycloalkenes
14 Dialkenes
15 Alkynes
16 n-alkylbenzenes
17 Other alkylbenzenes
18 Other monoaromatics
19 Napthalenes
20 other condensed rings
21 Diphenyl/polyaromatics
22 Terpenes
23 Other hydrocarbon rings
24 Inorganic gases
25 Aldehydes
26 Ketones
27 n-alcohols
28 other alcohols (aliph.)

29 Cycloaliphatic alcohols

30 Aromatic alcohols

31 Polyols

32 n-aliphatic acids

33 Other aliphat acids

34 Dicarboxylic acids

35 Aromatic carbox. acids

36 Anhydrides

37 Formates

38 Acetates

39 Propionates \& Butyrates

40 Other sat. aliph esters

41 Unsat. aliphatic esters

42 Aromatic esters

43 Aliphatic ethers

44 Other Ethers/Diethers

45 Epoxides

46 Peroxides

$47 \mathrm{C} 1 / \mathrm{C} 2$ Aliphatic chlorid

48 C3 \& higher aliph. chlo

49 Aromatic chlorides

$50 \mathrm{C}, \mathrm{H}, \mathrm{Br}$ compounds

$51 \mathrm{C}, \mathrm{H}, \mathrm{I}$ compounds

$52 \mathrm{C}, \mathrm{H}, \mathrm{F}$ compounds

53 C, H multihalog cmps

54 n-Aliphatic prim. amine

55 other aliphatic amines

56 Aromatic amines
57 Other amines, imines

58 Nitriles

$59 \mathrm{C}, \mathrm{H}, \mathrm{NO} 2$ compounds

60 Isocyanates/Diisocyana

61 Mercaptans

62 Sulfides/Theophenes

63 Polyfunctional acids

64 Polyfunctional esters

65 oth. Polyfunctional C,

66 Polyfunctional nitrile

67 Nitroamines

68 Polyfunc. Amides/Amine

69 Polyfunctional $\mathrm{C}, \mathrm{H}, \mathrm{O}, \mathrm{N}$

70 Polyfunctional $\mathrm{C}, \mathrm{H}, \mathrm{O}, \mathrm{S}$

71 Polyfunctional $\mathrm{C}, \mathrm{H}, \mathrm{O}, \mathrm{h}$

72 Polyfunc $\mathrm{C}, \mathrm{H}, \mathrm{N}$, halide

73 Other Polyfunc. Organi

74 Elements

5 Silanes/Siloxanes

76 Organic-Inorganic

77 Inorganic acids

78 Inorganic bases

79 Organic salts

80 Sodium salts

81 Other inorganic salts

82 Inorganic halides

83 Other inorganics

tailored to alternative refrigerants. It contains 43 refrigerants including many candidates for replacing HCFCs. Some are fluorinated ethers (E134, E245) that are not present in the DIPPR database.

In addition, we wanted to include represcntative substances from some families of chemicals not well represented in existing thermophysical property databases, such as fluorinated ethers, alcohols and amines. The fluorinated ethers are especially interesting since their atmospheric lifetimes may be significantly lower than those of chlorofluorocarbons. [3] Some of these have been identified as possible replacements for blowing agents, refrigerants, fire suppression agents, and as solvents. $[4,5,6,7,8,9]$ We selected several cyclic fluorinated ether compounds (fluorinated oxiranes, oxetanes and furans), some non-cyclic methyl ethers (HFE116, HFE125), fluorinated methyl ethyl ethers with two or fewer hydrogen atoms (HFE 227me, $\mathrm{HFE} 236 \mathrm{me})$, and some larger fluorinated ethers--perfluorodimethoxymethane $\left(\mathrm{CF}_{3} \mathrm{OCF}_{2} \mathrm{OCF}_{3}\right)$, perfluoropropyltrifluoromethyl ether $\left(\mathrm{CF}_{3} \mathrm{OCF}_{2} \mathrm{CF}_{2} \mathrm{CF}_{3}\right)$, heptafluoropropyl-1,2,2,2-tetrafluoroethyl ether $\left(\mathrm{CF}_{3} \mathrm{CHFOCF}_{2} \mathrm{CF}_{2} \mathrm{CF}_{3}\right)$ and methoxy-nonafluorobutane $\left(\mathrm{C}_{4} \mathrm{~F}_{9} \mathrm{OCH}_{3}, \mathrm{HFE7100}\right)$. In addition to the fluorinated ethers, we added two fluorinated amines to the list of substances to search and also the alternative refrigerant $\mathrm{HFC}-338 \mathrm{mccq} \quad\left(\mathrm{CH}_{2} \mathrm{FCF}_{2} \mathrm{CF}_{2} \mathrm{CF}_{3}\right)$ and the fluorinated alcohol 2,2,3,3,3-pentafluoropropanol $\left(\mathrm{CF}_{3} \mathrm{CF}_{2} \mathrm{CH}_{2} \mathrm{OH}\right)$.

The physical properties that are important for thermal agents are high latent heats of vaporization and high liquid and vapor heat capacities. We first searched the databases and the additional fluids mentioned above for high latent heats of vaporization. For fluids where data were unavailable, we estimated the critical properties using the NIST Structures and Properties program [10] and then estimated the latent heats using the approach of Fishtine [11]. We then eliminated substances on the list that either were identified as flammable, toxic, or 
had known ozone depletion problems. However, we did not have complete information on toxicity so some substances that appear on our final list will need to be investigated further to determine if there are potential deleterious health effects. We also did not use global warming potential or electrical conductivity as screening parameters. If one considers global warming potential, then the fully fluorinated (perfluorinated) alkanes such as R218 and decafluorobutane would probably have to be ruled out. We used information in the DIPPR database on flash points and upper and lower flammability limits. The DIPPR database does not contain any information on toxicity or other health effects. For this information we used manufacturers safety data sheets and Hawley [12]. We also used the web site at http://chemfinder.camsoft.com/ that gives information on ozone depletion and global warming.

Table 2 gives the list of compounds that remained, in order of decreasing heat of vaporization at the normal boiling point and includes R13Bl and water for reference. Table 3 identifies the source of the property data for critical points, normal boiling points, latent heat of vaporization, and liquid heat capacity. The general trend shown in Table 2 is quite predictable--the larger molecules have higher boiling points and higher heats of vaporization. Lactic acid is the only unusual fluid that appears is Table 2--all other fluids are basically $\{\mathrm{C}, \mathrm{F}, \mathrm{H}\},\{\mathrm{C}, \mathrm{F}\}$ or $\{\mathrm{C}, \mathrm{F}, \mathrm{O}\}$ compounds. Lactic acid, $\mathrm{CH} 3 \mathrm{CH}(\mathrm{OH}) \mathrm{COOH}$, is a strong irritant to the skin and corrosive in concentrated form and would not be a suitable agent. However, it may be at least partially soluble in fluorinated ethers such as HFE134 or in alternative refrigerants such as R227ea. It would be interesting to test a mixture of lactic acid with some of the other fluids on the list to see if a small amount of dissolved lactic acid would enhance the latent heat of vaporization.

The second property we searched on was liquid heat capacity at the normal boiling point. When data were unavailable, the liquid heat capacity was estimated using the Chueh-Swanson method. [13] This method provides the liquid heat capacity at $20{ }^{\circ} \mathrm{C}$ based on the structure of a compound. The results are shown in Table 4 in order of decreasing liquid-phase heat capacity at the normal boiling point and include R13BI and water for reference. Again, any compounds that were known to be flammable or toxic or to have known ozone depletion problems were eliminated. Table 4 indicates the same trend that was seen in Table 2, i.e., that larger compounds have higher boiling points and higher heats of vaporization and heat capacities. Also, in general, the ethers have higher boiling points and higher heats of vaporization at their normal boiling points than their alkane analogs. The fluorinated alcohol has a high boiling point due to the hydrogen bonding that occurs in alcohols.

In addition to looking at the latent heat of vaporization and the liquid heat capacity at the normal boiling point, one may also look at the total heat involved in going from the fluid at room temperature up to a temperature of $1400 \mathrm{~K}$, which was selected as a representative combustion temperature. Other choices are possible including the value of $1550 \mathrm{~K}$ identified later by the detailed chemical kinetic modeling. The actual valuc uscd is unlikely to affect the relative ordering of agents. The total heat absorbed consists of three contributions,

$$
\Delta H^{\text {Total }}=\Delta H_{1}+\Delta H_{2}+\Delta H_{3}
$$

where the first contribtion, $\Delta H_{l}$, is the heat involved in taking the liquid from room temperature up to the normal boiling point,

$$
\Delta H_{1}=\int_{298 K}^{T_{b}} C_{p}^{\text {liquid }} d T
$$

Since the heat capacity of a liquid does not change significantly over a small temperature range, we used the value of liquid heat capacity at the normal boiling point. If this was unavailable, we estimated the liquid phase 
Table 2. Results of Search for Compounds with High Heat of Vaporization at the Normal Boiling Point

\begin{tabular}{|c|c|c|}
\hline Compound & $T_{b}(\mathrm{~K})$ & $\Delta H_{v a p}(\mathrm{~kJ} / \mathrm{mol})$ \\
\hline lactic acid, $\mathrm{C}_{3} \mathrm{H}_{6} \mathrm{O}_{3}$ & 455 & 59.2 \\
\hline water & 373.1 & 40.0 \\
\hline 2,2,3,3,3-pentafluoropropanol, $\mathrm{C}_{3} \mathrm{~F}_{5} \mathrm{H}_{3} \mathrm{O}$ & 353.15 & 37.6 \\
\hline perfluoro-2-butyltetrahydrofuran, $\mathrm{C}_{8} \mathrm{~F}_{16} \mathrm{O}$ & 375.15 & 35.4 \\
\hline methoxy-nonafluorobutane, HFE7100 & 334.0 & 30.3 \\
\hline heptafluoropropyl-1,2,2,2-tetrafluoroethyl ether & 315.2 & 29.0 \\
\hline difluoromethyl-1,2,2,2-tetrafluoroethyl ether, E236me & 296.5 & 26.9 \\
\hline $1,1,1,2,2,3,3,4$-octafluorobutane, R338mccq & 301 & 26.8 \\
\hline tris(difluoromethyl)amine, $\mathrm{C}_{3} \mathrm{H}_{3} \mathrm{~F}_{6} \mathrm{~N}$ & 275 & 25.8 \\
\hline 1,1,2,2-tetrafluorodimethylether, E134 & 279.4 & 25.4 \\
\hline $1,1,1,2,3,3$-hexafluoropropane, $\mathrm{R} 236 \mathrm{ea}$ & 279.7 & 25.1 \\
\hline perfluorotrimethylamine, $\mathrm{C}_{3} \mathrm{~F}_{9} \mathrm{~N}$ & 264 & 23.9 \\
\hline trifluoromethyl-1,2,2,2-tetrafluoroethyl ether, E227me & 263.6 & 23.7 \\
\hline octafluorocyclobutane, $\mathrm{C}_{4} \mathrm{~F}_{8}$ & 267 & 23.2 \\
\hline decafluorobutane, $\mathrm{C}_{4} \mathrm{~F}_{10}$ & 271 & 23.2 \\
\hline perfluorodimethoxymethane, $\mathrm{CF}_{3} \mathrm{OCF}_{2} \mathrm{OCF}_{3}$ & 263 & 23.1 \\
\hline perfluoropropylmethyl ether, $\mathrm{C}_{3} \mathrm{~F}_{7} \mathrm{OCF}_{3}$ & 279.9 & 22.8 \\
\hline bis(trifluoromethyl)ether, E116 & 257 & 22.8 \\
\hline octafluorofuran, $\mathrm{C}_{4} \mathrm{~F}_{8} \mathrm{O}$ & 272.42 & 22.7 \\
\hline 1,1,2,2-tetrafluoroethane, $\mathrm{R} 134$ & 250 & 22.5 \\
\hline 1,1,1,2-tetrafluorocthanc, R 134a & 247 & 22.3 \\
\hline perfluoroisobutane, $\mathrm{C}_{4} \mathrm{~F}_{10}$ & 252.45 & 22.0 \\
\hline octafluoro-2-butene & 270.4 & 21.7 \\
\hline $1,1,1,2,3,3,3$-heptafluoropropane, R227ea & 257.5 & 21.4 \\
\hline perfluorooxetane, $\mathrm{C}_{3} \mathrm{~F}_{6} \mathrm{O}$ & 244.0 & 20.9 \\
\hline pentafluorodimethylether, E125 & 235 & 20.0 \\
\hline octafluoropropane, R218 & 236.4 & 19.7 \\
\hline hexafluoropropylene & 243.5 & 19.4 \\
\hline pentafluoroethane, R125 & 225.2 & 19.1 \\
\hline bromotrifluoromethane, R13B1 & 215.26 & 17.4 \\
\hline hexafluoroethane, R116 & 194.95 & 16.1 \\
\hline
\end{tabular}

heat capacity at $20^{\circ} \mathrm{C}$ using the method of Chueh and Swanson. [13] The second term, $\Delta H_{2}$, is the latent heat of vaporization at the normal boiling point. The third contribution, $\Delta H_{3}$, is found by integrating the gas-phase heat capacity from the normal boiling point to $1400 \mathrm{~K}$,

$$
\Delta H_{3}=\int_{T_{b}}^{1400 \mathrm{~K}} C_{p}^{\mathrm{gas}} d T
$$

We estimated the gas phase heat capacities using the method of Rihani and Doraiswamy [14], which is based on structural contributions. For agents with boiling points below $298 \mathrm{~K}$, the total heat involved is just the contribution $\Delta H_{3}$. Table 5 summarizes the results of this computation, with compounds listed in order of their $\Delta H^{\text {total }}$ expressed on a molar basis $(\mathrm{kJ} / \mathrm{mol})$. Table 6 gives the same quantity, but expressed on a mass basis 
Table 3. References for Property Data (Critical Point, Normal Boiling Point, Heat of Vaporization, Liquid Heat Capacity)

\begin{tabular}{|c|c|}
\hline Compound & References \\
\hline perfluoro-2-butyltetrahydrofuran, $\mathrm{C}_{8} \mathrm{~F}_{16} \mathrm{O}$ & $15,13,11$ \\
\hline methoxy-nonafluorobutane, HFE7100 & $16,13,11$ \\
\hline lactic acid, $\mathrm{C}_{3} \mathrm{H}_{6} \mathrm{O}_{3}$ & 1 \\
\hline heptafluoropropyl-1,2,2,2-tctrafluorocthyl cther & $10,13,11$ \\
\hline decafluorobutane, $\mathrm{C}_{4} \mathrm{~F}_{10}$ & 1 \\
\hline perfluoropropylmethyl ether, $\mathrm{C}_{3} \mathrm{~F}_{7} \mathrm{OCF}_{3}$ & $17,13,11$ \\
\hline perfluorodimethoxymethane, $\mathrm{CF}_{3} \mathrm{OCF}_{2} \mathrm{OCF}_{3}$ & $18,13,11$ \\
\hline octafluoro-2-butene & 1 \\
\hline octafluorofuran, $\mathrm{C}_{4} \mathrm{~F}_{8} \mathrm{O}$ & $17,13,11$ \\
\hline octafluorocyclobutane, $\mathrm{C}_{4} \mathrm{~F}_{8}$ & 1 \\
\hline perfluorotrimethylamine, $\mathrm{C}_{3} \mathrm{~F}_{9} \mathrm{~N}$ & $10,13,11$ \\
\hline $1,1,1,2,3,3,3$-heptafluoropropane, R227ea & 2 \\
\hline perfluoroisobutane, $\mathrm{C}_{4} \mathrm{~F}_{10}$ & $4,13,11$ \\
\hline tris(difluoromethyl)amine, $\mathrm{C}_{3} \mathrm{H}_{3} \mathrm{~F}_{6} \mathrm{~N}$ & $10,13,11$ \\
\hline trifluoromethyl-1,2,2,2-tetrafluoroethyl ether, E227me & $19,13,11$ \\
\hline $1,1,1,2,2,3,3,4$-octafluorobutane, R338mccq & $20,13,11$ \\
\hline 1,1,1,2,3,3-hexafluoropropan ${ }^{2}, \mathrm{R} 236 \mathrm{ea}$ & 2 \\
\hline difluoromethyl-1,2,2,2-tetrafluoroethyl ether, E236me & $19,13,11$ \\
\hline octafluoropropane, R218 & 2 \\
\hline 2,2,3,3,3-pentafluoropropanol, $\mathrm{C}_{3} \mathrm{~F}_{5} \mathrm{H}_{3} \mathrm{O}$ & $21,13,11$ \\
\hline perfluorooxetane, $\mathrm{C}_{3} \mathrm{~F}_{6} \mathrm{O}$ & $18,13,11$ \\
\hline 1,1,2,2-tetrafluorodimethylether, E134 & 22 \\
\hline bis(trifluoromethyl)ether, E116 & $10,13,11$ \\
\hline hexafluoropropylene & 1 \\
\hline pentafluorodimethylether, E125 & $17,13,11$ \\
\hline pentafluoroethane, R125 & 2 \\
\hline 1,1,2,2-tetrafluoroethane, R134 & 2 \\
\hline hexafluoroethane, R116 & 2 \\
\hline 1,1,1,2-tetrafluoroethane, $\mathrm{R} 134 \mathrm{a}$ & 2 \\
\hline bromotrifluoromethane, $\mathrm{R} 13 \mathrm{~B} 1$ & 1 \\
\hline water & 1 \\
\hline
\end{tabular}

$(\mathrm{kJ} / \mathrm{kg})$. We have also included some common agents such as nitrogen, argon, water and carbon dioxide for comparison.

The results of Table 5 indicate that the top candidates for streaming agents (defined here as having boiling points higher than $293 \mathrm{~K}$ ), on a molar basis, are perfluoro-2-butyltetrahydrofuran, methoxy-nonafluorobutane, heptafluoropropyl-1,2,2,2-tetrafluoroethyl ether, and 1,1,1,2,2,3,3,4-octafluorobutane. Table 6 indicates that methoxy-nonafluorobutane (IIFE7100) is high on the list when expressed on a mass basis. Methoxynonafluorobutane is available commercially [16], the others are not available commercially but have been synthesized and used for research $[17,18,19]$. The top total-flooding candidates (defined as having boiling points lower than $293 \mathrm{k}$ ) are perfluoropropyltrifluromethyl ether, perfluoroisobutane, decafluorobutane, and 
Table 4. Results of Search for Compounds with High Liquid Phase Heat Capacities at the Normal Boiling Point

\begin{tabular}{|c|c|c|}
\hline Compound & $T_{b}(\mathrm{~K})$ & $C_{p}(\mathrm{~J} / \mathrm{mol} \mathrm{K})$ \\
\hline perfluoro-2-butyltetrahydrofuran, $\mathrm{C}_{8} \mathrm{~F}_{16} \mathrm{O}$ & 375.15 & 364.2 \\
\hline methoxy-nonafluorobutane. HFE7100 & 334.0 & 292.8 \\
\hline lactic acid, $\mathrm{C}_{3} \mathrm{H}_{6} \mathrm{O}_{3}$ & 455 & 290.1 \\
\hline heptafluoropropyl-1,2,2,2-tetrafluoroethyl ether & 315.2 & 269.6 \\
\hline decafluorobutane, $\mathrm{C}_{4} \mathrm{~F}_{10}$ & 271 & 241.4 \\
\hline perfluoropropylmethyl ether, $\mathrm{C}_{3} \mathrm{~F}_{7} \mathrm{OCF}_{3}$ & 279.9 & 231.9 \\
\hline perfluorodimethoxymethane, $\mathrm{CF}_{3} \mathrm{OCF}_{2} \mathrm{OCF}_{3}$ & 263 & 226.0 \\
\hline octafluoro-2-butene & 270 & 218.1 \\
\hline octafluorofuran, $\mathrm{C}_{4} \mathrm{~F}_{8} \mathrm{O}$ & 272.42 & 217.6 \\
\hline octafluorocyclobutane, $\mathrm{C}_{4} \mathrm{~F}_{8}$ & 267 & 208.1 \\
\hline perfluorotrimethylamine, $\mathrm{C}_{3} \mathrm{~F}_{9} \mathrm{~N}$ & 264 & 204.0 \\
\hline $1,1,1,2,3,3,3$-heptafluoropropane, R227ea & 257.5 & 200.1 \\
\hline perfluoroisobutane, $\mathrm{C}_{4} \mathrm{~F}_{10}$ & 252.45 & 196.8 \\
\hline tris(difluoromethyl)amine, $\mathrm{C}_{3} \mathrm{H}_{3} \mathrm{~F}_{6} \mathrm{~N}$ & 275 & 194.6 \\
\hline trifluoromethyl-1,2,2,2-tetrafluoroethyl ether, E227me & 263.6 & 187.9 \\
\hline $1,1,1,2,2,3,3,4$-octafluorobutane, R338mccq & 301 & 186.4 \\
\hline 1,1,1,2,3,3-hexafluoropropane, R236ea & 279.7 & 185.4 \\
\hline difluoromethyl-1,2,2,2-tetrafluoroethyl ether, E236me & 296.5 & 184.9 \\
\hline octafluoropropane, R218 & 236.4 & 183.8 \\
\hline $2,2,3,3,3$-pentafluoropropanol, $\mathrm{C}_{3} \mathrm{~F}_{5} \mathrm{H}_{3} \mathrm{O}$ & 353.15 & 173.5 \\
\hline perfluorooxetane, $\mathrm{C}_{3} \mathrm{~F}_{6} \mathrm{O}$ & 244.0 & 171.9 \\
\hline 1,1,2,2-tetrafluorodimethylether, E134 & 279.4 & 150.8 \\
\hline bis(trifluoromethyl)ether, E116 & 257 & 150.3 \\
\hline hexafluoropropylene & 243.5 & 148.2 \\
\hline pentafluorodimethylether, E125 & 235 & 147.1 \\
\hline pentafluoroethane, $\mathrm{R} 125$ & 225.2 & 134.2 \\
\hline 1,1,2,2-tetrafluoroethane, R 134 & 250 & 133.3 \\
\hline hexafluoroethane, R116 & 194.95 & 130.6 \\
\hline 1,1,1,2-tetrafluoroethane, R134a & 247 & 129.4 \\
\hline bromotrifluoromethane, $\mathrm{R} 13 \mathrm{Bl}$ & 215.26 & 100.3 \\
\hline water & 373.1 & 76.0 \\
\hline
\end{tabular}

octafluorocyclobutane. Of these, decafluorobutane and octafluorocyclobutane are available commercially. [23] All of these compounds contain only $\mathrm{C}, \mathrm{H}, \mathrm{F}$ and $\mathrm{O}$. If any of these fluids show promise as fire extinguishing agents, mixtures may be investigated in order to adjust the boiling points and possibly to enhance effectiveness beyond that expected for simple linear mixing of the components.

\section{DETAILED CHEMICAL KINETIC MODELING OF EXTINGUISHMENT BEHAVIOR FOR THERMAL AGENTS IN METHANE/AIR DIFFUSION FLAMES}

A. Introduction

Combustion is a complicated physical process involving the interaction of fluid flow and chemical reaction accompanied by heat release. It is now recognized that combustion involves a large number of chemical 
Table 5. Results of Search for Compounds with High $\Delta H^{\text {Total }}$ (Molar Basis)

\begin{tabular}{|c|c|c|}
\hline Compound & $T_{b}(\mathrm{~K})$ & $\Delta \mathrm{H}^{\text {Total }}(\mathrm{kJ} / \mathrm{mol})$ \\
\hline perfluoro-2-butyltetrahydrofuran, $\mathrm{C}_{8} \mathrm{~F}_{16} \mathrm{O}$ & 375.2 & 608.4 \\
\hline heptafluoropropyl-1,2,2,2-tetrafluoroethyl ether & 315.2 & 421.9 \\
\hline methoxy-nonafluorobutane, HFE7100 & 334 & 407.6 \\
\hline perfluoropropyltrifluoromethyl ether, $\mathrm{CF}_{3} \mathrm{OCF}_{2} \mathrm{CF}_{2} \mathrm{CF}_{3}$ & 279.9 & 336.3 \\
\hline perfluoroisobutane, $\mathrm{C}_{4} \mathrm{~F}_{10}$ & 252.5 & 321.2 \\
\hline $1,1,1,2,2,3,3,4$-octafluorobutane, R338mccq & 301 & 321.0 \\
\hline decafluorobutane, $\mathrm{C}_{4} \mathrm{~F}_{10}$ & 271 & 318.5 \\
\hline octafluorocyclobutane, $\mathrm{C}_{4} \mathrm{~F}_{8}$ & 267 & 303.2 \\
\hline perfluorotrimethylamine, $\mathrm{C}_{3} \mathrm{~F}_{9} \mathrm{~N}$ & 264 & 293.8 \\
\hline lactic acid, $\mathrm{C}_{3} \mathrm{H}_{6} \mathrm{O}_{3}$ & 455 & 292.9 \\
\hline perfluorodimethoxymethane, $\mathrm{CF}_{3} \mathrm{OCF}_{2} \mathrm{OCF}_{3}$ & 263 & 286.8 \\
\hline octafluorofuran, $\mathrm{C}_{4} \mathrm{~F}_{8} \mathrm{O}$ & 272.4 & 289.8 \\
\hline 2,2,3,3,3-pentafluoropropanol, $\mathrm{C}_{3} \mathrm{~F}_{5} \mathrm{H}_{3} \mathrm{O}$ & 353.15 & 280.8 \\
\hline octafluoro-2-butene & 270 & 261.9 \\
\hline tris(difluoromethyl)amine, $\mathrm{C}_{3} \mathrm{H}_{3} \mathrm{~F}_{6} \mathrm{~N}$ & 275 & 256.5 \\
\hline trifluoromethyl-1,2,2,2-tetrafluoroethyl ether, E227me & 263.6 & 255.3 \\
\hline perfluorooxetane, $\mathrm{C}_{3} \mathrm{~F}_{6} \mathrm{O}$ & 244.0 & 252.9 \\
\hline octafluoropropane, R218 & 236.4 & 250.8 \\
\hline difluoromethyl-1,2,2,2-tetrafluoroethyl ether, E236me & 296.5 & 239.4 \\
\hline $1,1,1,2,3,3,3$-heptafluoropropane, R227ea & 257.5 & 236.5 \\
\hline $1,1,1,2,3,3$-hexafluoropropanc, R236ea & 279.7 & 222.2 \\
\hline bis(trifluoromethyl)ether, E116 & 257 & 196.2 \\
\hline hexafluoropropylene & 243.5 & 192.9 \\
\hline pentafluorodimethylether, E12.5 & 235 & 183.8 \\
\hline hexafluoroethane, R1 16 & 194.95 & 181.1 \\
\hline 1,1,2,2-tetrafluorodimethylether, E134 & 279.4 & 170.2 \\
\hline pentafluoroethane, $\mathrm{R} 125$ & 225.2 & 166.8 \\
\hline 1,1,1,2-tetrafluoroethane, $\mathrm{R} 134 \mathrm{a}$ & 247 & 156.8 \\
\hline 1,1,2,2-tetrafluoroethane, R134 & 250 & 152.8 \\
\hline bromotrifluoromethane, R13B I & 215.26 & 110.9 \\
\hline water & 373.1 & 87.5 \\
\hline carbon dioxide & $\mathrm{n} / \mathrm{a}$ & 56.2 \\
\hline nitrogen & 77.4 & 34.7 \\
\hline argon & 87.3 & 22.9 \\
\hline
\end{tabular}

species and reactions. The most important reactions are those involving radical species such as $\mathrm{OH}, \mathrm{HO}_{2}$, and $\mathrm{O}$ and $\mathrm{H}$ atoms. The most dominant reaction is usually recognized as the chain branching reaction leading to the breaking of the oxygen bond, i.e.,

$$
\mathrm{H}+\mathrm{O}_{2} \rightarrow \mathrm{OH}+\mathrm{O}
$$


Table 6. Results of Search for Compounds with High $\Delta H^{\text {Total }}$ (Mass Basis)

\begin{tabular}{|c|c|c|}
\hline Compound & $\mathrm{T}_{\mathrm{b}}(\mathrm{K})$ & $\Delta \mathrm{H}^{\text {total }}(\mathrm{kJ} / \mathrm{kg})$ \\
\hline water & 373.1 & 4855.7 \\
\hline lactic acid, $\mathrm{C}_{3} \mathrm{H}_{6} \mathrm{O}_{3}$ & 455 & 3251.6 \\
\hline $2,2,3,3,3$-pentafluoropropanol, $\mathrm{C}_{3} \mathrm{~F}_{5} \mathrm{H}_{3} \mathrm{O}$ & 353.15 & 1872.0 \\
\hline methoxy-nonafluorobutane, HFE7100 & 334 & 1630.4 \\
\hline $1,1,1,2,2,3,3,4$-octafluorobutane, R338mccq & 301 & 1588.7 \\
\hline $1,1,1,2$-tetrafluoroethane, $\mathrm{R} 134 \mathrm{a}$ & 247 & 1536.8 \\
\hline tris(difluoromethyl)amine, $\mathrm{C}_{3} \mathrm{H}_{3} \mathrm{~F}_{6} \mathrm{~N}$ & 275 & 1535.5 \\
\hline perfluorooxetane, $\mathrm{C}_{3} \mathrm{~F}_{6} \mathrm{O}$ & 244.0 & 1523.2 \\
\hline octafluorocyclobutane, $\mathrm{C}_{4} \mathrm{~F}_{8}$ & 267 & 1515.8 \\
\hline 1,1,2,2-tetrafluoroethane, R134 & 250 & 1497.6 \\
\hline heptafluoropropyl-1,2,2,2-tetrafluoroethyl ether & 315.2 & 1475.0 \\
\hline perfluoro-2-butyltetrahydrofuran, $\mathrm{C}_{8} \mathrm{~F}_{16} \mathrm{O}$ & 375.2 & 1462.3 \\
\hline $1,1,1,2,3,3$-hexafluoropropane, R236ea & 279.7 & 1461.4 \\
\hline 1,1,2,2-tetrafluorodimethylether, E134 & 279.4 & 1442.0 \\
\hline difluoromethyl-1,2,2,2-tetrafluoroethyl ether, E236me & 296.5 & 1424.7 \\
\hline $1,1,1,2,3,3,3$-heptafluoropropane, R227ea & 257.5 & 1390.9 \\
\hline pentafluoroethane, $\mathrm{R} 125$ & 225.2 & 1389.8 \\
\hline trifluoromethyl-1,2,2,2-tetrafluoroethyl ether, E227me & 263.6 & 1372.4 \\
\hline pentafluorodimethylether, E1.25 & 235 & 1351.3 \\
\hline perfluoroisobutane, $\mathrm{C}_{4} \mathrm{~F}_{10}$ & 252.5 & 1349.6 \\
\hline octafluorofuran, $\mathrm{C}_{4} \mathrm{~F}_{8} \mathrm{O}$ & 272.4 & 1341.5 \\
\hline decafluorobutane, $\mathrm{C}_{4} \mathrm{~F}_{10}$ & 271 & 1338.2 \\
\hline octafluoropropane, R218 & 236.4 & 1333.8 \\
\hline perfluorotrimethylamine, $\mathrm{C}_{3} \mathrm{~F}_{9} \mathrm{~N}$ & 264 & 1329.3 \\
\hline perfluoropropyltrifluoromethyl ether, $\mathrm{CF}_{3} \mathrm{OCF}_{2} \mathrm{CF}_{2} \mathrm{CF}_{3}$ & 279.9 & 1323.9 \\
\hline hexafluoroethane, R116 & 194.95 & 1312.2 \\
\hline octafluoro-2-butene & 270 & 1309.2 \\
\hline perfluorodimethoxymethane, $\mathrm{CF}_{3} \mathrm{OCF}_{2} \mathrm{OCF}_{3}$ & 263 & 1303.5 \\
\hline hexafluoropropylene & 243.5 & 1285.8 \\
\hline carbon dioxide, $\mathrm{CO}_{2}$ & $\mathrm{n} / \mathrm{a}$ & 1276 \\
\hline bis(trifluoromethyl)ether, E1 16 & 257 & 1273.9 \\
\hline nitrogen, $\mathrm{N}_{2}$ & 77.4 & 1238.3 \\
\hline bromotrifluoromethane, R13BI & 215.26 & 744.7 \\
\hline argon & 87.3 & 573.2 \\
\hline
\end{tabular}

Subsequent rcactions involving these free radicals release heat and ultimately maintain the combustion. Reaction (4) is strongly temperature dependent, and extinguishment of a flame is expected to occur when the temperature is lowered to a point where the rate of generation of free radicals becomes so slow that the ovcrall reactions cannot generate sufficient heat release to overcome the heat losses from the reaction zone (primarily by thermal diffusion, radiation, and incomplete combustion). 
During the past two decades the understanding of the chemical kinetics involved in combustion has reached the point where realistic detailed mechanisms including large numbers of reactants and reactions can be written for simple combustion systems, and mathematical techniques have been developed for simultaneously solving the large number of differential cquations which result. While still involving significant approximations (some of which are discussed below), such modeling has developed to the point where it can be used to gain useful insights into the behavior of practically relevant flames.

A number of different types of combustion systems have been modeled including plug flow reactors, perfectly stirred reactors, premixed flames, and opposed flow laminar diffusion flames. For studies of fire extinguishment, we have chosen to use an opposed flow laminar diffusion flame model because, for the vast majority of fires, the fuel and air are initially separated and therefore burn as diffusion flames. Most fires are large enough to be turbulent, so a laminar flame model is not strictly correct. However, the most widely used model for turbulent combustion incorporating detailed chemistry is the laminar flamelet concept which models the combustion as laminar flame sheets which are subject to the local strain rate field associated with the motions of the fluid induced by the fire. [24,25] Thus, the opposed flow diffusion flame should be the most appropriate detailed chemical kinetic model available for describing fire behavior.

There are three configurations of opposed flow diffusion flames which have been described in the literatureopposed jet, flow over a porous cylinder, and flow over a porous sphere. For the porous bodies, fuel typically flows from the surface, and the surrounding flow is the oxidizer. The three configurations are related in that a diffusion flame is stabilized in the region near the stagnation point in the flow. Numerous papers in the literature discuss these types of flames. Two excellent reviews have been provided by Tsuji [26] and DixonLewis [27]. The review by Tsuji includes a discussion of the use of such burners to experimentally characterize flame inhibition. Examples of early studies include References [28], [29], [30], [31], and [32]. All three configurations are represented. Recently, an opposed jet experiment has been used to investigate potential replacement agents for halons. [33]

The most common of the three configurations used in the recent past is the opposed jet laminar diffusion flame. This configuration has also been the choice for most of the available modeling investigations of opposed flow flames. For these reasons, we have chosen this configuration for this investigation.

The review of Dixon-Lewis focuses on detailed chemical kinetic modeling of opposed flow diffusion flames. [27] Detailed chemical models were initially developed in a series of steps. The earliest were designed to describe reactions between $\mathrm{H}_{2}$ and $\mathrm{O}_{2}$. The next step was to include $\mathrm{CO}$ with the $\mathrm{H}_{2}$ and $\mathrm{O}_{2}$. After these mechanisms were sufficiently developed, they were used as the basis for extended mechanisms describing the oxidation of methane. By the early 1980 s researchers had begun to calculate the structure of opposed flow laminar methane/air diffusion flames. The earliest such calculation we have identified is that of Hahn and Wendt [34] which was published in 1981. This was followed by the work of Dixon-Lewis et al. [35], Smooke et al. [36], Dixon-Lewis et al. [37], Puri et al. [38], and Chelliah et al. [39].

Before discussing the findings of thesc studies, it is important to introduce and clarify some ideas concerning the parameters used to characterize the flow field and its potential interactions with combustion reactions. Much of what follows is based on a review paper by Law. [40]

The degree of interaction between combustion and a flow field is often treated using the concept of flame stretch. This is particularly true for laminar premixed flames. Flame stretch, $K$, is defined as 


$$
K=\frac{1}{A} \frac{d A}{d t}
$$

where $A$ is the infinitesimal area of an arbitrary flame surface lying within the flamc structurc, c.g., an isotherm or isopleth, and $t$ represents time. In the general case, flame stretch can be broken into three individual contributions due to aerodynamic strain, flame curvature, and flame motion. For a planar, axisymmetric diffusion flame, however, the latter two effects are absent and $K$ is simply equal to the strain rate within the planar surface, $b$, with

$$
b=\frac{\partial v}{\partial r}
$$

where cylindrical coordinates have been introduced with $z$ and $r$ the directions perpendicular and parallel to the flame sheet, respectively, and $u$ and $v$ are the velocities in these directions. For the planar flame $u$ is assumed to be only a function of $z$. The velocities $u$ and $v$ arc dependent on each other through the continuity equation, which for a cylindrical coordinate system is written as

$$
\frac{\partial(r \rho u)}{\partial z}+\frac{\partial(r \rho v)}{\partial r}=0
$$

with $\rho$ equal to the local density.

Law discusses the effects of flame stretch on flame behavior in terms of the different roles of velocity gradient elements tangent to and normal to the flame surface. He notes that there has been a great deal of confusion in the literature in distinguishing between the roles of each element. He argues that it is the normal element of the axial velocity gradient which determines the residence time within the flame and that the Damkohler number, $D a$, defined as the ratio of the characteristic flow time to a characteristic reaction time, should be based on this velocity gradient element. As we shall see shortly, $D a$ is a dominant parametcr for describing flame extinction. For now, it is important to note that for planar diffusion flames the most important characteristic flow parameter is the element of the axial velocity gradient in the axial direction,

$$
a=\frac{\partial u}{\partial z}
$$

Returning now to the discussion of early detailed kinetic investigations of methane/air diffusion flames, the paper by Dixon-Lewis et al. is particularly interesting because it involved an intercomparison of calculated results for an opposed flow methanc/air diffusion flame by five different research groups. [35] Calculated flame structures were compared with the experimental measurements of Tsuji and Yamaoka [41,42] for the configuration of flow over a porous cylinder. All of the researchers used the samc model for the velocity field. A similarity transform was used to convert the two-dimensional flow field to a pseudo one-dimensional flow, thus greatly reducing the amount of computation required. The coordinate system employed for these calculations was actually rectilinear, but the following discussion will be in terms of cylindrical coordinates. The opposed flows for ambient locations outside of the reacting boundary layer were assumed to be potential flows generated from point sources located at infinity. One appealing aspect of such a flow is that the characteristic strain rate, usually defined as the radial velocity gradient element in the radial direction, 


$$
b_{p}=\frac{\partial v}{\partial r}
$$

is constant in the isothermal region. The continuity equation allows the following relationship between $a_{p}$ and $b_{p}$ to be derived,

$$
a_{p}=\frac{\partial u}{\partial z}=-\frac{1}{2} b_{p}
$$

Dixon et al. concluded that the models described the qualitative flame structure quite well, but that the quantitative agreement was not perfect. [35] In particular, they argued that the assumption of potential flow was inadequate to describe the actual flow field. The results from the different investigators within the intercomparison also differcd somcwhat, and additional study was suggested to identify the sources of these variations.

While the strain rate dictated by the potential flow provided a natural variable to characterize the velocity field, the authors also noted that the scalar dissipation rate at the stoichiometric surface of the flame, $\chi_{\mathrm{s}}$, is more commonly used to describe the effect of strain on diffusion flames in turbulent models. [24,25] The scalar dissipation rate is defined as

$$
\chi=2 D\left(\frac{\partial Z}{\partial x}\right)^{2}
$$

where $D$ is a molecular diffusion coefficient and $Z$ is the fuel mixture fraction, a conserved scalar. An expression was provided which allowed $\chi_{s}$ to be calculated from the flow parameters. Most of the calculations were performed for strain rates of $100 \mathrm{~s}^{-1}$, but one set was carried to higher velocities where flame extinction occurred. The calculated value of $a_{p}$ was $410 \mathrm{~s}^{-1}$, and the corresponding value of $\chi_{s}$ was $16.7 \mathrm{~s}^{-1}$. [35]

The limitations with regard to the use of potential flow conditions in opposed flow flame calculations continued to worry early workers in the area. It was recognized that most opposed jet configurations were designed to generate plug flows either through the use of nozzles or active flow straightencrs. In other words, the radial velocities at the burner exits were set to be zero with both $a$ and $b$ also equal to zero at these locations. Furthermore, the nozzles had finite diameters as opposed to the infinite diameters assumed in the model. In $1988 \mathrm{Kee}$ et al. demonstrated that it was possible to derive a pseudo one-dimensional similarity transform for problems which relaxed the condition imposed by the assumption of potential flow that $b_{p}$ and $a_{p}$ be constant throughout the isothermal region of the flow. [43] In their formulation, it is only required that the radial velocity profile vary linearly with radial position for a given axial position as opposed to having a constant value. Thus $b$ is allowed to vary along the primary flow direction. This approach allows the case of initial plug flows, i.e., $\partial v / \partial r=\partial u / \partial r=0$ at the burner exits, to be evaluated. The price paid for relaxing the potential flow boundary conditions was that the strain rate element normal to the flame surface, $a$, was no longer a constant for regions outside of the reacting boundary layer, but now varied with the similarity coordinatc. Thus there was no longer a single strain rate which could be used to characterize the flow field. Kee et al. used the approach to calculate the structure of opposed flow premixed methane/air flames.

The formulation used by Kee et al. [43] is related to earlier work by Seshadri and Williams [44] who considered flow in a two-dimensional channel. Their results can be used to derive a characteristic global strain rate, $a_{g}$, for the pseudo one-dimensional flow, which is written for axisymmetric flow as 


$$
a_{g}=\frac{-2 u_{o}}{L}\left[1+\frac{u_{f}}{\left(-u_{o}\right)} \sqrt{\frac{\rho_{f}}{\rho_{o}}}\right] \text {, }
$$

where $L$ is the separation distance of the two burners, $u_{f}$ and $u_{o}$ are the fuel and oxidizer velocities which have opposite signs for the opposed flow, and $\rho_{f}$ and $\rho_{o}$ are the fuel and oxidizer densities. This corresponds to the strain rate which would exist at the stagnation point for opposed flows if the boundary layer were infinitely thin. Flow fields with comparable values of $a_{g}$ are expected to have similar spatial variations of velocity. It should be mentioned that Eq. (12) is occasionally found in the literature without the factor of 2 . The form of Eq. (12) is correct for axisymmetric opposed flows.

Chelliah et al. [39] extended the formulation provided by Kee et al. [43] to treat opposed flow diffusion methane/air diffusion flames. Calculations were made for two different boundary conditions corresponding to either potential flow with a characteristic strain rate of $a_{p}$ for the boundaries located at $x=0$ and $x=L$ or plug flow conditions with strain rate $a(x=0, x=L)=0 \mathrm{~s}^{-1}$ at the burner exits. An important feature of this work was comparison of the calculational results with detailed experimental measurements of the velocity field. The flows were generated by nozzles and were expected to be closely top hat in shape. Therefore, plug flow conditions at the burner exits would be expected to provide better agreement with experiments. This was indeed found to be the case, although small disagreements were still observed.

Recall that plug flow conditions at the burner exits require that $a$ varies with axial location. The global strain rate given by Eq. (12) is one means for quantification. However, the reacting boundary layer is known to have $a$ finite thickness, and the volume expansion associated with the heat release causes $a$ to vary rapidly through the combustion region. As a result, the value of $a$ at the stagnation plane does not actually correspond to $a_{g}$. For this reason, the measured value $a$ on the oxidizer side of the flow just outside of the boundary layer, $a_{o}$, has been suggested for use as the characteristic strain rate for opposed-flow diffusion flames formed by plug flows. Chelliah et al. found that the values of $a_{g}$ and $a_{o}$ differed significantly. [39]

The calculations of Chelliah et al. were carried to high enough velocities to cause extinction of the flame. [39] For plug flow exit conditions the corresponding values of $a_{g}$ and $a_{o}$ at extinction were $610 \mathrm{~s}^{-1}$ and $391 \mathrm{~s}^{-1}$, respectively, while the experimental value of $a_{o}$ was $380 \mathrm{~s}^{-1}$. Values of $\chi_{\mathrm{s}}$ at extinction were also determined from the calculations. Interestingly, these values were nearly independent of the exit flow conditions, being roughly $14.7 \mathrm{~s}^{-1}$ in both cases. The experimental value was reported as $19.9 \mathrm{~s}^{-1}$.

The existence of the various definitions of characteristic strain rates, i.e., $a_{p}, a_{g}$, and $a_{o}$ have resulted in some confusion in the literature when different experiments and calculations are considered. Fisher et al. have compared values of $a_{o}$ measured in a propane/air counterflow diffusion flame with the corresponding oxidizer air flow rates and values of $a_{g}$. [45] In each case, a linear relationship was found. This suggests that for a given flow configuration, values of $a_{g}$ and $a_{o}$ should be related by a constant.

Early calculations involving opposed flow diffusion flames assumed the combustion occurred adiabatically and did not allow for the possibility of radiative heat loss. Recently, however, detailed chemical kinetic calculations for methane/air diffusion flames have begun to appear in which the effects of radiation from combustion gases have been included. $[46,47,48]$ The study by Maruta et al. considered laminar diffusion flames in the opposed jet configuration burning nitrogen-diluted methane. [46] Both detailed chemical kinetic modeling and experiments were reported. The experiments were performed in microgravity so that buoyancy effects on the flame were minimal. Their results showed that at high strain rates flame extinction was due primarily to strain effects. However, as the strain rate was lowered, the percentage of heat loss by radiation incrcascd rapidly, lowering the flame temperature and ultimately extinguishing the flame. As a result of these 
competing effects, plots of maximum flame temperature versus strain rate showed a maximum and plots of strain rate at extinction as a function of methane concentration in the fuel were double valued.

For their investigation, Chan et al. used a different modeling approach. [47] Their calculation is based on a steady-state laminar flamelet model which is solved in mixture fraction coordinates. The effects of strain were incorporated indirectly by varying $\chi_{s}$. . Both detailed chemical kinetics and radiation losses were included. These authors considered a methane/air diffusion flame. Their findings are consistent with those of Maruta et al. [46] The cffects of radiation were minimal at high strain rates and extinction occurred due to the well known strain-rate mechanism. Extinction was calculated to take place at $\chi_{s}=18.4 \mathrm{~s}^{-1}$, and the maximum flame temperature at extinction was $1773 \mathrm{~K}$ (1771 K with radiation losses included). However, as the strain rate was lowered, the percentage of the total heat release rate loss due to radiation increased dramatically. Calculations without radiation indicated a continual increase in maximum temperature with decreasing $\chi_{s}$, while the inclusion of radiation resulted in maximum temperatures which first increased, but then began to fall for values of $\chi_{\mathrm{s}}<2.5 \mathrm{~s}^{-1}$. The falling temperature ultimately led to a second extinction at $\chi_{\mathrm{s}}=0.029 \mathrm{~s}^{-1}$.

Gore et al. also found that radiation effects became more important at low strain rates. [48] Their calculations showed that there is a substantial range of strain rate for which the effects of strain rate and radiation losses nearly cancel, resulting in maximum flame temperatures which are roughly independent of strain rate.

There have been a number of investigations which have used detailed kinetic modeling to study flame inhibition and extinction processes. Most of these have involved the reduction of premixed flame speed due to the introduction of various inhibitors. Examples include the early studies of Westbrook [49,50,51] as well as a number of more recent works. [52,53,54,55] Very recently, inhibited flames studies have been extended to laminar opposed flow diffusion flames. [55,56,57,58,59]

Despite the large number of detailed kinetic modeling studies dealing with inhibition and extinction of flames by various agents, we have identified only one study which systematically considered the effects of inert thermal agents on a combustion system. Tuovinen calculated the structure of methane/air premixed flames in a well-stirred reactor with added $\mathrm{CO}_{2}, \mathrm{H}_{2} \mathrm{O}, \mathrm{N}_{2}$, and $\mathrm{He}$. [60] The author found that the extinguishing capability of these compounds was proportional to the heat capacity of the gases. The temperatures at extinguishment using the various agents were within $50 \mathrm{~K}$ for a given stoichiometric ratio, $\varphi$ (a range of $\varphi=$ $0.7-1.2$ was studied).

\section{B. Modeling Approach}

The current investigation seeks to calculate the effects of adding thermal agents to the air side of laminar opposed flow diffusion flames. There are a number of codes described in the literature for making these calculations. We desired to utilize a widely used code which was easily accessible to rescarchcrs. The code Oppdif [61] developed by Sandia National Laboratories was chosen. This code is now available commercially from Reaction Design ${ }^{1}$ of San Diego, CA. Oppdif is built on a number of general purpose subroutines, collectively known as Chemkin-III [62], which handle many of the tasks associated with the calculation. Data describing the reaction mechanism and thermodynamic and transport properties are either incorporated in Oppdif or accessed as databases.

\footnotetext{
${ }^{1}$ Certain commercial equipment, instruments, or material are identified in this paper in order to adequately specify the experimental procedure. Such identification does not imply recommendation or endorsement by the National Institute of Standards and Technology, nor does it imply that the materials or equipment are necessarily the best available for the purpose.
} 
Oppdif solves the psuedo-one-dimensional equations describing an axisymmetric opposed flow laminar diffusion flame. The equations are those originally reported by Kee et al. [43] for premixed flames to solve problems in which $b$ is constant at the boundaries and was later extended to diffusion flames by Chelliah et al. [39] This includes the case of plug flows, i.e., $b=a=0 \mathrm{~s}^{-1}$ at the burner exits, which was used for all of the calculations which follow.

A detailed chemical kinetic mechanism is required to model the flame. After reviewing the literature, we chose the widely used methane/air mechanism developed with the support of the Gas Rescarch Institutc. The version used was GRI-Mech 1.2. [63] There is a later version of the mechanism, GRI-Mech 2.11, which contains nitrogen chemistry. The earlier version was chosen for use since NOX formation is not of interest to the current investigation.

GRI-Mech 1.2 consists of 32 chemical species undergoing 177 reactions. One- and two-carbon species are included. Thermodynamic and transport data are provided as separate files. The mechanism was created by starting with appropriate estimates for the rate constants and then optimizing the mechanism to provide the best agreement with experimental measurements in such systems as premixed flames, shock tube studies, and flow reactor investigations. [63] Note that the mechanism was not optimized using diffusion flame results.

Oppdif was mounted on a Silicon Graphics Incorporated Origin 200 workstation. An initial test for a laminar hydrogen/air opposed flow diffusion flame yielded good agreement with the solution provided in the documentation. By simply replacing the mechanism provided for the hydrogen/air flame with GRI-Mech 1.2, we were able to obtain an initial solution for a methane/air diffusion flame.

The purpose of our calculations is to determine extinction behavior for the flame as a function of flow conditions and agent concentration and to use this information to better understand the effectiveness of thermal agents for extinction of diffusion flames. Extinction of diffusion flames can be understood in terms of the "S" curve which was originally described by Fendell [64] and Liñan [65]. The name refers to the shape of a plot of maximum flame temperature versus Damkohler number, $D a$, where $D a$ is the ratio of a characteristic flow mixing time and a characteristic combustion reaction time. The unique shape results from the highly nonlinear temperature dependence of combustion reactions. These authors showed that there were two possible solutions for mixtures of fuel and air-combustion and very slow reaction regimes. These two branches are connected by an unstable third branch which forms the central part of the "S", but is not physically observable. Starting well up on the burning branch, it is found that the maximum flame temperature decreases with decreasing $D a$. As the $D a$ is decreased still further, the temperature begins to drop faster and is ultimately predicted to curve onto the middle branch and continue to fall off with increasing $D a$. Such a dependence on $D a$ is physically unrealistic, and, as a result, the real flame system drops to the lower branch at the turning point. This is interpreted as flame extinction. A similar behavior applies to ignition. Starting on the lower branch, as the temperature is increased the reaction rate increases very slowly at first. However, a temperature is eventually reached where the rate begins to increase quickly and ultimately begins to increase with falling $D a$, passing onto the middle branch. However, due to the instability of this branch, the system actually jumps rapidly up to the burning branch. This is the process of spontaneous ignition.

For this study, the goal is to determine the flow conditions necessary to cause extinction of a flame formed by fuel and either air or air with added agent. Thus the problem becomes one of identifying the turning point for a plot of temperature versus $\mathrm{Da}$. Either the velocity, appropriate characteristic strain-rate, or stoichiometric scalar dissipation rate can be used as the dependent variable, and since the mixing time associated with these parameters is inversely related to their values, the curve is reversed from that for a $D a$ plot, with the maximum flame temperature decreasing with increasing velocity, characteristic strain rate, or scalar dissipation rate. 
Early calculations of flame extinction simply increased the controlling parameter for burning solutions until further increases resulted in a nonburning solution (e.g., see [35]). Due to the rapid changes in temperature with flow parameters near the extinction point, solutions of opposed flow diffusion flames can become unstable, and there may be some uncertainty associatcd with the extinction value. As a result, so-called continuation methods have been implemented which allow calculations to be extended onto the unstable solution branch. $[66,67]$ In this way it is possible to determine the turning point corresponding to extinction unambiguously.

Unfortunately, continuation approaches are not implemented in Oppdif. For this reason, we chose to employ the direct approach in which higher and higher flow velocities were used until either a nonburning solution was found or the differential solver was unable to find a solution. In order to minimize the associated uncertainties, very small incremental increases in velocity were utilized near the extinction point (the solver is more efficient when an earlier solution for similar conditions is used as the starting point). An arbitrary, but stringent, criterion was adopted which defined the extinction velocity as that for which a burning solution was still obtained, but for which an increase of only $0.01 \mathrm{~cm} / \mathrm{s}$ in the fuel and air initial velocities either resulted in a failure to find a solution or a nonbuming solution. Additional small increases in velocity always resulted in nonburning solutions. As we shall show, plots of maximum flame temperature versus the controlling parameters (e.g., velocity) indicate that the flames were indeed near the extinction point as reflected by large temperature drops for small changes in the control parameter. It is believed that this approach results in small errors for estimates of the calculated extinction condition.

A number of parameters are relevant to Oppdif calculations. [61] Many of these are summarized in Table 7. The general procedure was to find a solution for a methane/air diffusion flame by first solving an isothermal case and using the solution as the input for a calculation in which the energy equation was added. Once a solution was available, it could be used as the starting point for calculations in which such parameters as the oxidizer and flow velocities were changed. Only the formulation including the energy equation was solved for the "restarted" cases. The new solution then became the starting point for cases involving further changes in the controlling parameters. Oppdif allows the grid for the calculations to be adapted to best match the latest solution. This feature was used frequently for these calculations. Normally, between 130 and 150 grids points were used for a final solution. For simplicity, the opposed (i.e., opposite signs for velocity) fuel and oxidizer exit velocity magnitudes were always set equal to each other. The exit temperatures were $300 \mathrm{~K}$.

The final solutions for a particular problem were saved in binary files. A program named Postopp was supplied by Reaction Design [61] which reads these files and generates ASCII files containing such parameters as temperature, density, fuel mixture fraction, axial and radial velocities, and axial and normal strain rate elements $a$ and $b$ as functions of distance from the fuel nozzle $(\mathrm{z}=0 \mathrm{~cm})$. This program was modified to also output the largest absolute value $a$ on the oxidizer side, $a_{o}$, the stoichiometric mixture fraction, and the scalar dissipation rate at the location corresponding to a stoichiometric mixture fraction. The derivatives required in Eq. (11) were calculated by simple forward differencing of mixture fraction values, and values of $D$ were corrected for variations in the local temperature using the expression recommended by Norton et al. [68]

Figure 1 shows a plot of maximum temperature, $T_{\max }$, versus flow velocity (equal magnitudes for the fuel and oxidizer opposed velocities) calculated for a laminar opposed flow methane/air diffusion flame. The fuel is $100 \%$ methane and air is assumed to be composed of $78.1 \% \mathrm{~N}_{2}, 21.0 \% \mathrm{O}_{2}$, and $0.9 \%$ Ar. As expected, $T_{\max }$ decreases with increasing velocity. Extinction occurs for a velocity of $320.12 \mathrm{~cm} / \mathrm{s}$ for a maximum flame temperature of $1785 \mathrm{~K}$. A global strain rate, $a_{g}$, of $558 \mathrm{~s}^{-1}$ is calculated for the extinction condition using Eq. (12). Puri and Seshadri [69] have reported an experimental value for $a_{g}$ of $542 \mathrm{~s}^{-1}$ while Chelliah et al. [39] measured a value of $a_{g}=610 \mathrm{~s}^{-1}$ The calculated value is in reasonable agreement with these results. 
Table 7. Some Parameters Used in Most Oppdif Calculations

\begin{tabular}{|c|c|}
\hline Keyword & \\
\hline ENRG & Energy Equation Included \\
\hline NOFT & Skip the Fixed Temperature Problem \\
\hline RSTR & Restart From Earlier Solution \\
\hline IRET (retirement period) & 20 \\
\hline RTOL (relative convergence for Newton's method) & $1 . \mathrm{E}-3$ \\
\hline ATOL (absolute convergence for Newton's method) & $1 . \mathrm{E}-6$ \\
\hline ATIM (absolute convergence for timestepping) & $1 . \mathrm{E}-6$ \\
\hline RTIM (relative convergence for timestepping) & $1 . \mathrm{E}-3$ \\
\hline XEND (physical length) & $2 \mathrm{~cm}$ \\
\hline TFUE, TOXI (fuel and oxidizer initial temperatures) & $300 \mathrm{~K}$ \\
\hline PRES & 1 atmosphere \\
\hline AFUE, AOXI (radial gradient at inlet) & $0 \mathrm{~s}$-1 \\
\hline MIX & Mixture-Averaged Formula for Diffusion Velocities \\
\hline
\end{tabular}

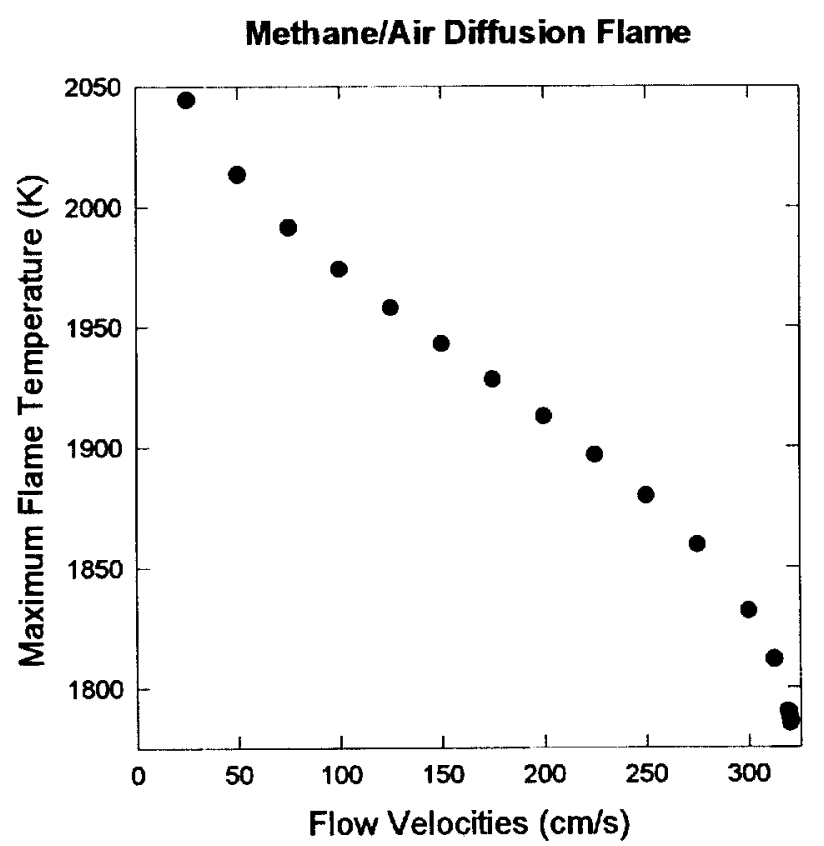

Figure 1. Maximum flame temperature plotted as a function of the equal fuel and air velocity magnitudes for a methane/air opposed flow diffusion flame.

Figure 2 shows two examples, one for relatively low fuel and air velocity magnitudes and one for a flame very close to extinction, of the variation of the local characteristic strain rate, $a$, with position. Several interesting behaviors can be seen. First, as expected, absolute values of $a$ are higher for the case with higher initial 


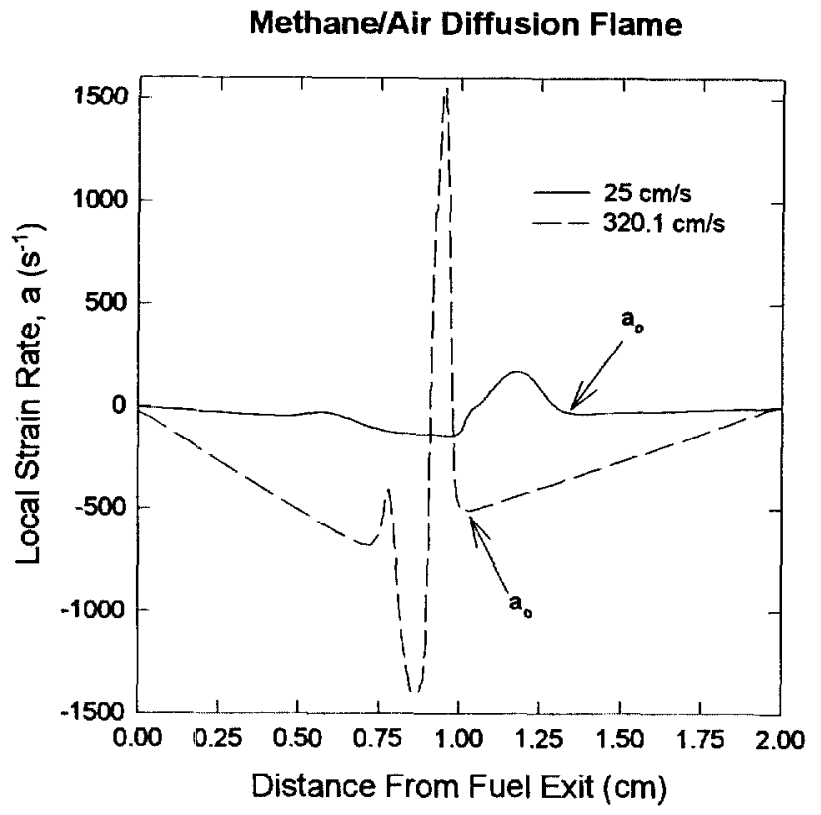

Figure 2. Calculated strain rates, $a$, are plotted as a function of distance from the fuel exit for low exit velocity magnitudes (25 cm/s for fuel and air) and for a condition very close to extinction $(320.1 \mathrm{~cm} / \mathrm{s})$.

velocities. For regions outside of the boundary layer, $a$ values increase or decrease roughly linearly with increasing position, but large intense variations are evident in the vicinity of the flame front. These large fluctuations within the flame zone result from the volume expansion due to heat release. It is clear that the boundary layer width for the low velocity case is considerably broader than for the higher flow velocity. This is expected since higher absolute velocities should more effectively overcome the effects of molecular diffusion and result in a narrower mixing layer.

The first maximum in the absolute value of $a$ on the oxidizer side (see Figure 2) can be taken to be the largest value outside of the boundary layer, i.e., $\left|a_{o}\right|$. Figure 3 shows a plot of maximum flame temperature versus $\left|a_{o}\right|$ for the various flow velocities. As expected, the maximum flame temperature decreases with increasing $\left|a_{0}\right|$. Extinction is calculated to occur when $\left|a_{\nu}\right|$ is increased to $509 \mathrm{~s}^{-1}$. Three experimental measurements of $\left|a_{o}\right|$ at extinction are available in the literature for methane/air diffusion flames. Chelliah et al. reported cxtinction for $\left|a_{o}\right|=380 \mathrm{~s}^{-1}$ [39], Papas et al. report $(405 \pm 25) \mathrm{s}^{-1}$ [33], and Du and Axelbaum report $(375 \pm 10) \mathrm{s}^{-1}[70]$. These values should be considered equal within experimental uncertainty. The value calculated here is roughly $30 \%$ higher. Two possible reasons for this are different boundary conditions in the experiment and model and the possible dependence of the results on chemical mechanism. Reasons for the difference are discussed further below.

Figure 4 shows the mixture fraction, i.e., the fraction of the mass of the combustion mixture derived from fuel, plotted as a function of distance from the fuel source for the two same conditions used for Figure 2. The narrowing of the boundary layer due to increased strain rate is clearly evident. The shape of the curve becomes more asymmetric as the velocity decreases. Since values of the mixture fraction are now available, it is 


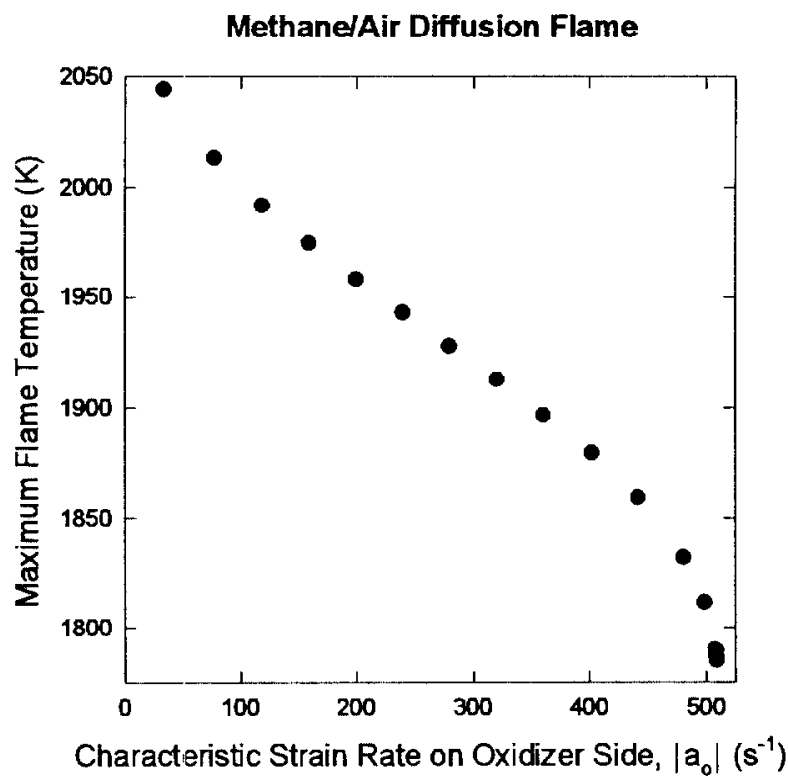

Figure 3. The maximum flame temperature is plotted against a characteristic local strain rate, $\left|a_{o}\right|$, defined to be equal to the highest absolute value of $a$ on the air side observed outside of the boundary layer associated with the flame.

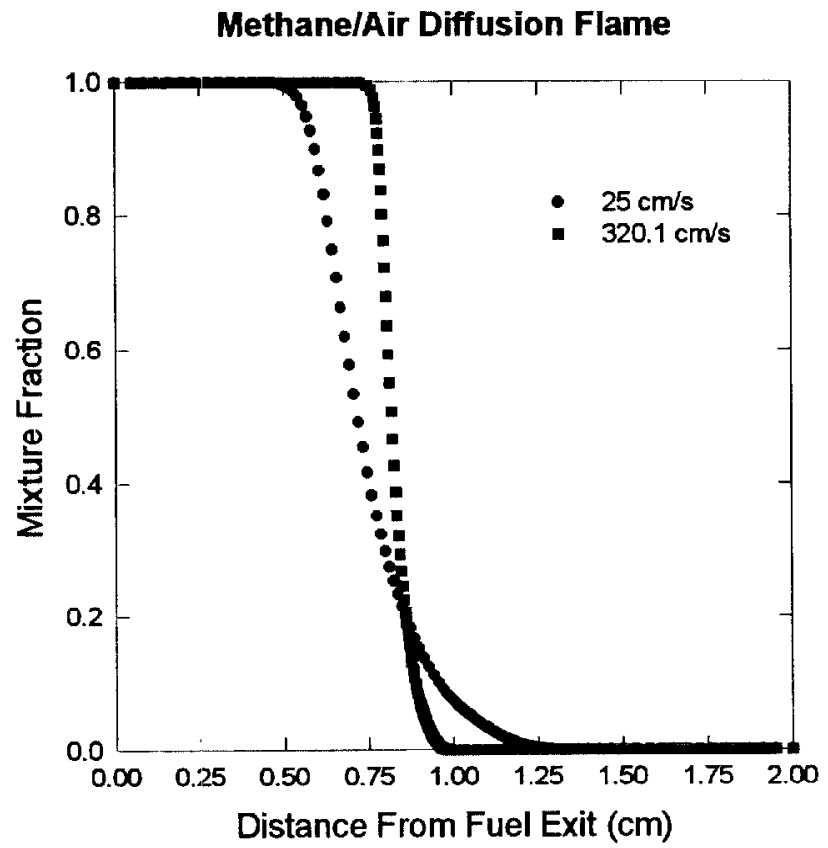

Figure 4 Mixture fraction is plotted as a function of distance from the fuel exit for low exit velocity magnitudes $(25 \mathrm{~cm} / \mathrm{s}$ for fuell and air) and for a condition very close to extinction $(320.1 \mathrm{~cm} / \mathrm{s})$. 


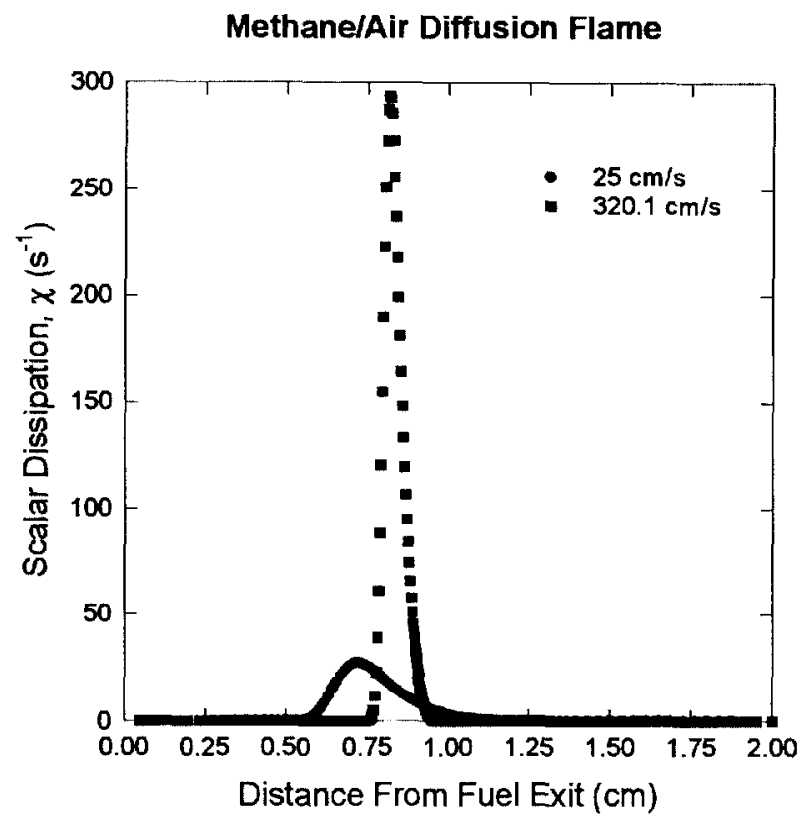

Figure 5. Calculated scalar dissipation rates, $\chi$, are plotted as a function of distance from the fuel exit for low exit velocity magnitudes $(25 \mathrm{~cm} / \mathrm{s}$ for fuel and air) and for a condition very close to extinction $(320.1 \mathrm{~cm} / \mathrm{s})$.

possible to calculate the scalar dissipation rate, $\chi$, as a function of $x$ using Eq. (11). Figure 5 shows the results, which demonstrate the strong dependence of $\chi$ on the flow velocities. The value of $\chi$ at the stoichiometric surface, $\chi_{s}$, can now be determined by interpolating the results to find the value of $\chi$ for a mixture fraction of 0.055 , the stoichiometric value. The results are $\chi_{\mathrm{s}}=1.70 \mathrm{~s}^{-1}$ and $\chi_{\mathrm{s}}=20.7 \mathrm{~s}^{-1}$ for fuel and air exit velocity magnitudes of $25 \mathrm{~cm} / \mathrm{s}$ and $320.1 \mathrm{~cm} / \mathrm{s}$, respectively.

In Figure 6 maximum calculated flame temperatures are plotted as a function of $\chi_{\mathrm{s}}$ for a series of methane/air flames in which the fuel and air velocities were varied. The temperature drops with increasing $\chi_{\mathrm{s}}$, and extinction is calculated to occur for $\chi_{\mathrm{s}}=20.7 \mathrm{~s}^{-1}$.

In order to obtain insights into the effect of the separation of the fuel and oxidizer sources, calculations were also performed for $L=1.0 \mathrm{~cm}$. Table 8 compares the various measures used to quantify extinction for the two sets of calculations and includes the maximum flame temperature at extinction. While the initial flow velocities required for extinguishment depend strongly on $L$, the various measures for the effects of strain vary only slightly for the two cases. These minor differences are most likely due to the variations in the grids used for the calculations. These limited results suggest that for the assumed initial conditions, i.e., no radial gradients at the fuel and air exits, the velocities of fuel and air required for extinction are roughly proportional to $L$, while the various measures used to describe the role of strain are roughly independent of $L$.

It is of interest to compare the results of the current calculations with comparable modeling results found in the literature. Parameters used to characterize methane/air diffusion flames near extinction are included in Table 8 for a number of studies. Substantial variations are evident for calculated extinction parameters in terms of $a_{g}$, $\left|a_{o}\right|$, and $\chi_{\mathrm{s}}$. The three sets of results for Tanoff et al. provide a strong clue as to a possible reason for these 


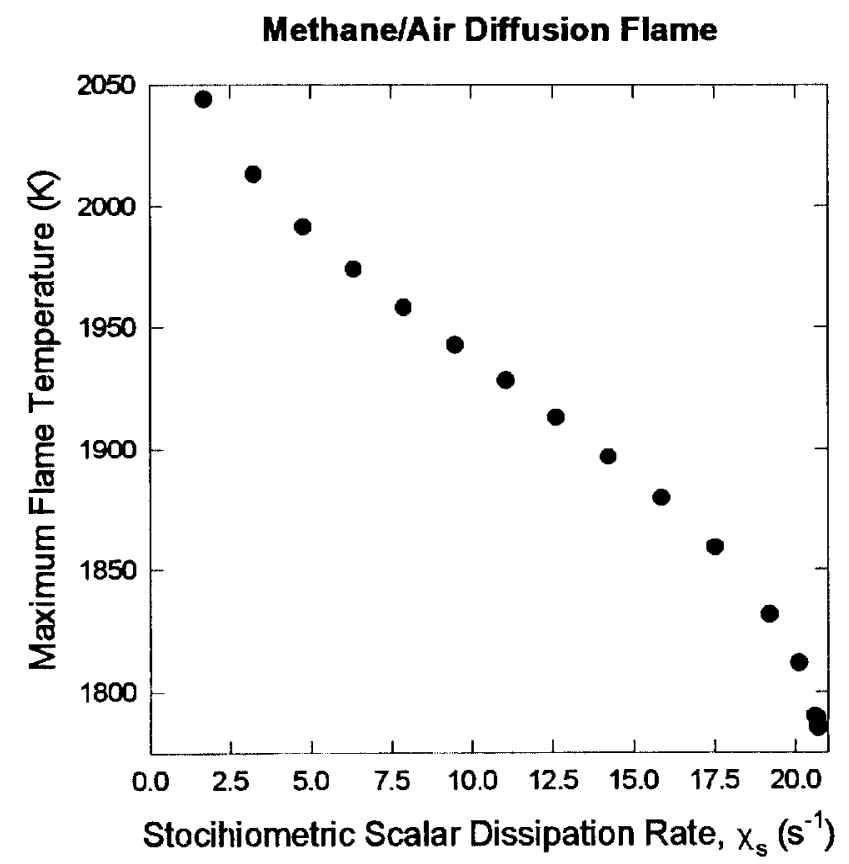

Figure 6. Values of maximum flame temperature for opposed-flow methane/air diffusion flames are plotted as a function of $\chi_{\mathrm{s}}$ which is varied by changing the velocities of the fuel and air. Extinction is calculated to occur for $\chi_{s}=20.7 \mathrm{~s}^{-1}$.

Table 8. Various Measures of Strain Rate Calculated for the Methane/Air Diffusion Flame at Extinction

\begin{tabular}{|c|c|c|c|c|c|c|c|}
\hline Source & $\mathrm{L}(\mathrm{cm})$ & $\mathrm{u}_{\mathrm{f}}(\mathrm{cm} / \mathrm{s})$ & $\mathrm{u}_{\mathrm{o}}(\mathrm{cm} / \mathrm{s})$ & $\mathrm{a}_{\mathrm{g}}\left(\mathrm{s}^{-1}\right)$ & $\mathrm{a}_{\mathrm{o}}\left(\mathrm{s}^{-1}\right)$ & $\chi_{\mathrm{s}}\left(\mathrm{s}^{-1}\right)$ & $\mathrm{T}_{\max }(\mathrm{K})$ \\
\hline This Work & 1.0 & 157 & -157 & 547 & 500 & 19.9 & 1792 \\
\hline This Work & 2.0 & 320 & -320 & 558 & 509 & 20.7 & 1785 \\
\hline Dixon-Lewis et al. $^{35}$ & 1.0 & - & - & - & - & 16.7 & 1769 \\
\hline Chelliah et al. $^{39}$ & 1.0 & 185 & -135 & 610 & 391 & 14.7 & 1758 \\
\hline Du and Axelbaum $^{70}$ & 0.8 & - & - & - & 494 & - & 1770 \\
\hline Tanoff et al. $^{57}$ & - & - & - & & 350 & - & 1808 \\
\hline Tanoff et al. $^{57}$ & - & - & - & - & 490 & - & - \\
\hline Tanoff et al. $^{57}$ & & & - & & 585 & - & - \\
\hline Chan et al. $^{47}$ & - & - & - & - & - & 19.4 & 1773 \\
\hline Lentati and Chelliah $^{58}$ & 1.0 & - & - & - & 425 & - & 1790 \\
\hline
\end{tabular}

variations. [57] The only changes between the calculations are that different detailed chemical kinetic mechanisms were used for each. Values of $\left|a_{o}\right|$ vary by nearly a factor of two. One of the mechanisms used by Tanoff et al. was GRI-Mech 2.11 which would be expected to provide similar results to the calculations reported here. The actual difference is roughly $15 \%$. This is somewhat larger than expected. We are not able to provide an explanation for the discrepancy. The only other study which used GRI-Mech 2.11 was that of Chan et al. [47] Their value of $\chi_{s}=19.4 \mathrm{~s}^{-1}$ is quite close to those of $19.9 \mathrm{~s}^{-1}$ and $20.7 \mathrm{~s}^{-1}$ given in Table 8 for 
the current investigation. We conclude that the current results are consistent with existing literature findings, but there is a relatively large uncertainty in the quantitative results which are sensitive to the detailed chemical mechanisms used.

\section{Effects of Nitrogen Addition on Diffusion Flame Extinction and Extinguishment}

The purpose of these calculations was to investigate the effects of thermal agents on the structure of opposed flow diffusion flames and to use the findings to gain insights into flame extinguishment by these agents. Note that we are purposefully distinguishing the meanings of flame "extinction" and "extinguishment". Extinction is used to describe a flame which goes out due to the local strain rate or other conditions causing the flame to become unstable. Flame extinguishment refers to the more specific conditions necessary to put out buoyancydominated flames which are expected to be characteristic of most fires. The cup burner test is an example of an cxperimental technique designed to characterize extinguishment. Thus flame extinguishment can be considered as a particular case of flame extinction.

In order to evaluate the effectiveness of the calculations, it is necessary to compare with experimental findings. The most appropriate measure for characterizing diffusion flame extinguishment is the amount of thermal agent required to extinguish a buoyancy dominated flame burning at standard gravity. This concentration is related to the concept of a limiting oxygen index (LOI), which is the lowest oxygen concentration which can support a flame under such conditions. The minimum agent amount required to meet this condition is sometimes referred to as the inerting concentration. Appropriate experimental data are often reported in terms of inerting concentrations or LOIs.

Despite the large number of studies previously reported for methane combustion, we were only able to identify three measurements which provided the LOI for methane flames burning in air with an added thermal agent. All three studied the effect of added nitrogen. Simmons and Wolfhard [71], Ishizuka and Tsuji [72], and Puri and Seshadri [69] reported LOI values for added nitrogen of $0.139,0.143$, and 0.15 , respectively, which correspond to $33.8 \%, 31.9 \%$, and $28.6 \%$ by volume nitrogen added to air. These three measurements are in reasonable agreement. Simple averaging of the two higher values yields an estimate of $33 \%$ which will be taken as the extinguishing concentration for nitrogen. Simmons and Wolfhard calculated the adiabatic flame temperature for a stoichiometric premixed flame corresponding to their extinction condition as $1820 \mathrm{~K}$. Ishizuka and Tsuji used thermocouples to measure the maximum flame temperature in their diffusion flame as $1483 \mathrm{~K}$ for the LOI condition, while Puri and Seshadri recorded a value of $1595 \mathrm{~K}$.

A series of calculations were performed for methane opposed-flow diffusion flames reacting with air containing various percentages of added nitrogen. Figure 7 shows the results. Several points are immediately obvious. As the percentage of added nitrogen increases, the fuel and oxidizer velocity magnitudes sufficient to cause flame extinction decrease. The maximum flame temperaturc at cxtinction also decreases with increasing nitrogen concentration. The negative slopes of the plots for $T_{\max }$ versus velocity increase in absolute value as the concentration of nitrogen increases.

The concentration of added nitrogen estimated to correspond to the experimental LOI is $33 \%$. The value of $T_{\max }$ at extinction for this condition is $1545 \mathrm{~K}$. This is very close to the experimental values of $1483 \mathrm{~K}$ and 1595 reported by Ishizuka and Tsuji. [72] and Puri and Seshadri [69], respectively. In fact, the agreement is probably better than a simple comparison indicates since the thermocouple measurements of Ishizuka and Tsuji were not corrected for radiative heat losses, which would be expected to decrease the measured temperature below the actual temperature. The thermocouple measurements of Puri and Seshadri were corrected for radiative heat losses. The calculated temperature is expected to be a slight overestimate due to neglect of radiative heat losses from flame gases. 
Nitrogen Dilution of $\mathrm{CH}_{4} /$ Air Diffusion Flames

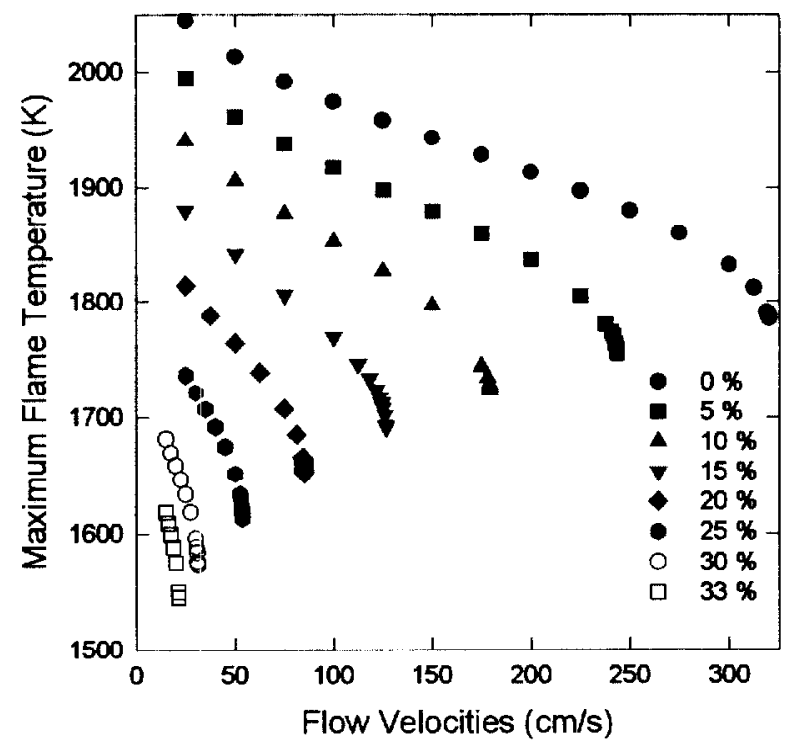

Figure 7. Maximum calculated flame temperatures are plotted against methane and oxidizer exit velocity magnitudes for a series of methane/air opposed flow diffusion flames diluted with nitrogen. Symbols correspond to the percentage of added nitrogen.

These estimates for the maximum flame temperature at extinguishment are consistent with others available in the literature. Sheinson et al. indicate that hydrocarbon combustion is not sustainable when the maximum flame temperature drops below roughly $1600 \mathrm{~K}$. [73] This estimate is based upon work by Roberts and Quince. [74] Very recently, Babb et al, have reported flame temperature measurements in heptane flames near their extinguishment points using air diluted by $\mathrm{N}_{2}$ and $\mathrm{CO}_{2}$. [75] For both thermal agents maximum flame temperatures at extinguishment were on the order of $1500 \mathrm{~K}$. Similar measurements using propane as fuel gave maximum flame temperatures of $1600 \mathrm{~K}$ and $1700 \mathrm{~K}$ for $\mathrm{N}_{2}$ and $\mathrm{CO}_{2}$, respectively.

For the conditions corresponding to the assumed LOI for nitrogen, the velocities of the fuel and air at extinction are calculated to be $21.42 \mathrm{~cm} / \mathrm{s}$. Corresponding values for the various measures uscd to characterize the flow condition at extinction are $a_{g}=37.5 \mathrm{~s}^{-1},\left|a_{o}\right|=27.0 \mathrm{~s}^{-1}$, and $\chi_{\mathrm{s}}=0.80 \mathrm{~s}^{-1}$. It is interesting to see how the various measures vary relative to each other with added nitrogen concentration. Figure 8 shows $a_{g} /\left|a_{o}\right|, a_{g} / \chi_{\mathrm{s}}$ and $\left|a_{o}\right| / \chi_{\mathrm{s}}$ versus percentage of added nitrogen. It is clear that the three measures have different dependencies on the amount of thermal agent added. The reason for this is the variation in the thickness of the boundary layer as the flow velocities are changed. The dependence on concentration requires that great care be exercised when comparing results in terms of different measures of strain rate.

An important question is: what strain rate is appropriate to use when determining the minimum value of an added thermal agent required to extinguish buoyancy-dominated diffusion flames at normal gravity? The only discussion of this point of which we are aware was presented by Hamins et al. [76] These authors compared cup burner measurements (heptane fuel) of extinguishing concentrations for a variety of agents with corresponding measurements made in a counterflow flame. The counterflow measurements were made over a range of flow velocities which wcrc characterized in terms of a global strain rate appropriate for the oxidizer flow impinging on a liquid surface. In agreement with the current calculations, the required strain rate to 
Nitrogen-Diluted Methane/Air Diffusion Flames

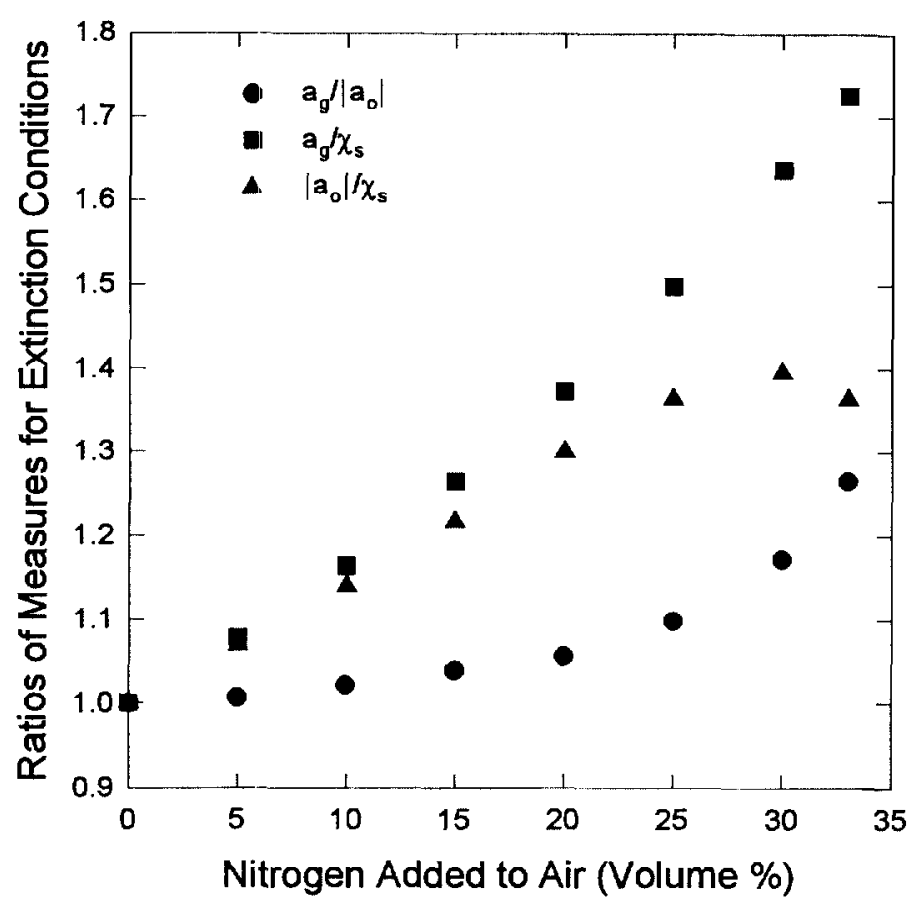

Figure 8. Ratios for the indicated measures of conditions at flame extinction are plotted as a function of the percentage of nitrogen added to the air for methane/air flames.

cause extinction of the counterflow flame decreased with the concentration of added agent. When the concentration of added agents for the opposed flame were comparable to those observed in the cup burner test, the global strain rate was on the order of $50 \mathrm{~s}^{-1}$. Due to the different boundary conditions and fuels used between the current investigation and those for Hamins et al., as well as slightly different definitions for the global strain rates, direct quantitative comparisons are not appropriate. However, it is clear that the strain rates have comparable magnitudes in each case. It is important to note that the strain rate appropriate for characterizing the LOI is much lower than typically used for experimental and modeling investigations of opposed-flow laminar diffusion flames. In their early work, Puri and Seshadri reported that extinguishment by nitrogen added to air occurred when $a_{g}$ was decreased to approximately $50 \mathrm{~s}^{-1}$. [69]

It is interesting to speculate as to why lower and lower strain rates can not be sustained for the flames at normal gravity. The most likely reason is that buoyancy effects result in a lower limit for the minimum strain rate element perpendicular to a flame surface. Buoyancy always accelerates hot combustion gases relative to the cold oxidizer with the result that the flame surface will be subject to a nonzero perpendicular strain rate. The results of Hamins et al. [76] and the current findings suggest this minimum strain rate is on the order of a few tens of inverse seconds. 


\section{Effects of Argon Addition on Extinction and Extinguishment of Methane Diffusion Flames Burning in Argon "Air"}

As already pointed out, we have identified no additional measurements of LOI for thermal agents added to methane/air diffusion flames. However, Ishizuka and Tsuji did make measurements for methane burning in an artificial "air", consisting of $21 \%$ oxygen and $79 \%$ argon. [72] This "air" was diluted with argon until a LOI was found. The result corresponded to an added argon concentration of $54.3 \%$. The measured maximum flame temperature for the LOI flame was $1443 \mathrm{~K}$, or roughly $40 \mathrm{~K}$ less than for standard air diluted with nitrogen. In order to test the ability to predict LOI concentrations of added thermal agents, a series of calculations for argon "air" diluted with argon were made.

Figure 9 shows a plot of the maximum calculated flame temperature as a function of the percentage of argon added to the argon "air" and the equal fuel and oxidizer velocity magnitudes. Comparison with Figure 7 shows that replacing nitrogen with argon has a dramatic effect on the flame behavior. First, flame temperatures are considerably higher for given diluent concentration and fuel and oxidizcr velocitics for the argon "air". This is due to the lower heat capacity of argon as compared to nitrogen. As a result of the increase in temperature, much higher flow velocities are required to generate the characteristic strain rate necessary to result in extinction of the methane flame. For the same reason, higher concentrations of argon must be added to achieve the LOI than in the nitrogen case.

The flame formed by oxidizer diluted with $50 \%$ argon is calculated to undergo extinction with a maximum temperature of $1610 \mathrm{~K}$ and methane and oxidizer velocity magnitudes of $37.8 \mathrm{~cm} / \mathrm{s}$. The corresponding results for $54 \%$ argon, corresponding to the experimental LOI, are $1473 \mathrm{~K}$ and $15.9 \mathrm{~cm} / \mathrm{s}$. These values are both slightly smaller than found for the methane/air flame diluted with nitrogen, $1545 \mathrm{~K}$ and $21.4 \mathrm{~cm} / \mathrm{s}$, respectively. However, they are remarkably close when one recalls that the use of argon instead of nitrogen should result in a significantly different flame structure due to changes in heat capacity and thermal diffusivity on going from nitrogen to argon. In fact, if one simply assumes that the LOI occurs for the same maximum flame temperature, i.e., roughly $1550 \mathrm{~K}$, as for the nitrogen-dilutcd air flamc, it is possible to cstimate the required argon concentration as $52 \%$ from Figure 9 . This is only $4 \%$ less than the experimental value. Thus, assuming that the LOI corresponds to the added concentration necessary to reduce the maximum calculated flame temperature at extinction to $1550 \mathrm{~K}$ should provide an excellent estimate for the percentage of an arbitrary thermal agent required to extinguish a fire. This estimation method is similar to the approach suggested by Sheinson et al. [73]

\section{E. Calculated Extinguishing Concentrations for Several Gaseous Thermal Agents}

Opposed flow diffusion flame calculations have been used to estimate the required extinguishing concentration, i.e., the added concentration corresponding to the LOI, for a number of gases which are expected to act primarily as thermal agents. Figures $10-13$ show plots of the maximum calculated flame temperature as a function of the fuel and oxidizer velocity magnitudes, where air has been diluted by the indicated percentages of argon, helium, carbon dioxide, and water, respectively. It should be noted that both water and carbon dioxide are products of methane combustion and could conceivably modify the combustion chemistry slightly. However, both are believed to act primarily as thermal agents. For water, the vapor pressure at the lower temperatures is less than required to generate the concentrations assumed in the calculations. As an example, at $300 \mathrm{~K}$ the water vapor pressure is $3.57 \mathrm{kPa}$, which corresponds to a mole fraction of 0.035 in atmospheric air. Therefore, for temperatures near $300 \mathrm{~K}$, the higher water vapor concentrations are assumed to be supersaturated. 


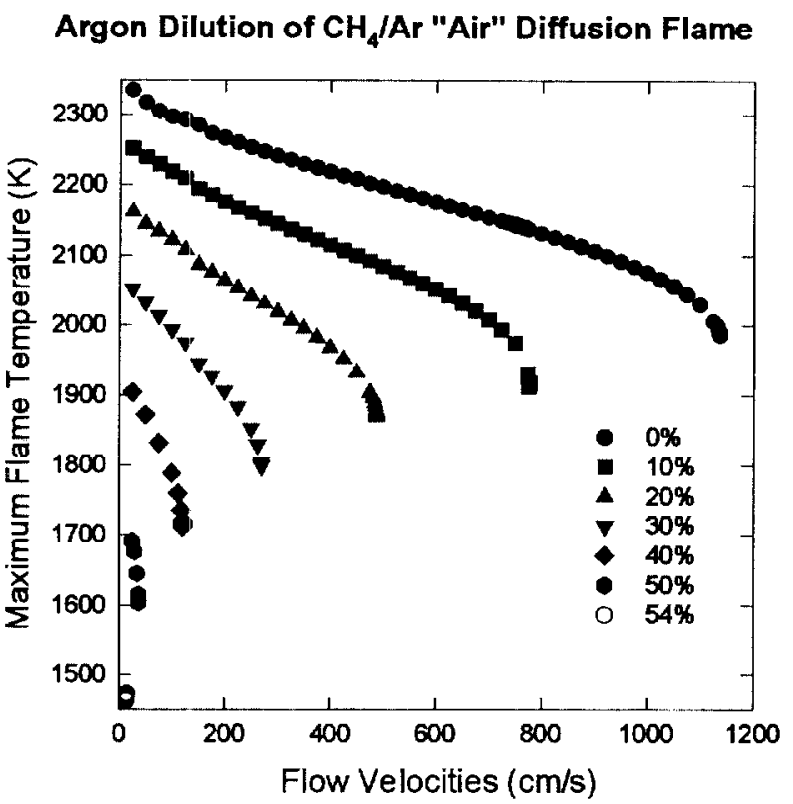

Figure 9. Maximum calculated flame temperatures are plotted against methane and oxidizer flow velocity magnitudes for a series of methane/argon "air" opposed flow diffusion flames diluted with argon. Symbols correspond to the percentage of added argon.

Argon Dilution of $\mathrm{CH}_{4}$ /Air Diffusion Flames

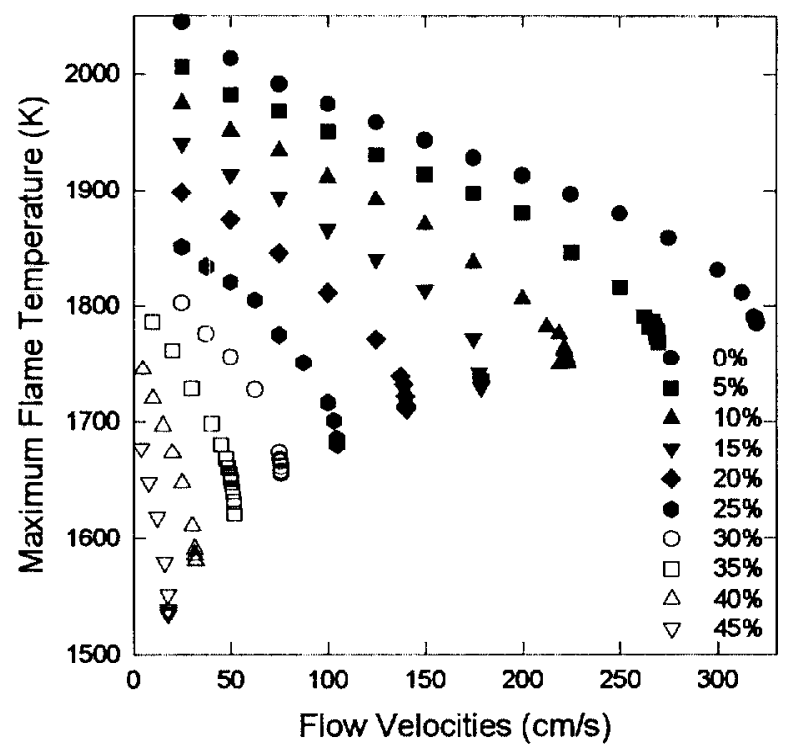

Figure 10. Maximum calculated flame temperatures are plotted against methane and oxidizer flow velocity magnitudes for a series of methane/air opposed flow diffusion flames diluted with argon. Symbols correspond to the percentage of added argon. 
Helium Dilution of $\mathrm{CH}_{4} /$ Air Diffusion Flames

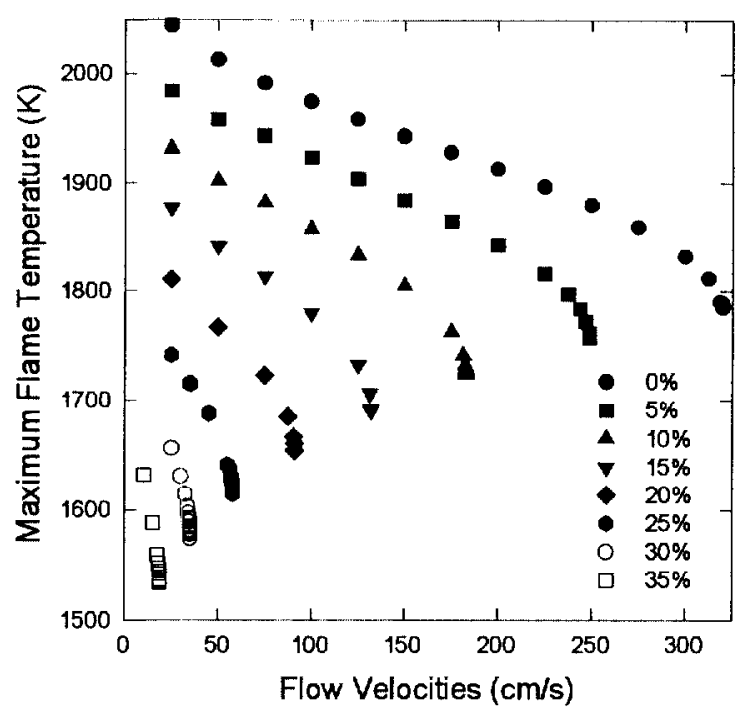

Figure 11. Maximum calculated flame temperatures are plotted against methane and oxidizer flow velocity magnitudes for a series of methane/air opposed flow diffusion flames diluted with helium. Symbols correspond to the percentage of added helium.

Carbon Dicxide Dilution of $\mathrm{CH}_{4} /$ Air Diffusion Flames

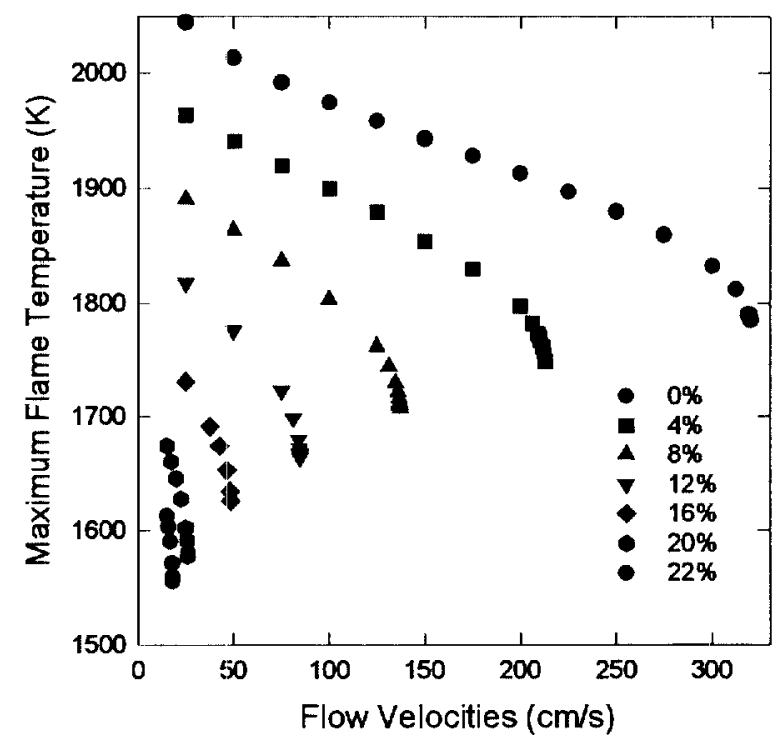

Figure 12. Maximum calculated flame temperatures are plotted against methane and oxidizer flow velocity magnitudes for a series of methane/air opposed flow diffusion flames diluted with carbon dioxide. Symbols correspond to the percentage of added carbon dioxide. 


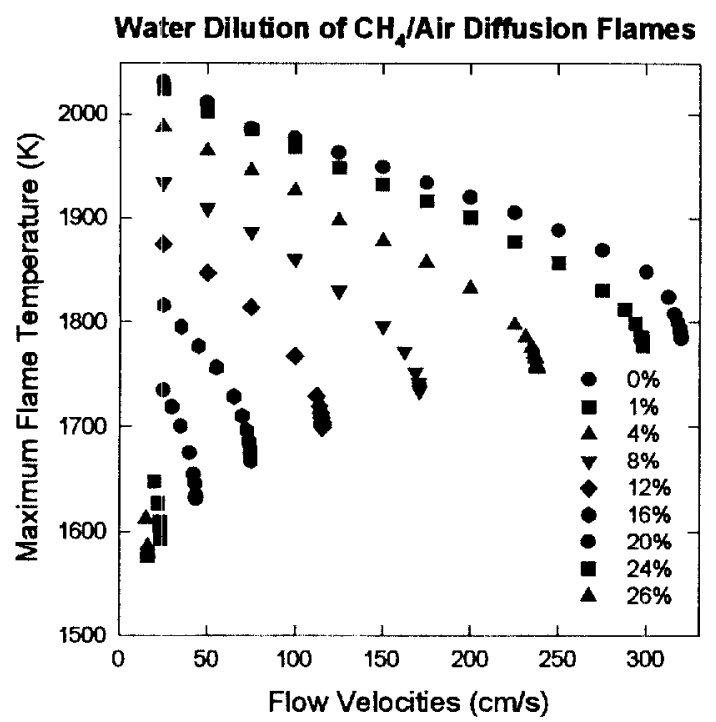

Figure 13. Maximum calculated flame temperatures are plotted against methane and oxidizer flow velocity magnitudes for a series of methane/air opposed flow diffusion flames diluted with water vapor. Symbols correspond to the percentage of added water vapor.

Table 9. Extinguishing Concentrations (Mole Fraction) of Thermal Agents

\begin{tabular}{|c|c|c|c|c|c|}
\hline Thermal Agent & Current Work & Cup Burner [73] & Cup Burner [75] & Cup Burner [77] & Cup Burner [78] \\
\hline Nitrogen & 0.33 & 0.30 & 0.33 & 0.32 & 0.30 \\
\hline Argon & 0.43 & 0.41 & - & 0.41 & 0.38 \\
\hline Helium & 0.34 & 0.32 & - & 0.31 & - \\
\hline Carbon Dioxide & 0.22 & 0.21 & 0.20 & 0.23 & 0.20 \\
\hline Water & 0.28 & - & - & - & - \\
\hline
\end{tabular}

By assuming the limit temperature is $1550 \mathrm{~K}$, it is possible to estimate the extinguishing concentrations for each of these thermal agents. These estimates are tabulated in Table 9. As already discussed, the only experimental values for opposed flow methane diffusion flames we have identified for these agents are for nitrogen dilution. Cup burner determinations of extinguishing concentrations using heptane as fuel have been reported for some of these thermal agents by Sheinson et al. [73], Babb et al. [75], Hamins et al. [77] and Moore et al. [78] These values are included in Table 9 for comparison purposes. The maximum difference between values calculated for methane and the experimental values for heptane is $12 \%$, with the vast majority being less than $10 \%$. With the exception of carbon dioxide, the cup burner measurements are somewhat lower than for the counterflow flame. The differences between the cup burner and opposed flow flame results could be due to the use of different fuels or to differences in burner configuration. The heptane fires are burning just above a liquid fuel in a coflow of oxidizer, and it may be easier to blow out this type of flame than the opposed flow diffusion flame which is stabilized away from surfaces. The close tracking of the calculated results and the experimental findings suggests that detailed chemical kinetic modeling can accurately predict the amount of a thermal agent required to extinguish opposed flow diffusion and cup burner flames. 
The differences in the extinguishing concentrations of helium and argon are interesting since these agents are both monatomic gases and have the same heat capacities. The difference is clear in both the calculations and the experimental values. The fact that helium is a more efficient extinguishing agent means that at least one other parameter, in addition to heat capacity, is important in determining extinguishing efficiency. A related observation was reported by Coward and Hartwell for the inerting of premixed flames and was attributed to the much higher thermal conductivity of helium which distributes the heat of combustion over a larger region of space and therefore weakens the flame. [79] The same explanation is most likely valid for diffusion flames. Sheinson et al. reached the same conclusion. [73]

Inspection of the various curves for the dependence of calculated maximum flame temperature on the fuel and oxidizer velocity magnitudes in Figs. 7 and 10-13 shows that for given velocities and extinction temperatures, they have very similar shapes. This is true despite the fact that the amount of added agent and, therefore, the oxygen concentration and stoichiometric ratio vary dramatically with agent. This is confirmed by Figure 14 which shows the maximum flame temperature at extinction as a function of fuel and oxidizer exit velocity magnitudes for the five thermal agents added to air as well as the results for argon added to argon "air". The data fall within a narrow band on either side of a well defined curve.

Closer inspection of Figure 14 shows that the data for argon "air" tend to fall at higher temperatures by amounts which decrease with dilution, while the water vapor data tend to lie near the top of the band by amounts which increase with dilution. The difference between adding argon to air and argon "air" is most likely duc to the different physical propertics of argon and nitrogen. Apparently, these differences are most important for high strain rates and are relatively minor at the lower strain rates typical of buoyancy-dominated diffusion flames. Recall that the estimated value of the extinguishing concentration for argon added to argon "air" was in good agreement with the experimental value of Ishizuka and Tsuji. [72] The increasing differences with decreasing strain rate for water may be due to two possible effects. The first is the higher thermal diffusivity expected for the relatively small water molecule. However, the results for helium, which has a much higher thermal diffusity, fall close to the results for nitrogen, argon, and carbon dioxide. The second possible explanation is that the water vapor slightly modifies the chemical structure of the flame and seems the more likely of the two. Increases in water concentration can interact with the flame chemistry through a number of reactions including the well known water-gas shift reaction,

$$
\mathrm{H}_{2} \mathrm{O}+\mathrm{CO} \Leftrightarrow \mathrm{CO}_{2}+\mathrm{H}_{2}
$$

The addition of water to the oxidizer is expected to drive this equilibrium towards the right, resulting in additional heat release and a slightly higher temperature, as observed. The findings of Lentati and Chelliah indicate that water does display a small chemical effect. [59] Dilution with carbon dioxide would be expected to drive the equilibrium in Eq. (13) in the opposite direction, however, this effect on extinguishment must be small since the carbon dioxide results lie very close to those for nitrogen, argon, and helium.

Simply plotting the results in terms of the exit velocity magnitudes of methane and oxidizer at extinction leads to a collapse of the results for different thermal agents to a well defined curve. It is of interest to see if the collapse is improved by plotting the data in terms of the global strain rate given by Eq. (12), $a_{g}$, or the maximum absolute value of the characteristic strain rate element on the oxidizer side lying outside of the boundary layer, $\left|a_{o}\right|$. Figure 15 and Figure 16 show the data plotted in terms of these two characteristic strain rates. The overall appearances of the two plots are very similar to Figure 14, which is simply in terms of the exit velocities. For this reason, further discussion is based only on the flow velocity magnitudes for methane and oxidizer. 


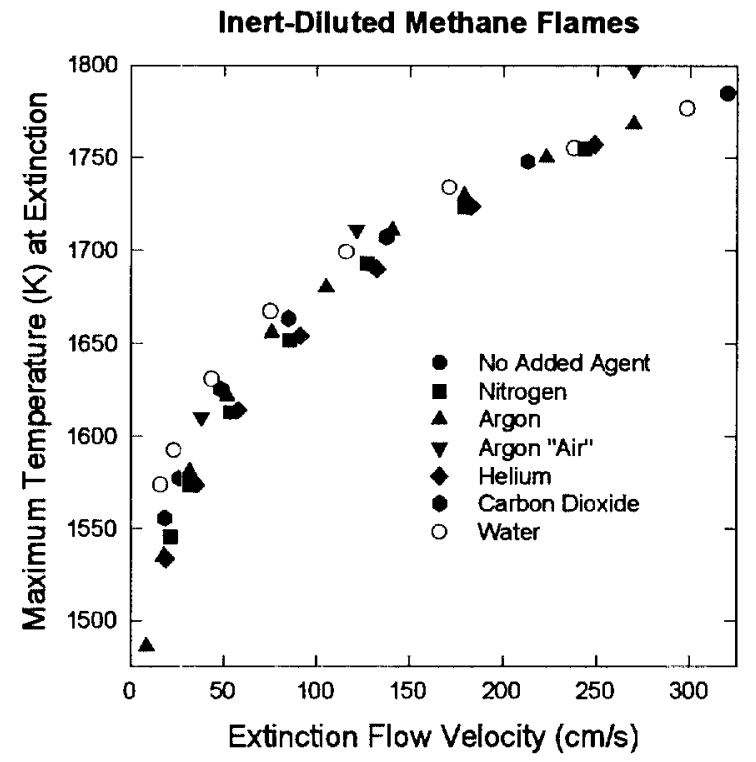

Figure 14. Values of maximum flame temperature at extinction are plotted as a function of the corresponding fuel and oxidizer velocity magnitudes for a range of concentrations of various thermal agents.

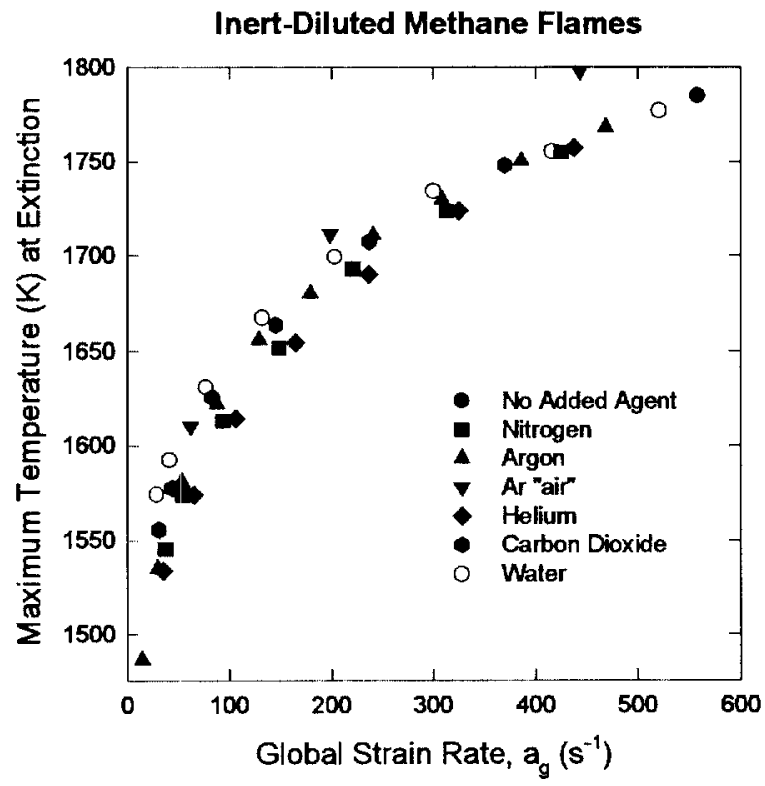

Figure 15. Values of maximum flame temperature at extinction are plotted as a function of the corresponding global strain rates, $a_{g}$, for a range of concentrations of various thermal agents. 


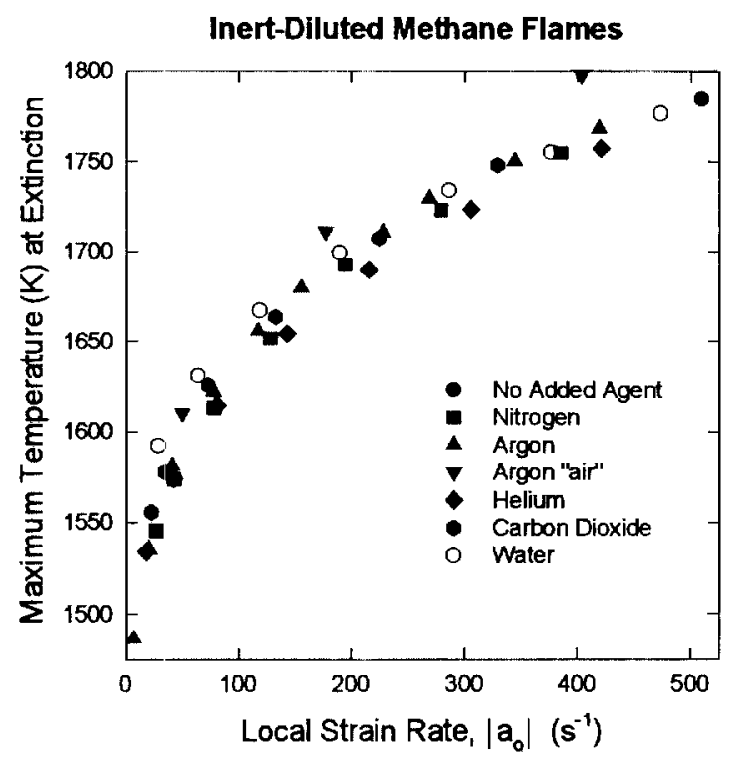

Figure 16. Values of maximum flame temperature at extinction are plotted against the corresponding characteristic local strain rates, $\left|a_{o}\right|$, defined as the highest absolute value of strain rate observed outside of the boundary layer on the oxidizer side of the flame, for a range of concentrations of various thermal agents.

A more quantitative idea of the degree of correlation between the maximum calculated flame temperatures at extinction and the fuel and oxidizer flow velocity magnitudes is obtained from Figure 17 where the results for $\mathrm{N}_{2}$, Ar, $\mathrm{He}$, and $\mathrm{CO}_{2}$ addition have been consolidated and fit to two piecewise fourth order polynomials on either side of $105 \mathrm{~cm} / \mathrm{s}$. The resulting fits are drawn as a solid line. The coefficients of determination for the nonlinear curve fits were 0.97 and 0.98 , which indicate a high degree of confidence in the fits. The polynomials can be used to predict values of maximum temperature for given exit velocities.

To determine if there is a relationship between added agent concentration and the calculated maximum temperature at extinction, the temperatures were plotted versus the ratio of the percentage of added agent and that required for extinguishment as shown in Figure 18. The results for argon added to argon "air" lie well away from the remaining data. The trend of less effectiveness of water vapor at low velocities is also evident. While the data partially collapse for the remaining agents, the spread indicates that simply calculating a single extinction condition for a single agent concentration will not suffice for predicting the extinguishing concentration for that agent.

\section{F. Effects of Dilution and Heat Extraction Location Relative to the Flame Front on Extinction and Extinguishment of Diffusion Flames}

An important advantage of modeling investigations is the ability to perform calculations for conditions which are not physically possible in order to leam details concerning the role of various system parameters. One question which has been the subject of speculation is the relative importance of heat extraction and dilution on the effectiveness of a thermal agent. Here dilution effects refer to any role of a thermal agent which is not simply due its ability to extract heat. In order to obtain insights into this behavior, an artificial agent was 


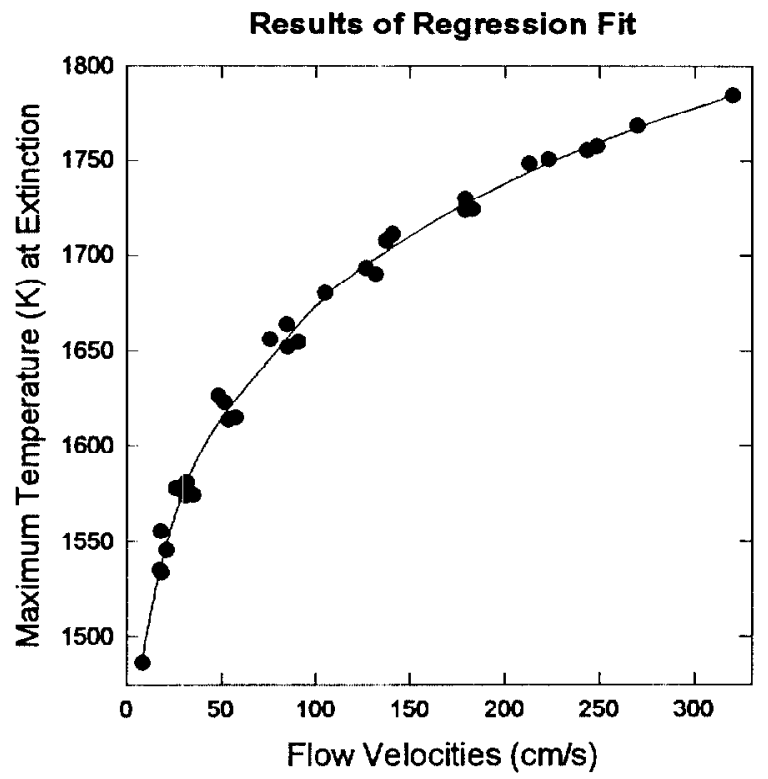

Figure 17. Maximum flame temperatures at extinction for $\mathrm{N}_{2}, \mathrm{Ar}, \mathrm{Ie}$, and $\mathrm{CO}_{2}$ as a function of the corresponding fuel and oxidizer velocity magnitudes are fit by two piecewise fourth order polynomials (solid line).

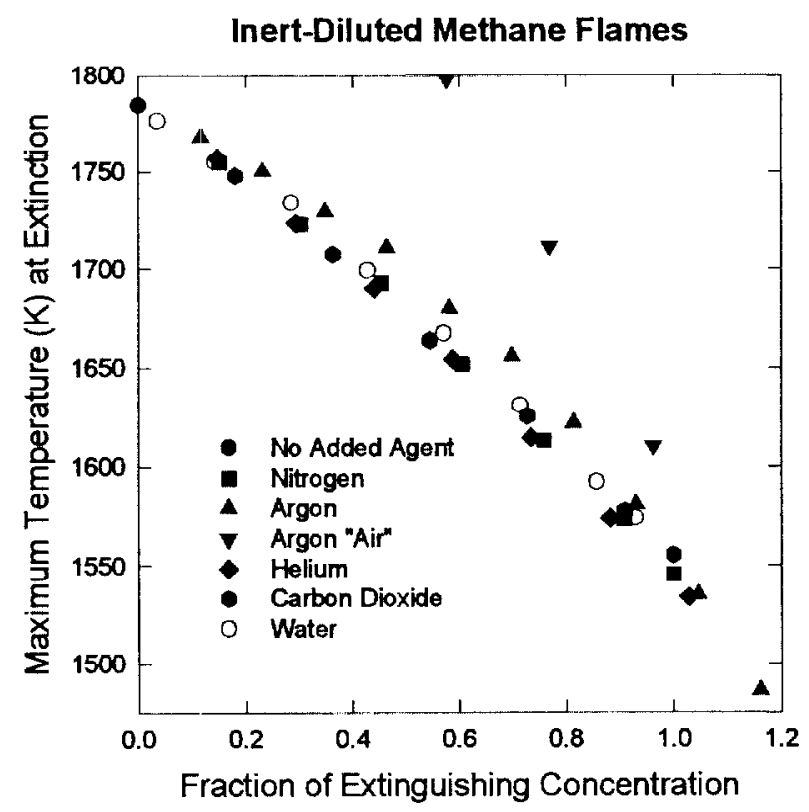

Figure 18. The maximum temperature at extinction for counterflow methane flames is plotted as a function of the percentage of a thermal agent added to air divided by the amount calculated to be required for flame extinguishment. 
created by starting with argon and setting its heat capacity to zero. Direct comparison with the results for added argon allows the relative roles of heat extraction and dilution to be characterized. Sheinson et al. have discussed the effects of dilution on extinguishment. [73] They concluded that they are relatively small compared to direct heat removal due to heat capacity for the thermal agents $\mathrm{CF}_{4}$ and $\mathrm{SF}_{6}$.

Figure 19 is a plot of calculated maximum flame temperature versus fuel and oxidizer velocity magnitudes for the zero-heat-capacity argon added to air. It is obvious that this species does decreases the strength of the flame, but that its effect is much smaller than for the argon results shown in Figure 10 . Based on an extinguishment temperature of $1550 \mathrm{~K}$, the extinguishing concentration can be estimated as $73 \%$ or roughly 1.7 times greater than required for argon. This corresponds to an oxygen concentration of $5.7 \%$ at the $\mathrm{LOI}$. Interestingly, the dependence of the maximum flame temperature at extinction on the fuel and oxidizer velocities is very similar for both sets of calculations as can be seen in Figure 20 where they are compared. The solid line is that shown in Figure 17, which was derived by fitting to the results for $\mathrm{N}_{2}, \mathrm{Ar}, \mathrm{He}$, and $\mathrm{CO}_{2}$. The data for the zero-heat-capacity argon fall slightly below those for argon, but it is clear that simple dilution of air has a similar effect on the flame as heat absorption by an inert. Assuming that the effects of heating an inert and dilution are additive, as suggested by this close correspondence, the effectiveness of $\mathrm{Ar}$ as a thermal agent is estimated to be $41 \%$ due to dilution and $59 \%$ due to heat extraction.

The availability of detailed flame structure information from the calculations allows the effect of a zero-heatcapacity diluent to be understood. As a starting point, it is important to recognize that flames burning in air and air diluted with a zero-heat-capacity agent have identical adiabatic flame temperatures. This suggests that the observed decreases in maximum temperature must be due to redistribution of the heat generated by combustion over a larger region of space and/or a reduction in the amount of heat released. In order to investigate this point, results for a methane counterflow diffusion flame burning in air are compared with those for a flame burning air diluted with $60 \%$ of the zero-heat capacity diluent in Figure 21 . It is evident that while the maximum flame temperature is significantly reduced by the addition of the agent, the spatial temperature distributions are very similar for the two flames. This suggests that the primary effect of dilution is to reduce the amount of heat released.

Figure 22 shows $\mathrm{CH}_{4}$ and $\mathrm{O}_{2}$ mole fractions as a function of distance from the burner on a semi-log plot for both flames. It can be seen that while the primary fuel is completely reacted at the flame surface, some $\mathrm{O}_{2}$ "leaks" from the oxidizer side to the fuel side. $\mathrm{O}_{2}$ reaching the fuel side of the reaction layer eventually diffuses to a location where the temperature is low enough that reaction can no longer occur. At this point the $\mathrm{O}_{2}$ acts like a diluent having a heat capacity with the result that the maximum temperature in the flame zone is reduced. Close inspection of Figure 22 shows that a significantly larger fraction of the available $\mathrm{O}_{2}$ leaks through to the fuel side of the flame when the oxidizer is diluted air as opposed to air. This difference explains the lower maximum flame temperatures calculated for burning in air diluted by an agent having no heat capacity.

The leakage of $\mathrm{O}_{2}$ through the flame front is due to the finite rates of reaction for oxidation reactions. Liñan and Williams provide a good introductory discussion of this behavior and the reasons for it. [80] Oxygen leakage was observed experimentally several decades ago [81] and was predicted by early calculations of counterflow diffusion flames [35]. Du and Axelbaum discuss the effect of $\mathrm{O}_{2}$ leakage with respect to a series of methane flame where they systematically varied the stoichiometric mixture fraction while maintaining a constant adiabatic flame temperature. [70] These authors found that the flame strength increased with increasing stoichiometric mixture fraction and argued that this was due to the shift of the $\mathrm{O}_{2}$ profile into regions of higher temperature. Decreased $\mathrm{O}_{2}$ flame leakage was also evident in the calculations with higher stoichiometric mixture fraction. Lentati and Chelliah have also noted the importance of oxygen leakage for understanding flame extinction. [59] The incrcascd $\mathrm{O}_{2}$ leakage and decreased maximum flame temperature 
Dilution by Argon Having No Heat Capacity

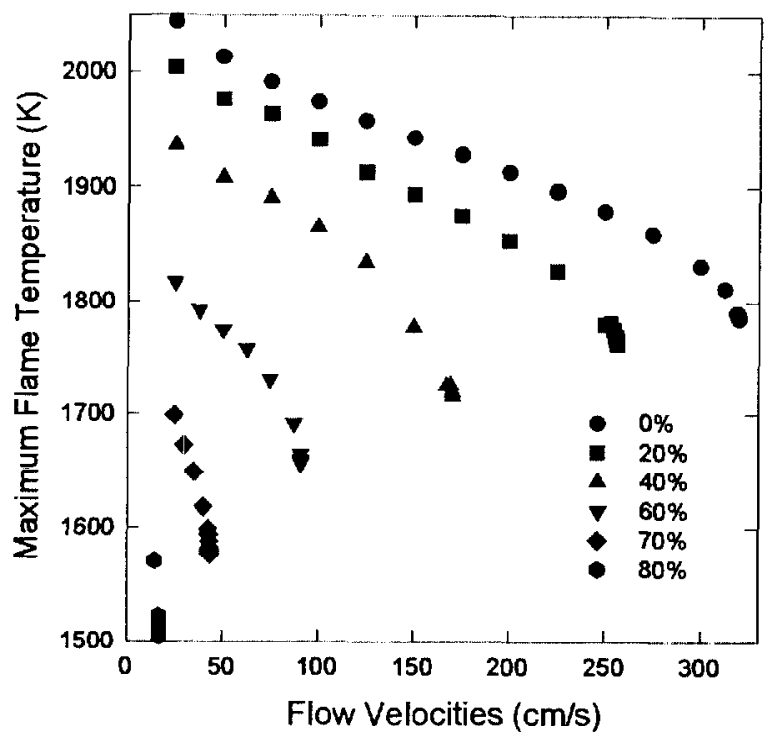

Figure 19. Maximum calculated flame temperatures are plotted against methane and oxidizer exit velocity magnitudes for a series of methane/air opposed flow diffusion flames diluted with a surrogate agent similar to argon, but with $C_{p}=0$. Symbols correspond to the percentage of surrogate agent added.

Diluted Methane/Air Flames

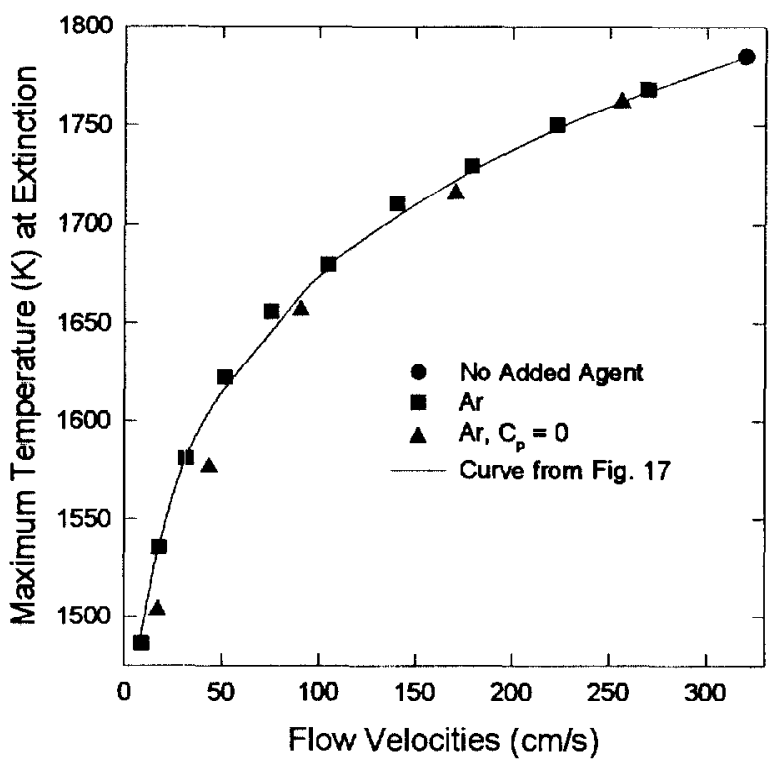

Figure 20. Values of maximum flame temperature at extinction are plotted as a function of fuel and oxidizer extinction velocity magnitudes for a range of concentrations of argon and a similar surrogate agent having $C_{p}=0$. The solid line is the result of the regression fits shown in Figure 17. 


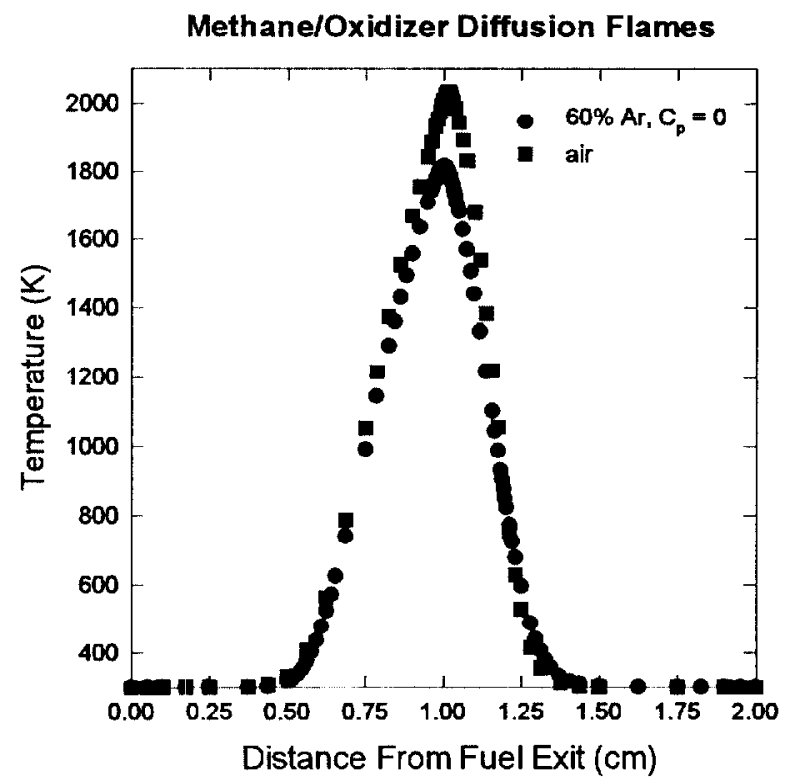

Figure 21. Temperature is plotted as a function of distance from the fuel exit for methane flames burning in air and air mixed with $60 \%$ of a diluent having similar properties to $\mathrm{Ar}$, but with zero heat capacity. Fuel and air exit velocity magnitudes are $25 \mathrm{~cm} / \mathrm{s}$ for both flames.

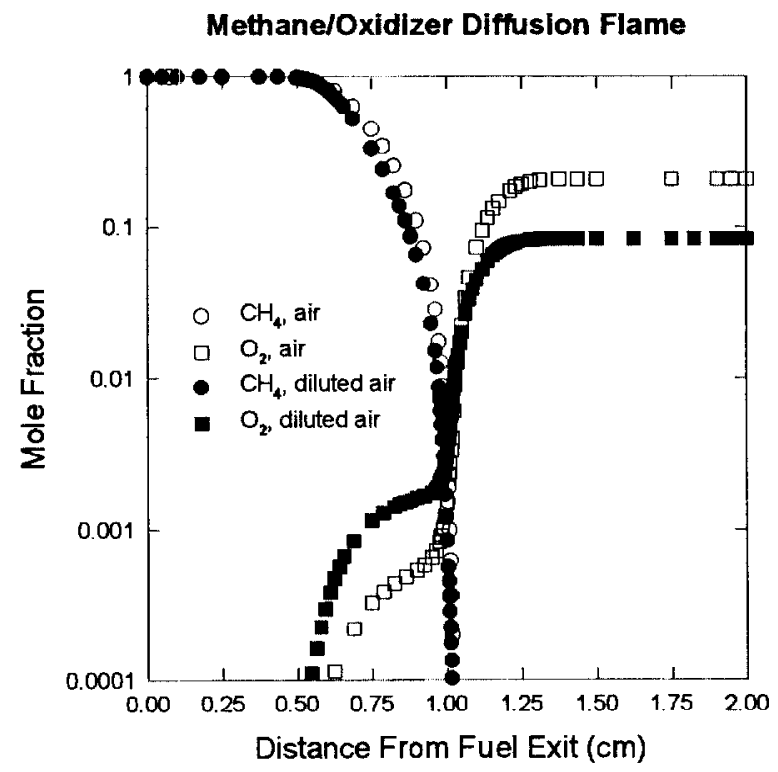

Figure 22. Calculated methane and oxygen mole fractions are shown on a semi-log plot as a function of distance from the fuel exit for methane flames burning in air (open symbols) and air mixed with $60 \%$ of a diluent having similar properties to Ar, but with zero heat capacity. Fuel and air exit velocity magnitudes are $25 \mathrm{~cm} / \mathrm{s}$ for both flames. 
observed with decreasing stoichiometric mixture fraction found for the current calculations are consistent with these trends.

One of the goals of the current work was to test the hypothesis that the effectiveness of a thermal agent depends on the location, relative to the high temperature flame zone, where heat extraction occurs. A surrogate thermal agent, $X$, was used for these calculations. The molecular weight, thermodynamic propertics, and transport properties of $\mathrm{X}$ are identical to those of argon, but it is capable of undergoing a simple reaction with ambient gases to generate a new species, Y, i.e.,

$$
\mathrm{X}+\mathrm{M} \rightarrow \mathrm{Y}+\mathrm{M}
$$

$\mathrm{Y}$ is also very similar to argon, the only difference being that its heat of formation is assigned an arbitrary positive value instead of being zero. As a result, when Reaction (14) takes place it extracts heat and cools the local surroundings by an amount equal to the heat of reaction, $\Delta H_{X-\mathrm{Y}}$. Since $\mathrm{X}$ and $\mathrm{Y}$ do not react with any other species, the reaction is effectively simply a heat sink, and $\mathrm{X}$ therefore meets the definition of a thermal agent.

The rate constant for Reaction (14) is expressed as

$$
k_{X \rightarrow Y}=A T^{\beta} e^{-E_{a} / R T},
$$

where $A$ is the pre-exponential factor, $\beta$ is the temperature exponent, $E_{a}$ is the energy of activation, $R$ is the gas constant, and $T$ is temperature. By varying the parameters $A, \beta$, and $F_{a}$ it is possible to change the temperature range over which the reaction occurs and hence the location relative to the flame zone for heat extraction. For the calculations which follow, initial values were chosen for $A$ and $\beta$, and only the value of $E_{\alpha}$ was changed in order to vary $k_{X-Y}$. One problem faced in such calculations is that due to the variations in the residence time, which depends on the velocities of the fucl and oxidizer, the completeness of reaction over a given temperature range can vary with initial conditions. For this reason, a set of calculations was performed for one value of fuel and oxidizer exit velocity magnitudes in which $E_{a}$ was varied. A relatively low value of $25 \mathrm{~cm} / \mathrm{s}$ was chosen because this condition is close to that for which flame extinguishment occurs. An initial calculation was run for which the parameters in Eq. (15) were set to $A=1 \times 10^{10} \mathrm{~cm}^{3} /\left(\right.$ mole-s), $\beta=0$, and $E_{a}=$ $25.1 \mathrm{~kJ} / \mathrm{mole}$, and the heat of formation for $\mathrm{Y}$ was chosen to be $96.1 \mathrm{~kJ} / \mathrm{mole}$. The concentration of $\mathrm{X}$ added to the air was $5 \%$. Figure 23 compares the resulting temperature profile across the flame with that calculated for the case when $5 \%$ argon is added. The heat extracted by agent $\mathrm{X}$ has lowered the temperature on the oxidizer side below ambient. The maximum flame temperature with $\mathrm{X}$ is reduced, and its position has been shifted towards the oxidizer side relative to the case with argon.

It is clear from Figure 23 that the majority of the heat extraction is occurring at low temperatures for $E_{a}=$ $25.1 \mathrm{~kJ} / \mathrm{mole}$. This can seen in Figure 24 which shows $\mathrm{X}$ and $\mathrm{Y}$ mole fractions plotted as a function of distance from the fuel exit. The corresponding temperature profile is included as the solid line. The conversion of $\mathrm{X}$ to $\mathrm{Y}$ is well advanced before the boundary layer is reached at roughly $1.3 \mathrm{~cm}$ from the fuel exit, and then rapidly accelerates. The concentration of $\mathrm{X}$ has become nearly zero by the time the location on the oxidizer side is reached where the temperature has increased to $1200 \mathrm{~K}$. The maximum calculated temperature for this flame is $1928 \mathrm{~K}$, which can be compared with a value of $2006 \mathrm{~K}$ when $5 \%$ argon is used as the diluent. 


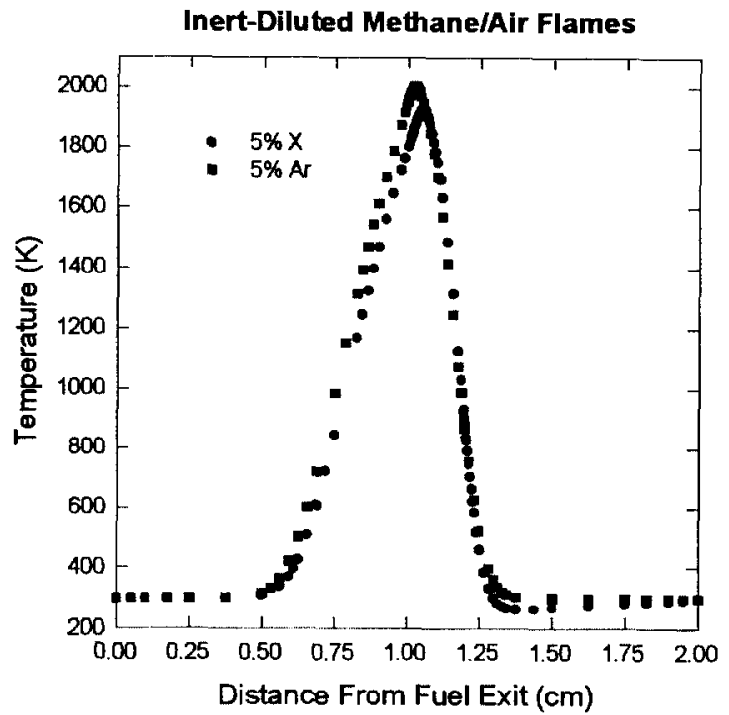

Figure 23. Calculated flame temperature is plotted as a function of distance from the fuel exit for methane/air diffusion flames where the oxidizer is diluted with $5 \%$ of either argon or the hypothetical agent $X$ which reacts to form $Y$ with $E_{a}=25.1 \mathrm{~kJ} / \mathrm{mole}$ and $\Delta H_{X \rightarrow Y}=96.1$ $\mathrm{kJ} / \mathrm{mole}$. Methane and oxidizer exit velocity magnitudes are $25 \mathrm{~cm} / \mathrm{s}$.

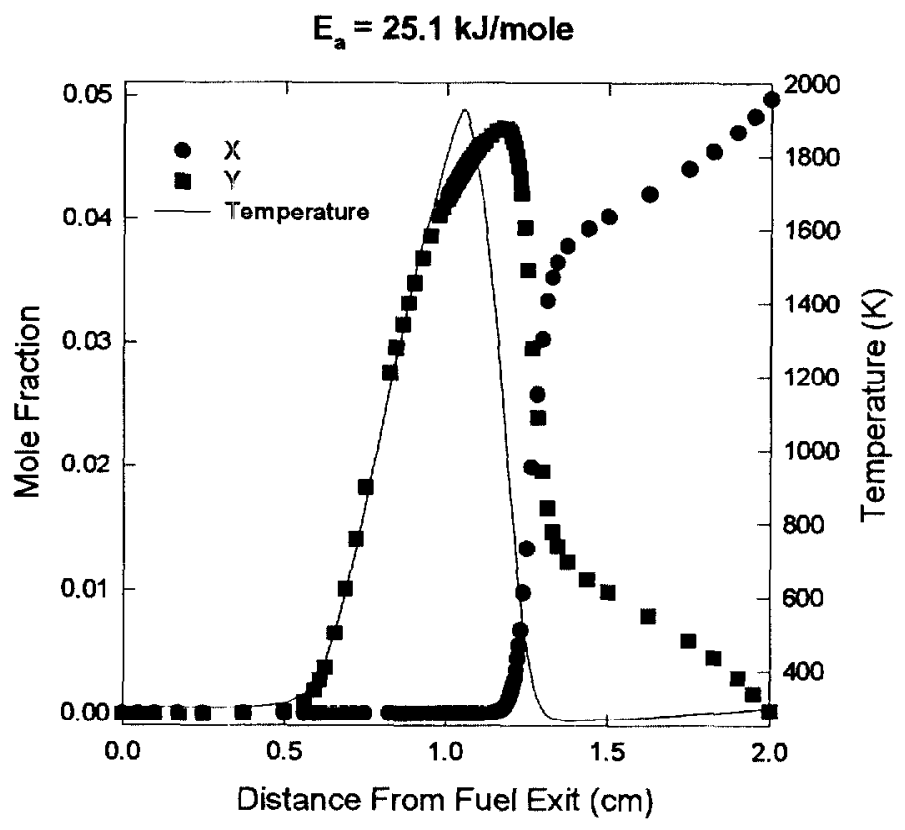

Figure 24. The mole fractions of $X$ and $Y$ are plotted as a function of distance from the fuel exit for a methane flame burning in air with $5 \%$ added $X$. X reacts to form $Y$ with $E_{a}=25.1 \mathrm{~kJ} / \mathrm{mole}$ and $\Delta H_{X-Y}=96.1 \mathrm{~kJ} / \mathrm{mole}$. The spatial variation of temperature is also shown as the solid line. Methane and oxidizer exit velocity magnitudes are $25 \mathrm{~cm} / \mathrm{s}$. 
In order to change the location where heat extraction takes place, the calculation was repeated for a series of increasing $E_{a}$. Figure 25 is similar to Figure 24 , but is for the case with $E_{a}$ increased to $58.6 \mathrm{~kJ} / \mathrm{mole}$. The reaction behavior of $\mathrm{X}$ is very different than observed for the lower $E_{a}$. The concentration of $\mathrm{X}$ does not decrease appreciably until the temperature begins to increase at the boundary layer. As the temperature begins to rise on the oxidizer side, conversion of $\mathrm{X}$ to $\mathrm{Y}$ begins and accelerates with increasing temperature. A substantial fraction of the conversion takes place for temperatures greater than $1600 \mathrm{~K}$, but, even so, the amount of unreacted $\mathrm{X}$ reaching the rich side of the flame is minimal. A maximum temperature of $1934 \mathrm{~K}$ is calculated. This is very close to the value found for $E_{a}=25.1 \mathrm{~kJ} / \mathrm{mole}$.

Figure 26 shows the results when the $E_{a}$ is increased to $83.7 \mathrm{~kJ} / \mathrm{mole}$. For this large energy of activation, the conversion of $\mathrm{X}$ to $\mathrm{Y}$ has become so slow that a substantial fraction of $\mathrm{X}$ passes through the high temperature zone without conversion to $\mathrm{Y}$. As the temperature falls on the rich side of the flame, the reaction slows down, and the remaining $X$ becomes kinetically "frozen" and simply diffuses toward the fuel side. As a result, the amount of heat absorption is less than that occurring when $\mathrm{X}$ fully reacts. This is reflected in the maximum calculated flame temperature of $1963 \mathrm{~K}$, which is intermediate between that found for X with lower $E_{a}$ 's and that for $5 \%$ argon, which only has dilution and heat capacity effects.

Figure 27 shows the maximum calculated flame temperature as a function of assumed $E_{a}$ for a series of calculations carried out for $5 \% \mathrm{X}$ added to the air. For $E_{a} \leq 50 \mathrm{~kJ} / \mathrm{mole}$ the calculated temperature is constant within the variations expected for the different grids used for the calculations. As the $E_{a}$ is increased further, the maximum temperature begins to incrcasc. As we have secn, this is due to some fraction of $\mathrm{X}$ passing through the flame to the rich side without reacting to form $\mathrm{Y}$. Since the temperature range over which the heat is absorbed by the reaction of $\mathrm{X}$ to $\mathrm{Y}$ varies widely as the $E_{a}$ increases from $25 \mathrm{~kJ} /$ mole to $50 \mathrm{~kJ} / \mathrm{mole}$, these findings show that the maximum flame temperature and, by extension, flame extinction only depend on the amount of heat extracted and not where it occurs relative to the flame zone. It is concluded that the original hypothesis concerning the role of heat absorption location by gaseous thermal agents on extinguishment is not valid. This conclusion should be contrasted with the recent results of Lentati and Chelliah, who report that the location where heat extraction occurs can be important for flame inhibition when evaporating water droplets are added to the oxidizer flow. [58,59] Their finding seems to be associated with the fact that larger water droplets do not follow the oxidizer flow streamlines, whereas gaseous agents do.

A complete set of calculations was carried out for species $\mathrm{X}$ having $\Delta H_{X-Y}=96.1 \mathrm{~kJ} / \mathrm{mole}$ and $E_{a}=41.8$ $\mathrm{kJ} / \mathrm{mole}$. The results are plotted in Figure 28 as maximum calculated flame temperature versus exit velocity magnitudes for methane and oxidizer. Based on an extinction temperature of $1550 \mathrm{~K}$, the extinguishing concentration for $X$ in air is estimated to be $15.9 \%$. The corresponding value for argon was $43 \%$. Thus the heat extracted by the reaction of $X$ to $Y$ has reduced the amount of agcnt requircd by ncarly $2 / 3$. Figure 29 compares calculated values of maximum flame temperature as a function of velocity for $15 \%, 30 \%$, and $45 \%$ added argon with the corresponding results for $5 \%, 10 \%$, and $15 \% \mathrm{X}$. The two set of curves fall close together, but the agreement is not complete. At the lower concentrations the results for $\mathrm{X}$ fall slightly below those for Ar, while the opposite is true for the highest concentrations. This behavior is most likely associated with the nonlinear dependence of the maximum flame temperature on concentration evident in Figure 18 and the contribution of dilution to extinguishment.

The effect of doubling the amount of heat absorbed by $\mathrm{X}$ was considered by running a series of calculations for $\Delta H_{X-Y}=192.1 \mathrm{~kJ} /$ mole. Calculated maximum flame temperatures are plotted as a function of the exit velocity magnitudes for methane and oxidizer in Figure 30. From these results the extinction concentration for $\mathrm{X}$ with the higher heat absorption can be estimated as $9.7 \%$. This value is roughly $60 \%$ of that found with $\Delta H_{X \rightarrow Y}=95.2 \mathrm{~kJ} / \mathrm{mole}$, or $20 \%$ higher than would be expected if flame extinguishment was due solely to the heat extractcd. The most likely source for the difference is the effect of dilution discussed earlier. The 


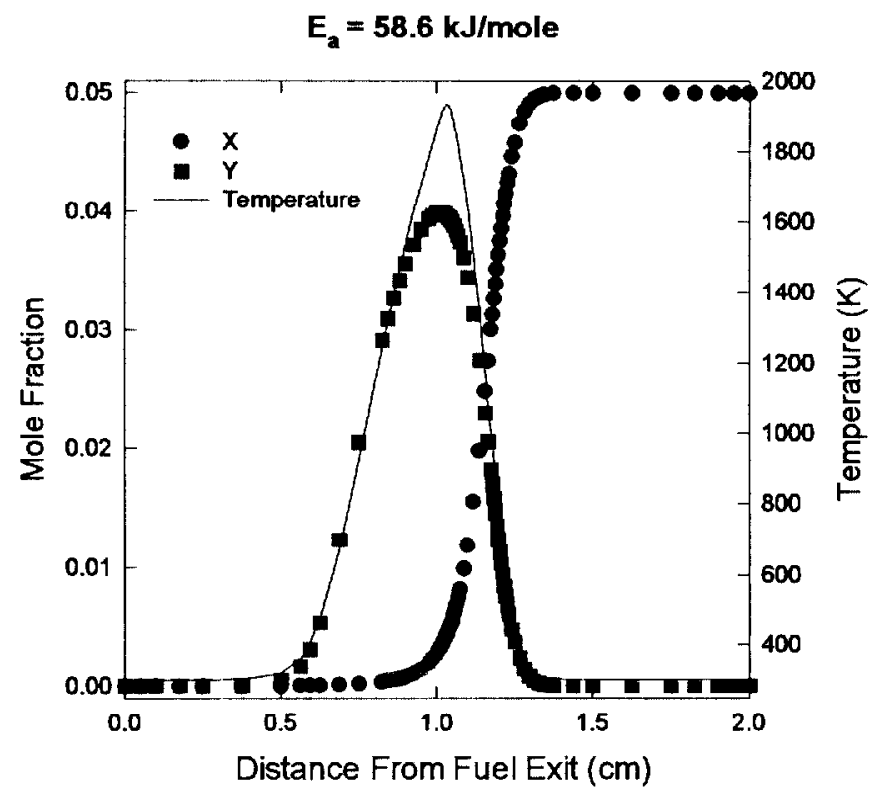

Figure 25. The mole fractions of $X$ and $Y$ are plotted as a function of distance from the fuel exit for a methane flame burning in air with $5 \%$ added $X$. X reacts to form $Y$ with $E_{a}=58.6 \mathrm{~kJ} / \mathrm{mole}$ and $\Delta H_{X \rightarrow Y}=96.1 \mathrm{~kJ} /$ mole. The spatial variation of temperature is also shown as the solid line. Methane and oxidizer exit velocity magnitudes are $25 \mathrm{~cm} / \mathrm{s}$.

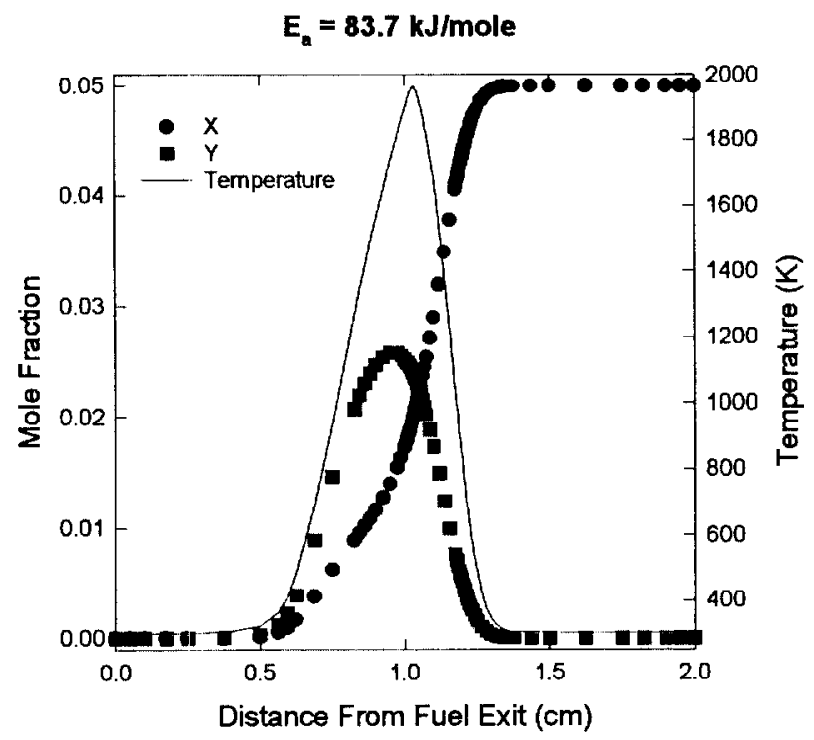

Figure 26. The mole fractions of $\mathrm{X}$ and $\mathrm{Y}$ are plotted as a function of distance from the fuel exit for a methane flame burning in air with $5 \%$ added $X$. X reacts to form $Y$ with $E_{a}=83.7 \mathrm{~kJ} / \mathrm{mole}$ and $\Delta H_{X \rightarrow Y}=96.1 \mathrm{~kJ} / \mathrm{mole}$. The spatial variation of temperature is also shown as the solid line. Methane and oxidizer exit velocity magnitudes are $25 \mathrm{~cm} / \mathrm{s}$. 


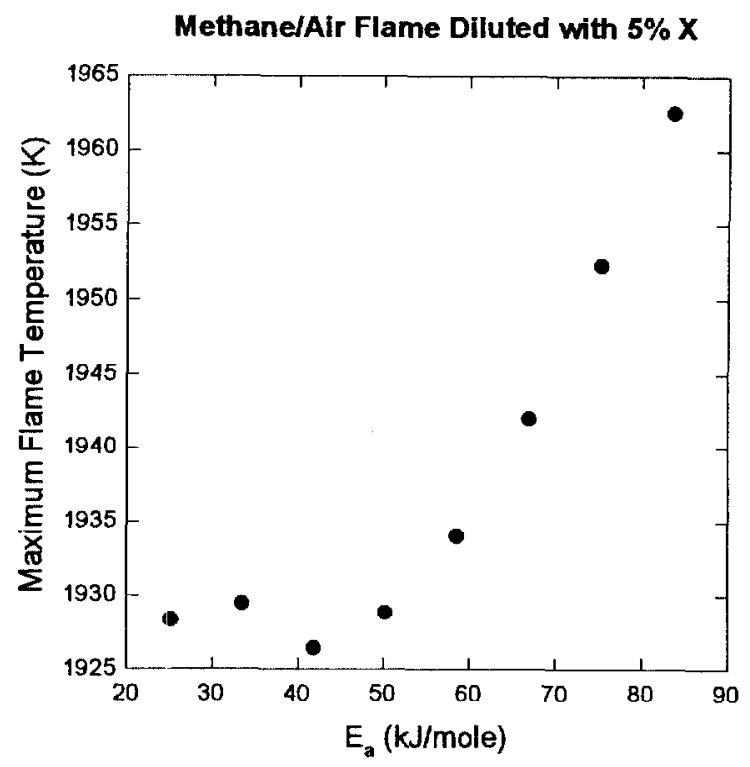

Figure 27. Values of maximum flame temperature for methane flames burning in air diluted with $5 \% \mathrm{X}$ are plotted as a function of the energy of activation for the conversion of $X$ to $Y$. Methane and oxidizer exit velocity magnitudes are $25 \mathrm{~cm} / \mathrm{s}$.

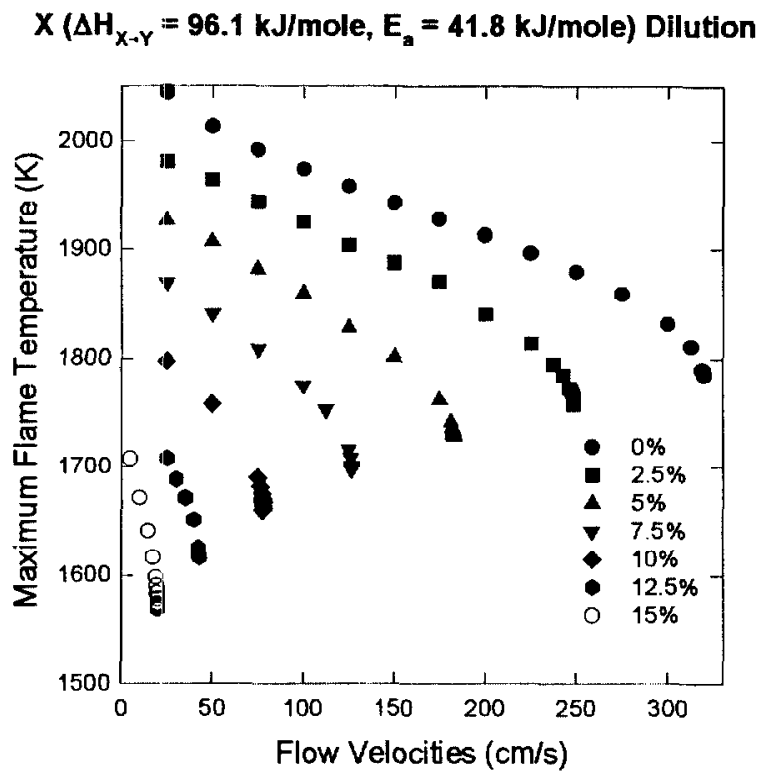

Figure 28. Maximum calculated flame temperatures are plotted against methane and oxidizer exit velocity magnitudes for a series of methane/air opposed flow diffusion flames diluted with agent $X$ which reacts to form $Y$ with $E_{a}=41.8 \mathrm{~kJ} / \mathrm{mole}$ and $\Delta H_{X-Y}=96.1 \mathrm{~kJ} / \mathrm{mole}$. Symbols correspond to the percentage of added $X$. 
Ar and $X\left(E_{-}=41.8 \mathrm{~kJ} / \mathrm{mole}, \Delta H=96.1 \mathrm{~kJ} / \mathrm{mole}\right)$ Dilution

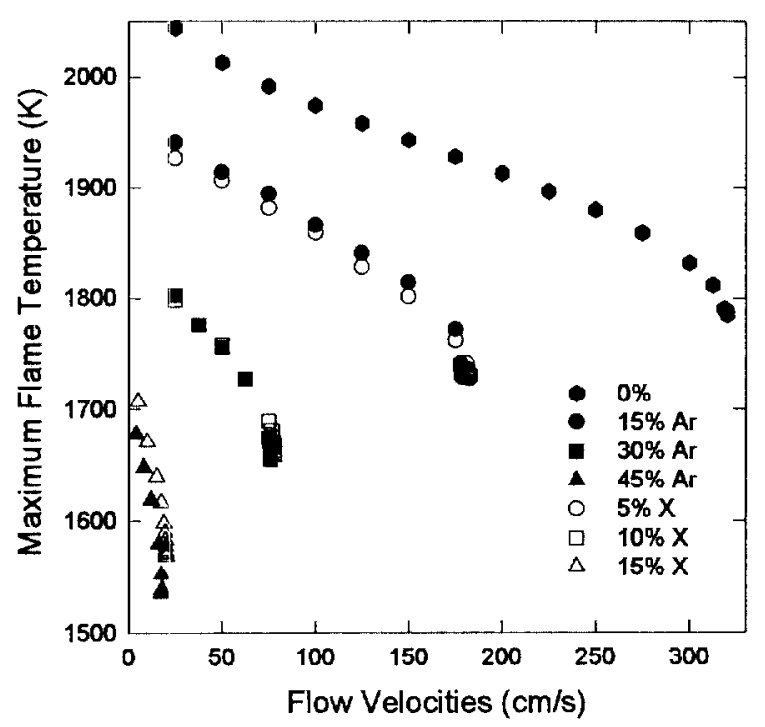

Figure 29. Maximum calculated flame temperatures are plotted against methane and oxidizer exit flow velocity magnitudes for a series of methane/air opposed flow diffusion flames diluted with argon and agent $X\left(E_{a}=41.8 \mathrm{~kJ} / \mathrm{mole}\right.$ and $\left.\Delta H_{X \cdot Y}=96.1 \mathrm{~kJ} / \mathrm{mole}\right)$.

$X\left(\Delta H_{X \cdot Y}=192 \mathrm{~kJ} /\right.$ mole, $E_{a}=41.8 \mathrm{~kJ} /$ mole $)$ Dilution

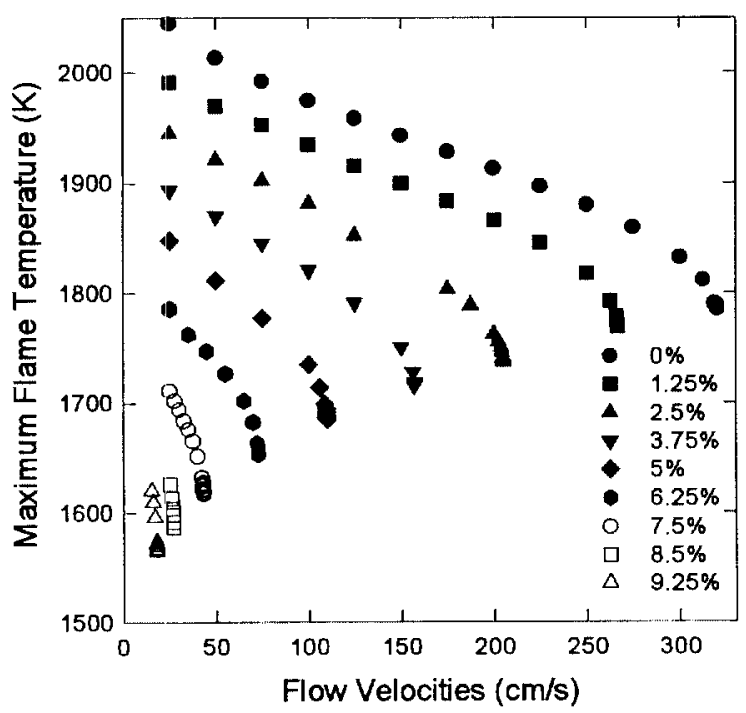

Figure 30. Maximum calculated flame temperatures are plotted against methane and oxidizer exit flow velocity magnitudes for a series of methane/air opposed flow diffusion flames diluted with agent $X$ which reacts to form $Y$ with $E_{a}=41.8 \mathrm{~kJ} / \mathrm{mole}$ and $\Delta H_{X-Y}=192.1 \mathrm{~kJ} / \mathrm{mole}$. Symbols correspond to the percentage of added $X$. 


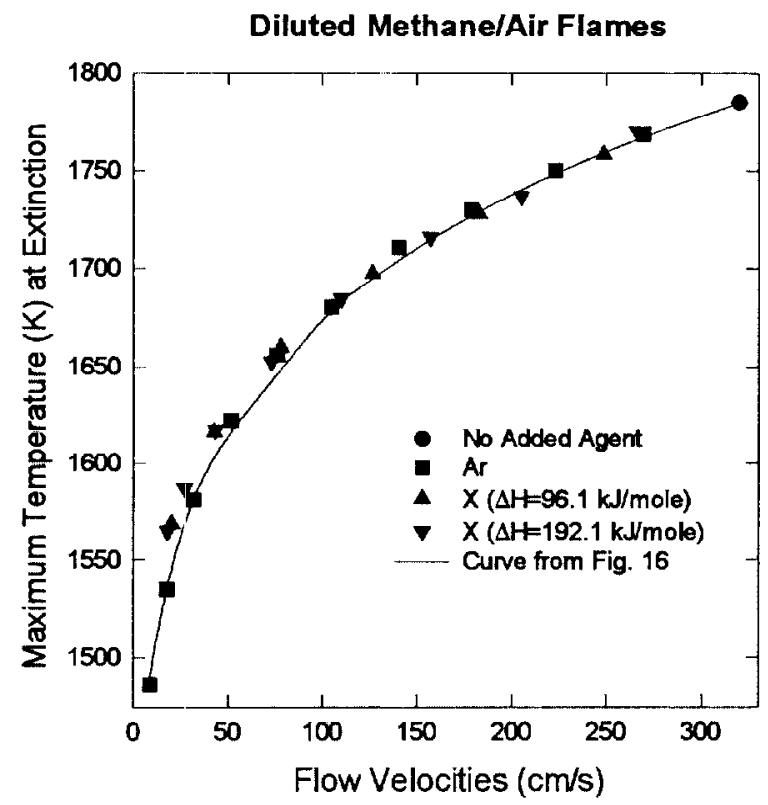

Figure 31. Values of maximum flame temperature at extinction are plotted as a function of fuel and oxidizer exit velocity magnitudes for air diluted with a range of concentrations of argon and surrogate agent $X$ having $\Delta H_{X \rightarrow Y}=96.1 \mathrm{~kJ} / \mathrm{mole}$ or $192.1 \mathrm{~kJ} / \mathrm{mole}$. The solid line is the result of the regression fits shown in Figure 17.

concentration of added agent required for flame extinguishment decreases as the amount of heat it can absorb increases, but the decreased concentration reduces the degree of dilution, with the result that the effectiveness of extracting additional heat is offset somewhat.

The role of dilution has an important implication with regard to simple estimates of extinguishing efficiency for thcrmal agents which are often obtained by taking ratios of heat capacities for various agents. If the agents have a large heat capacity difference, and the percentages required for extinguishment therefore differ substantially, a simple linear dependence on heat capacity should not be observed. In fact, the agent having the largest heat capacity should be less effective than expected, as observed in the current calculations.

Figure 31 shows a plot of maximum flame temperature at extinction versus exit flow velocity magnitudes for air diluted with various concentrations of argon and $\mathrm{X}$ with $\Delta H_{X-Y}=96.1 \mathrm{~kJ} / \mathrm{mole}$ and $192.1 \mathrm{~kJ} / \mathrm{mole}$. The solid line is the result shown in Figure 17 based on a fit to data for known thermal agents. Despite the fact that the amount of agent required for extinction varies nonlinearly with $\Delta H_{X-Y}$, the data all fall very close together. This supports the conclusion that assuming a common extinction temperature should provide excellent estimates for flame extinguishing concentrations of thermal agents. The slight variations present near the extinguishing concentration are likely due to dilution effects.

\section{G. Prediction of Extinguishing Concentration for HFE7100}

The first section of this report summarizes data base searches which yielded a list of thermal agents which are expected to be particularly effective. In order to obtain some idea of the concentrations which might be 


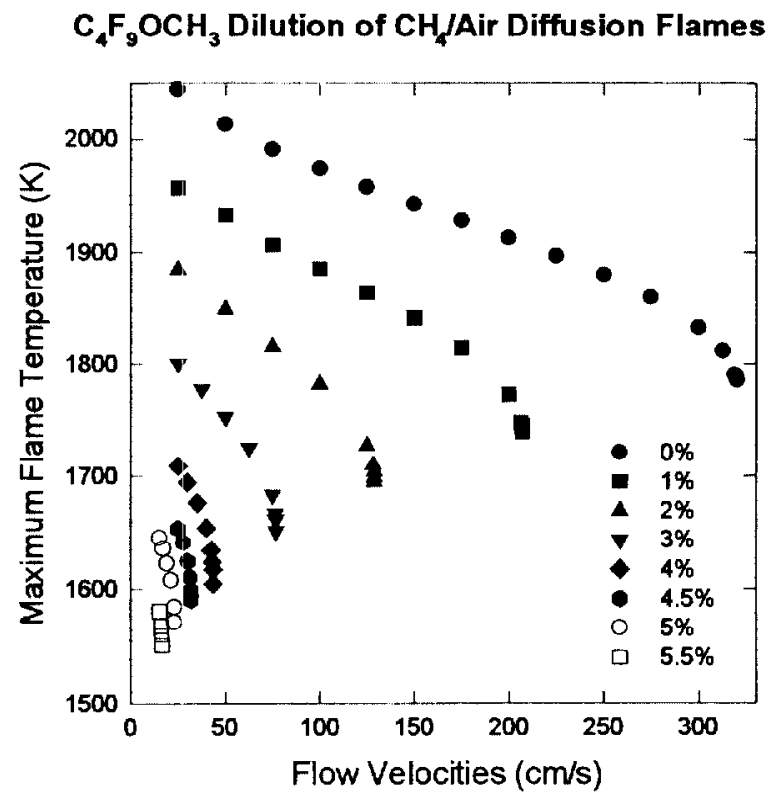

Figure 32. Maximum calculated flame temperatures are plotted against methane and oxidizer exit velocity magnitudes for a series of methane/air opposed flow diffusion flames diluted with $\mathrm{C}_{4} \mathrm{~F}_{9} \mathrm{OCH}_{3}$. Symbols correspond to the percentage of added $\mathrm{C}_{4} \mathrm{~F}_{9} \mathrm{OCH}_{3}$.

required for extinguishment by such agents, a series of calculations were carried out for a compound which is predicted to be one of the more effective, methoxy-nonafluorobutane $\left(\mathrm{C}_{4} \mathrm{~F}_{9} \mathrm{OCH}_{3} ; \mathrm{HFE7100}\right)$. It was assumed that the only mechanism for heat extraction was the heat capacity of the gaseous agent, even though significant heat could also be removed by evaporation if the agent were released as a liquid at room temperature. It is also true that this molecule is likely to decompose as it enters the high temperature region of the flame and will react to form final products. Reaction of the agent was not modeled. Due to the presence of a large number of fluorine atoms, it is also likely that the extinguishing efficiency will include a small chemical component. $[33,52,53,54]$ On this basis it might be expected that the result of this calculation will be an upper limit for the required extinguishing concentration.

Figure 32 shows maximum flame temperature as a function of the methane and oxidizer exit velocity magnitudes. As now expected, the curves have similar appearances to those found for the other thermal agents. However, what is particularly noteworthy is the relatively small mole fraction of $\mathrm{C}_{4} \mathrm{~F}_{9} \mathrm{OCH}_{3}$ required to lower the maximum flame temperature to the extinguishment temperature of $1550 \mathrm{~K}$. The addition of only $5.5 \%$ of $\mathrm{C}_{4} \mathrm{~F}_{9} \mathrm{OCH}_{3}$ is calculated to be sufficient. The high heat capacity of this molecule due to its large number of atoms makes it a particularly effective thermal agent in molar terms. If liquid vaporization and chemical effects improve its effectiveness still further, this species may well approach the effectiveness of halon 1301, which has an extinguishing concentration of $2.9 \%$ [78] on a molar basis. On a mass basis this fluorinated ether will be less effective, based on the molecular weights of $148.9 \mathrm{~g} / \mathrm{mole}$ for halon 1301 and 250 $\mathrm{g} /$ mole for $\mathrm{C}_{4} \mathrm{~F}_{9} \mathrm{OCH}_{3}$, but not dramatically so. It might be expected that the mass fraction of $\mathrm{C}_{4} \mathrm{~F}_{9} \mathrm{OCH}_{3}$ which must be added would be similar to other agents which do not have a strong component of chemical effectiveness. [76] 
The vapor pressure for $\mathrm{C}_{4} \mathrm{~F}_{9} \mathrm{OCH}_{3}$ as a function of temperature is given by [16]

$$
P_{C_{4} F_{9} O C H_{3}}=e^{10.839-\frac{3627.2}{T}},
$$

where $P_{C_{4} F_{9} O C H_{3}}$ is the partial pressure of $\mathrm{C}_{4} \mathrm{~F}_{9} \mathrm{OCH}_{3}$ in atmospheres and $T$ is the temperature in $\mathrm{K}$. For 300 $\mathrm{K}$ and atmospheric pressure the saturation percentage of the ether in air is calculated to be $29 \%$. Thus the saturation pressure at room temperature should be more than sufficient to extinguish a diffusion flame.

Two experimental measurements of the concentration of methoxy-nonafluorobutane required to extinguish diffusion flames have been identified. Unpublished measurements from the New Mexico Engineering Institute using a standard cup burner with heptane fuel yielded an extinguishing concentration of 6.1 volume per cent. [82] In a patent disclosure, Flynn and Scott also reported that a value of 6.1 volume per cent was sufficient to extinguish a butane flame in a "micro-cup bumer". [83] These values are $11 \%$ higher than estimated using detailed chemical kinetic modeling for the cxtinguishment of a methane flame.

Earlier it was shown that cup bumer measurements using heptane fuel for agents known to act only thermally yielded extinguishing concentrations which were roughly $90 \%-95 \%$ of those estimated using detailed kinetic modeling. This would suggest that the expected difference between calculated and experimental values for $\mathrm{C}_{4} \mathrm{~F}_{9} \mathrm{OCH}_{3}$ are actually somewhat greater than indicated above. A plausible explanation for this difference is the effect of chemical reactions. If this is the indeed the case, the results indicate that the net effect of reactions involving this agent is to decrease its effectiveness slightly from that expected if it acted simply as a nonreactive thermal agent. Other reaction effects must counteract the expected small chemical enhancement due to the fluorine atoms.

\section{H. Discussion and Summary}

Detailed chemical kinetic modeling of counterflow diffusion flames has been shown to be an effective approach for improving the understanding of the effects of thermal agents and for predicting flame extinction and extinguishment behaviors. Important findings of the study are summarized here.

Exil flow velocities, the various strain rates, and the stoichiometric scalar dissipation rate calculated for extinction of a given flame are strongly dependent on the detailed chemical kinetic mechanism used. The mechanism employed here, GRI-Mech 1.2, predicts flames which are more robust than observed experimentally. On the other hand, the maximum flame temperatures for flames at extinction seem to be relatively independent of mechanism. This is relevant for the current work because a particular maximum flame temperature at extinction is used as the criteria for flame extinguishment.

Flame radiation is expected to have a noticeable effect on flame structure for the conditions relevant to extinguishment of diffusion flames. Recent detailed modeling investigations which incorporate radiation indicate that the relative importance of radiation increases with decreasing strain rate. For the strain rates typical of extinguishment of buoyancy-dominated diffusion flames, the effects of radiation represent a relatively small fraction of the total heat release. The neglect of radiation does not appear to seriously limit predictions of extinguishing concentrations, even though its neglect would be expected to change such properties as the extinguishing limit temperature and strain ratc.

Assuming a maximum flame temperature at extinction of $1550 \mathrm{~K}$ for extinguishing conditions provides good agreement between the experimental result and the model prediction of the extinguishing concentration for 
nitrogen added to the air side for laminar methane/air diffusion flames. Similarly, the calculated extinguishing concentration for Ar added to Ar "air" agrees well. Even though experimental data for extinguishment of methane/air flames is lacking for other thermal agents, comparisons of extinguishing concentration predictions for $\mathrm{Ar}, \mathrm{CO}_{2}$, and $\mathrm{He}$ added to air agree closely with values for cup burners fueled with heptane. The strain rates which generate this extinguishment temperature depend very weakly on agent. For all cases the strain rates are on the order of a few tens of inverse seconds.

Surrogate thermal agents having unrealistic physical behaviors have been used to computationally investigate particular aspects of flame extinguishment. Use of an agent having no heat capacity has shown that dilution effects can weaken and ultimately extinguish diffusion flames due to an increase in the amount of oxygen leaking through the flame front. An agent $X$ which is capable of reacting to form $Y$ while extracting a well characterized amount of heat was used to demonstrate that the effectiveness of a thermal agent is insensitive to the location where heat extraction occurs relative to the flame front for steady flames as long as the cooled gases are ultimately convected into the flame zone. By varying the heat absorbed by a given amount of $\mathrm{X}$, it was shown that there is not a one-to-one correspondence between the amount of heat extracted by an agent and the concentration required for flame extinguishment. This observation was attributed to the role of dilution on extinguishment.

The extinguishing concentration of methoxy-nonafluorobutane for methane flames was estimated as 5.5 mole per cent using the approach developed during the current investigation. It was assumed that this species acts simply as a thermal agent. Experimental values for heptane- and butane-fueled diffusion flames were roughly $11 \%$ larger. The small difference between prediction and experiment was attributed to the decomposition and subsequent reaction of this agent in the flame, i.e., to chemistry effects.

\section{SURFACE COOLING}

\section{A. Introduction}

When liquid suppressant droplets released from a discharge port approach a fire, several things can happen. Droplets with sufficient momentum to penetrate the flame, depending on their sizes, can either be consumed in the flame (participate directly in the suppression processes through physical and/or chemical mechanisms) or reach the fuel surface. Droplets with little momentum (e.g., very small droplets) may not penetrate the fire and will be deflected away by the rising hot plume. [84] These deflected droplets will eventually evaporate or strike adjacent objects. For droplets landing outside the burning area, the cooling of the adjacent and surrounding surfaces could mitigate or contain the flame spread processes. Therefore, droplet interaction with surfaces is an integral part in the understanding of the overall suppression processes.

One of the possible fire suppression mechanisms using a liquid fire suppressant (e.g., water) is fuel surface cooling. The relatively cool impacting droplets will interact with the relatively hot fuel surface. One of the droplet/surface interactions is the extraction of heat from the surface to vaporize the continuously deposited droplets, thereby reducing the surface temperature. The burning rate falls, which leads to a decrease in heat feedback to the fuel surface. Eventually, a critical burning rate is reached beyond which combustion can no longer be sustained. The other effect of the deposited droplets on the burning rate is the reduction of mass transfer area on the fuel surface, which also causes a reduction in burning rate.

In order to understand surfacc cooling without resorting to a detailed analysis of the coupling between the transient thermal response of the fuel bed as a result of the application of liquid agent and the heat feedback 
from the flame to the fuel, the transient coupling process is considered as a series of quasi-steady steps. At any instant in time, a steady-state energy balance at the fuel surface can be written as:

$$
\dot{m}_{\text {fuel }}^{\prime \prime} \Delta H_{\text {fuel }}=Q_{c o n d}^{\prime \prime}+Q_{c o n v}^{\prime \prime}+\varepsilon_{\text {flame }} \sigma T_{\text {flame }}^{4}-\varepsilon_{s} \sigma T_{\text {surf }}^{4}-q^{\prime \prime}
$$

where $\dot{m}_{\text {fuel }}^{\prime \prime}$ is the fuel burning mass flux, $\Delta H_{\text {fuel }}$ is the effective heat of gasification of the fuel, $Q_{c o n d}^{\prime \prime}$ is the conductive heat flux to the fuel surface, $Q_{c o n v}^{\prime \prime}$ is the convective heat flux to the fuel surface, $\varepsilon_{\text {flame }}$ is the flame emissivity, $\sigma$ is the Stefan-Boltzmann constant, $T_{\text {flame }}$ is the average flame temperature, $\epsilon_{s}$ is the surface emissivity, $T_{\text {surf }}$ is the fuel surface temperature, and $q^{\prime \prime}$ is the heat flux removal from the fuel surface due to surface cooling.

The surface cooling heat flux, $q^{\prime \prime}$, depends on the interaction of the liquid droplets with the surface. There are many different scenarios of droplet impact on a surface. The impacting processes depend on the thermophyscial and geometrical properties of the drop and of the target surface and on the magnitude and direction of the impact velocity vector. In addition, for a flaming surface, the droplet will traverse through an environment different from that of a non-buming surface before impact. However, in the literature, droplet/surface interaction studies focus almost exclusively on non-burning surfaces.

When relatively cool liquid droplets impact on a solid surface, cooling of the surface occurs as a result of heat transfer between the surface and the droplets. A liquid droplet impacting a solid surface has been extensively studied in the literature. $[85,86,87,88,89,90,91,92,93]$ Maps which identify the various impact and heat transfer regimes over a wide range of experimental conditions have been constructed. Spray cooling or quenching of hot metallic surfaces has also been extensively studied. [94,95,96,97,98,99] Many empirical heat transfer correlations for spray cooling applications exist.

For a liquid droplet interaction with a liquid surface, several scenarios need to be considered, and the impact dynamics are complicated by the ability of the liquid surface to deform and to displace in response to the impinging droplet and by the internal fluid motion of the liquid pool initiated by the impact processes. [100] If the droplet has a very high impact velocity, it can cause a crater in the liquid pool and a splash upon impact. For a burning liquid pool, the splash may result in a sudden increase in burning rate due to an increase in the liquid surface area causcd by the splash droplets. If the droplet is soluble in the liquid, mass transfer between the penetrating droplet and the liquid will occur. Depending on droplet impact parameters, differences in miscibilities and physical properties (surface tension and viscosity) between the droplet and the target liquid, and the depth of the liquid layer, the droplet may float on the surface, may coalesce into the liquid pool with little or no splashing and produce a vortex ring, may rebound or splash, forming a crater and a small jet or column of liquid at the surface, or may dissolve into the liquid pool. Most work in the literature has examined the isothermal impact of a liquid droplet onto a surface of the same liquid (e.g., see the review article of Rein $[100]$ and the references therein). In a fire suppression scenario, the impacting droplet encounters a different liquid target (suppression fluid versus fuel) with different physical properties. The temperature of the droplet can be much lower than that of the liquid surface (especially, in the case of burning), and the contact between a cold droplet with a hot liquid may sometimes results in vapor explosion [101], an unwanted situation. All of these complicated factors render the study of heat transfer processes between liquid droplets and a liquid surface an arduous and daunting task. To the best of our knowledge, appropriate heat transfer correlations do not cxist in the literature; therefore, liquid surface cooling calculations, in spite of the importance of the process, will not be attempted here. 
In this section, we will discuss droplet evaporation and solid surface cooling by droplets. Droplet evaporation is considered because it is an integral part of the surface cooling problem. If the droplets evaporate completely before reaching the fuel surface, the heat removal from the surface will decrease significantly due to the fact that the liquid latent heat of vaporization does not play a role. Under this circumstance, the surface will only be cooled by a vapor jet, which is not an effective cooling mechanism.

Another important aspect in surface cooling is the ability of the droplets to reduce the surface temperature of metallic components in the vicinity of a fire to prevent re-ignition, which is a potential problem in suppressing aircraft engine nacelle fires. If sufficient cooling of hot surfaces cannot be achieved after the release of fire suppressant, re-ignition of residual fuel vapor/air mixture by hot surfaces may occur.

In the following discussion, the five fluicls (water, lactic acid, $\mathrm{C}_{3} \mathrm{~F}_{5} \mathrm{H}_{3} \mathrm{O}, \mathrm{HFE7100}$, and $\mathrm{R} 338 \mathrm{mccq}$ ) identified in Section II as having the highest $\Delta H^{\text {iotal }}$ (mass basis) are considered to evaluate their droplet vaporization and surface cooling characteristics. Low boiling-point fluids will not be considered here because under typical operating conditions, these fluids can be easily flash-vaporized soon after they leave the discharge opening; thus they likely arrive at the surface in the form of a vapor.

\section{B. Evaporation of Liquid Droplets}

The estimation of liquid droplet evaporation is based on the classical $\mathrm{d}^{2}$-law, which gives the droplet diameter as a function of time as

$$
D^{2}=D_{o}^{2}-K t
$$

where $D$ is the instantaneous droplet diameter, $D_{o}$ is the initial droplet diameter, $t$ is the time, and $K$ is the evaporation constant. The cvaporation constant can be calculated by

$$
K=\frac{8 k_{g} \ln (1+B)}{\rho_{F} C_{p g}},
$$

where $B$ is the transfer number, $k_{g}$ is the gas-phase thermal conductivity, $C_{p g}$ is the gas-phase heat capacity, and $\rho_{F}$ is the liquid density. The $B$ number based on mass transfer considerations is given by

$$
B_{M}=\frac{Y_{F S}-Y_{F \infty}}{1-Y_{F S}}
$$

where $Y_{F S}$ and $Y_{F \infty}$ are the vapor-phase mass fraction at the droplet surface and ambiance, respectively. The mass fraction, $Y_{F S}$, can be evaluated by

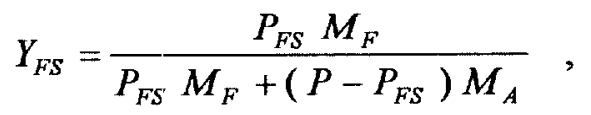

where $P_{F S}$ is the liquid vapor pressure at the droplet surface, $P$ is the ambient pressure, which is equal to the sum of the liquid vapor pressure and partial pressure of air at the droplet surface, and $M_{F}$ and $M_{A}$ are the molecular weights of liquid and air, respectively.

The $B$ number based on heat transfer considerations is given by 


$$
B_{T}=\frac{C_{p g}\left(T_{o}-T_{s}\right)}{\Delta H_{v a p}} \text {, }
$$

where $T_{o s} T_{s}$, and $\Delta H_{\text {vap }}$ are the ambient temperature, droplet surface (wet-bulb) temperature, and latent heat of vaporization of the liquid, respectively. Under steady-state conditions, $B_{M}=B_{T}$, and either Eq. (20) or Eq. (22) may be used to calculate the evaporation constant in Eq. (19).

If $T_{s}$ is known, the calculation of evaporation constant is straightforward; however, under normal circumstances it is necessary to determine $T_{s}$ in order to evaluate $B$ and $K$. The calculation procedure can be found in references $[102,103,104]$. The basic idea is to find $T_{s}$ such that $B_{M}=B_{T}$. Spalding [102] and Kanury [103] used a graphical approach. By plotting $B_{M}$ and $B_{T}$ against $T_{s}$, the intersection of these two curves defines the wet-bulb temperature and the corresponding $B$. An iterative method was used by Chin and Lefebvre. [104] The calculations presentcd herc usc the latter approach.

To calculate $K$, the reference temperature and mass fractions (based on the one-third rule [104]) were used to estimate the gas-phase thermophysical properties,

$$
\begin{gathered}
T_{r}=T_{s}+\frac{T_{\infty}-T_{s}}{3} \\
Y_{F r}=Y_{F S}+\frac{Y_{F \infty}-Y_{F S}}{3} \\
Y_{A i r}=1-Y_{F r},
\end{gathered}
$$

where $Y_{\text {air }}$ is the air mass fraction at the reference state. The equation for calculating the gas-phase heat capacity, $C_{p g}$, is given by

$$
C_{p g}\left(T_{r}\right)=Y_{A i r} C_{p A}\left(T_{r}\right)+Y_{F r} C_{p F}\left(T_{r}\right)
$$

where $C_{p A}$ is the heat capacity of air and $C_{p F}$ is the gas-phase heat capacity of the fluid, all evaluated at $T_{r}$. The thermal conductivity of the gas phase is estimated by the following equation,

$$
k_{g}\left(T_{r}\right)=Y_{A i r} k_{A}\left(T_{r}\right)+Y_{F r} k_{F}\left(T_{r}\right)
$$

where $k_{A}$ is the thermal conductivity of air and $k_{F}$ is the gas-phase thermal conductivity of the liquid, all evaluated at $T_{r}$.

The conditions used in the calculations were: (1) $T_{\infty}=1400 \mathrm{~K}$ (to simulate a flaming ambiance), (2) $Y_{F \infty}=0$, and (3) $P=0.101 \mathrm{MPa}$.

The thermophysical properties of air, water, and lactic acid were obtained from the database of the Design Institute for Physical Properties. [1] The properties of $\mathrm{C}_{3} \mathrm{~F}_{5} \mathrm{H}_{3} \mathrm{O}$, HFE7100, and R338mccq were estimated by methods described in Reid et al. [105]; the modified Rackett technique was used for $\rho_{F}$, the method of Joback for $C_{p F}$, the method of Lee and Kesler for $P_{F S}$, the method of Pitzer's acentric factor correlation for $\Delta H_{v a p}$, and the method of Ely and Hanley for $k_{F}$. 


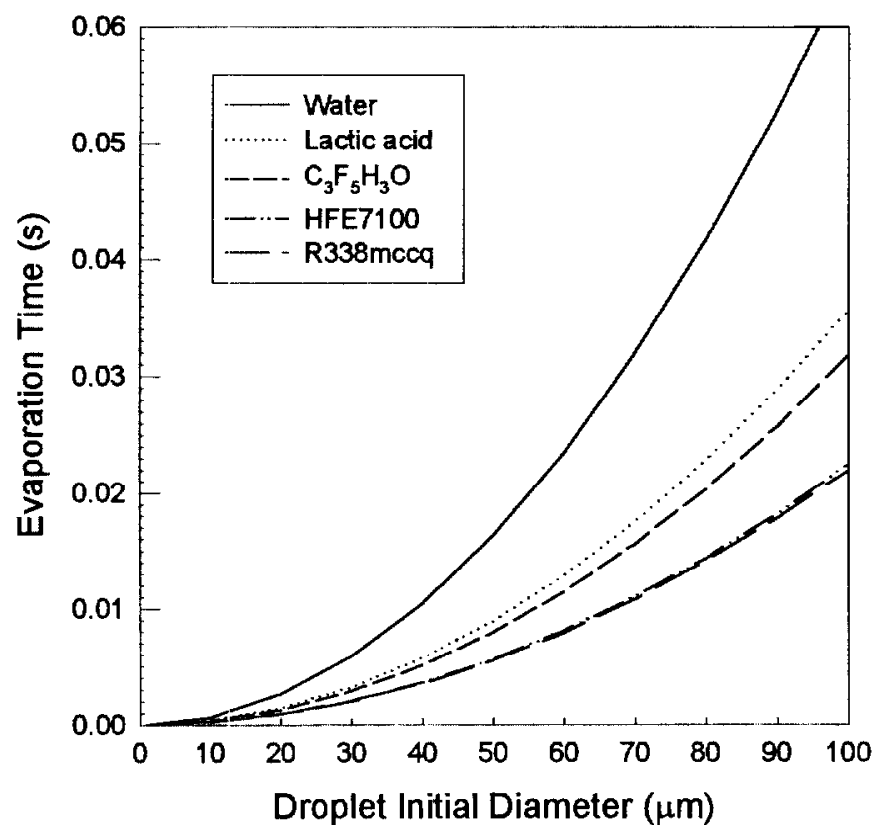

Figure 33. Droplet evaporation time as a function of initial droplet diameter.

Figure 33 shows droplet evaporation times, $t_{b}$, as a function of initial droplet diameter. The droplet evaporation time can be easily obtained by assigning $D=0$ in Eq. (18) once $K$ is known,

$$
t_{b}=\frac{D_{o}^{2}}{K}
$$

For a given initial droplet diameter under the same ambient conditions, the evaporation time for a water droplet is the longest and for a R338mccq droplet the shortest. For the five fluids examined, the ranking based on droplet evaporation times is

$$
t_{b, R 338 m c c q}<t_{b, H F E 7100}<t_{b, C_{3} F_{5} H_{3} O}<t_{b, \text { lactic acid }}<t_{b, \text { water }} .
$$

How fast a droplet evaporates determines whether it will still remain as a droplet upon reaching the surface. However, if flame cooling is the dominant fire suppression mechanism, then it would be better to have the droplet completely vaporized in the flame.

\section{Spray Cooling}

In order to assess surface cooling, we consider the literature on spray cooling and quenching of hot metallic surfaces. The application of spray-cooling correlations to fuel surface cooling is only appropriate when the fuel surface is solid (e.g., a PMMA or wood slab). Even in this case, care should be exercised because subtle differences in cooling mechanisms exist. A burning PMMA surface in reality is in a molten state, and wood forms a porous char layer. The interactions of droplets with molten and porous surfaces remain very difficult 


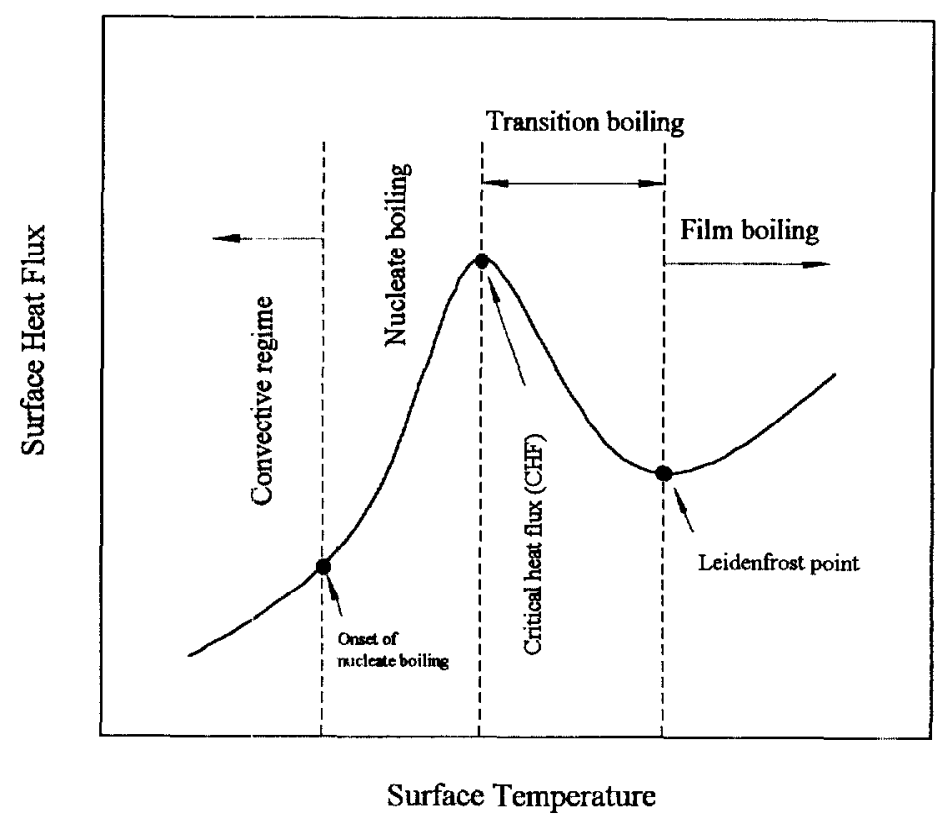

Figure 34. An illustration of a typical boiling curve associated with quenching of a hot surface.

problems to tackle. Differences also arise between fuel surface cooling and quenching of metallic surfaces. In the latter, radiation heat transfer to the droplets only comes from the heated surface; however, in the former, it also comes from the flame. Strictly speaking, the following calculations are more applicable to the cooling of a hot surface to prevent re-ignition than to the cooling of a burning fuel surface.

Depending on the surface temperature, when a hot surface is being quenched by a liquid spray, its surface will experience several distinct heat transfer regimes which can be followed along the "boiling curve". Such a curve is a plot of surface heat flux versus surface temperature and represents the strong relationship between heat flux and surface tempcrature during quenching. The charactcristics of the boiling curve are classified as (with increasing surface temperature): (1) convective, (2) nucleate boiling, (3) critical heat flux, (4) transition boiling, (5) Leidenfrost point, and (6) fillm boiling. Detailed descriptions are available. [94,95] Figure 34 is an illustration of a boiling curve associated with spray cooling of a hot surface. The general features of the curve are similar to those for a pool boiling curve.

Since the boiling curve of one fluid may differ from that of other fluids, there are several important assumptions that have to be made in the following analysis.

When a comparison of surface heat fluxes is made, it is assumed that for the prevailing surface temperature, these fluids are in the same regime on the boiling curve. This assumption may not be valid because, for example, the surface temperatures at which the critical heat flux and Leidenfrost phenomena occur may be significantly different among the fluids studied; therefore, while one fluid may be at the critical heat flux, the other fluid may be in the nucleate boiling regime at the prevailing surface temperature. Unfortunately, in most cases, it is not possible a priori to determine the demarcation point (surface temperature) from one cooling regime to another without resorting to experimental observations.

The second assumption is that the dimensionless heat transfer correlations obtained in the literature using water (in most cases) are applicable to other fluids considered here. A third assumption is that the effect of surface roughness on surface heat flux is not considered. Furthermore, the spray parameters used in the 
following calculations were chosen to be within the range of applicability of the empirical correlations. These operating parameters, though encountered in spray quenching applications, may not be identical to those appropriate for fire fighting applications. In addition, since different droplet generation techniques (sprays $v s$. mono-dispersed droplet streams) have been used to obtain the heat transfer correlations in various regimes, it is imperative that a cómparison among the calculated surface heat fluxes should be made with these fluids in the same regime.

\section{Convective Regime}

Mudawar and co-workers $[94,95]$ have performed extensive studies on cooling of metal surface in this regime using water sprays. Their heat transfer data were correlated using the Nusselt number, the Reynolds number, and the Prandtl number by the following expression,

$$
\frac{h D_{32}}{k_{f}}=N u=2.512\left[\frac{Q^{\prime \prime} D_{32}}{v_{f}}\right]^{0.76}\left[\frac{C_{p f} \mu_{f}}{k_{f}}\right]^{0.56}=2.512 \operatorname{Re}^{0.76} \operatorname{Pr}^{0.56}
$$

where $h$ is the heat transfer coefficient, $k_{f}$ is the thermal conductivity of the liquid, $v_{f}$ is the liquid kinematic viscosity, $C_{p f}$ is the liquid heat capacity, and $\mu_{f}$ is the liquid viscosity. The Reynolds number is based on the volumetric spray flux, $Q^{\prime \prime}$, and the Sauter mean diameter, $D_{32}$, of the spray. All the liquid properties are evaluated at $\left(T_{\text {surf }}+T_{j}\right) / 2$ where $T_{f}$ is the droplet temperature before impact.

Figure 35 shows the calculated hcat flux as a function of $T_{\text {surf }}-T_{f}$. The calculations were performed using $Q^{\prime \prime}$ $=0.005 \mathrm{~m}^{3} / \mathrm{m}^{2}-\mathrm{s}, T_{f}=295 \mathrm{~K}$, and $D_{32}=0.5 \mathrm{~mm}$. The thermophysical properties of water and lactic acid were obtained from the DIPPR. [1] The properties of $\mathrm{C}_{3} \mathrm{~F}_{5} \mathrm{H}_{3} \mathrm{O}$, HFE7100, and R338mccq were estimated by methods described in Reid et al. [105]; the boiling point method of Sato was used for $k_{f}$, the corresponding states method of Rowlinson for $C_{p f}$, and the method of Brule and Starling for $\mu_{f}$. In this regime, water removes heat from the surface more efficiently than the other four fluids. It should be noted that it may not be feasible in practice to maintain the same $D_{32}$ with a fixed $Q^{\prime \prime}$ (the conditions used in the calculations) for the five fluids because the atomization characteristics at the spray nozzle would be vastly different among the fluids owing to their thermophysical properties, thus resulting in different $D_{32}$. [106]

\section{E. Nucleate Boiling Regime}

Compared to other regimes on the boiling curve, the nucleate boiling regime in spray cooling is probably the least studicd. In this regime, the heat flux removal from the surface was found to scale only with $T_{\text {surf }}-T_{f}$ in the studies by Mudawar and co-workers $[94,95]$ where a water spray was used. The heat flux, $q^{\prime \prime}$, was correlated in the form of

$$
q^{\prime \prime}=1.87 \times 10^{-5}\left(T_{\text {surf }}-T_{f}\right)^{5.55}
$$

In the work of Qiao and Chandra [107] on nucleate boiling enhancement using a surfactant/water solution, the heat flux measurements could also be correlated well by scaling with $T_{\text {surf }}-T_{f}$ in a form similar to Eq. (31),

$$
q^{\prime \prime}=0.56 \times 10^{-5}\left(T_{\text {surf }}-T_{f}\right)^{6}
$$

If we assume that the proportionality constant and the power in the scaling law do not change significantly among the five chemical compounds and that the heat flux can be scaled with $\left(T_{\text {surf }}-T_{f}\right)$, then the heat flux 


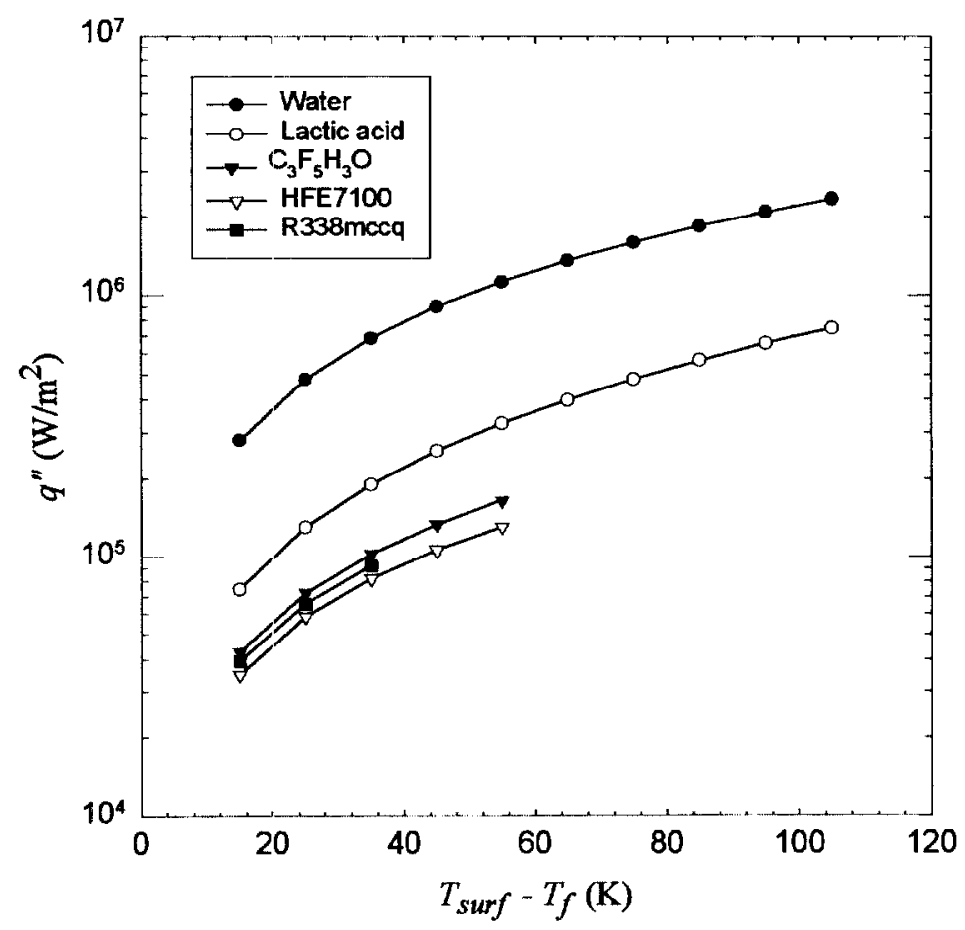

Figure 35. Calculated boiling curve in the convective regime.

removal from the surface in the nucleate boiling regime using these five liquids should be similar for a given $T_{\text {sur. }}$.

\section{F. Critical Heat Flux}

The dimensionless correlation developed by Mudawar and Valentine [94] for water spray cooling over a wide range of flow rates is used to estimate the critical heat flux $(\mathrm{CHF})$,

$$
\frac{C H F}{\rho_{g} L Q^{\prime \prime}}=122.4\left\{1+0.0118\left[\frac{\rho_{g}}{\rho_{F}}\right]^{1 / 4}\left[\frac{\rho_{F} C_{p f}\left(T_{s a t}-T_{f}\right)}{\rho_{g} L}\right]\right\}\left(\frac{\sigma_{f}}{\rho_{F} Q^{\prime \prime 2} D_{32}}\right)^{0.198}
$$

where $\rho_{g}$ is the vapor density of the fluid, $T_{\text {sat }}$ is the saturation temperature of the fluid, and $\sigma_{f}$ is the surface tension of the fluid. All the fluid properties are evaluated at the fluid saturation temperature.

Using $Q^{\prime \prime}=0.005 \mathrm{~m}^{3} / \mathrm{m}^{2}-\mathrm{s}, T_{f}=295 \mathrm{~K}$, and $D_{32}=0.5 \mathrm{~mm}$, the resulting $C H F \mathrm{~s}$ for water, lactic acid, $\mathrm{C}_{3} \mathrm{~F}_{5} \mathrm{H}_{3} \mathrm{O}$, HFE7100, and R338mccq are $0.63 \times 10^{7} \mathrm{~W} / \mathrm{m}^{2}, 0.86 \times 10^{7} \mathrm{~W} / \mathrm{m}^{2}, 0.33 \times 10^{7} \mathrm{~W} / \mathrm{m}^{2}, 0.23 \times 10^{7} \mathrm{~W} / \mathrm{m}^{2}$, and $0.21 \times 10^{7} \mathrm{~W} / \mathrm{m}^{2}$, respectively. In the calculations, surface tensions of water and lactic acid were obtained from the DIPPR [1]; while those of $\mathrm{C}_{3} \mathrm{~F}_{5} \mathrm{H}_{3} \mathrm{O}$, HFE7 100, and $\mathrm{R} 338 \mathrm{mccq}$ were cstimated using the method of Brock and Bird. [105] Although lactic acid and water have the highest and second highest $C H F \mathrm{~s}$, respectively, 
under the conditions used in the calculations, it should be noted that it is inappropriate to compare the $C H F$ s unless they occur at the same surface temperature for the five fluids, a situation highly unlikely given the differences in the thermophysical properties of these fluids.

\section{G. Transition and Film Boiling Regimes}

Based on dimensional analysis, Deb and Yao [108] statistically derived an equation for heat transfer effectiveness $(\varepsilon)$ in terms of droplet Weber number $(W e)$, dimensionless wall superheat $\left(B_{w}\right)$ and vapor parameters $\left(K_{d}\right)$, and surface factor $(S F)$ for surface material effect,

$$
\varepsilon=0.027 \exp \left[\frac{0.08 \sqrt{\ln \left(\frac{W e}{35}+1\right)}}{\left(B_{w}+\frac{S F}{60.5}\right)^{1.5}}\right]+0.21 K_{d} B_{w} \exp \left[-\frac{90}{W e+1}\right],
$$

with $\quad W e=\frac{\rho_{F} V_{i} D_{o}}{\sigma_{f}}, \quad B_{w}=\frac{C_{p F}\left(T_{s u r f}-T_{s a t}\right)}{L}, \quad K_{d}=\frac{k_{F}}{C_{p F} \mu_{v}}$, and

$$
S F=\sqrt{\frac{k_{s} \rho_{s} C_{p s}}{\left(k \rho C_{p}\right)_{s t e e l}}}-1
$$

where $V_{i}$ is the droplet impact velocity, $K_{d}$ is the dimensionless vapor parameter, $\mu_{v}$ is vapor viscosity, and $k_{s}$, $\rho_{s}$, and $C_{p s}$ are the thermal conductivity, density, and heat capacity of the surface material, respectively. All liquid and vapor properties are evaluated at $T_{\text {sat }}$. The heat transfer effectiveness is defined as the ratio of actual heat transfer from the hot surface to the total heat transfer required for complete evaporation of the droplets.; therefore, the heat flux from the surface is

$$
q^{\prime \prime}=\varepsilon G\left[L+C_{p f}\left(T_{s a t}-T_{f}\right)\right]
$$

where $G$ is the liquid mass flux. Equation (34) was obtained by fitting data mainly from experiments using a single stream of droplets. The experimental conditions covered the film boiling regime and to some extent the adjacent transition boiling regime and Leidenfrost point.

Figure 36 shows the calculated heat fluxes for the five fluids as a function of the surface temperature. The calculations were performed using $T_{f}=295 \mathrm{~K}, V_{i}=2.5 \mathrm{~m} / \mathrm{s}, D_{o}=0.3 \mathrm{~mm}$, and $G=0.5 \mathrm{~kg} / \mathrm{m}^{2}-\mathrm{s}$. For illustration, a stainless steel, SS 304, was used as the target surface. Under the conditions used in the calculations, the resulting droplet $W e$ numbers are $31,97,181,297$, and 339 for water, lactic acid, $\mathrm{C}_{3} \mathrm{~F}_{5} \mathrm{H}_{3} \mathrm{O}$, HFE7100, and R338mccq, respectivcly. The range of surface temperatures used in the calculations was chosen so that the calculated $\varepsilon$ did not exceed 1. The three boiling regimes (transition boiling, Leidenfrost condition, and film boiling) are apparent in Figure 36. If we assume that at $T_{\text {surf }} \geq 800 \mathrm{~K}$, all five fluids exhibit film boiling, and lactic acid has the highest surface heat flux.

Figure 36 also demonstrates again the difficulty in comparing the heat fluxes at a given surface temperature. For example, at $T_{\text {surf }}=550 \mathrm{~K}, \mathrm{C}_{3} \mathrm{~F}_{5} \mathrm{H}_{3} \mathrm{O}$, HFE7100, and $\mathrm{R} 338 \mathrm{mccq}$ are in the film boiling regime, whereas, water and lactic acid are in the transition boiling regime. As stated above, unless the surface temperature at 


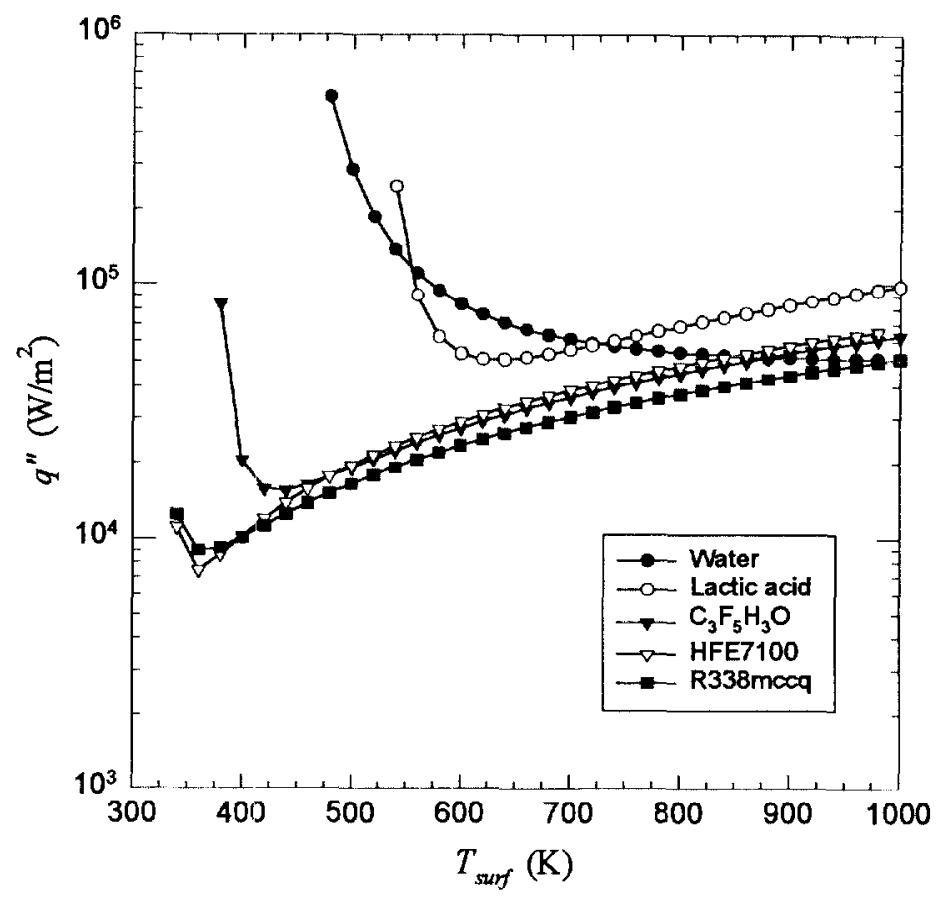

Figure 36. Calculated boiling curve in the transition and film boiling regimes.

which the onset of a particular boiling regime is known a priori, it is not possible to know which heat flux correlation pertaining to which boiling regime should be applied in the estimation.

\section{H. Summary and Concluding Remarks}

Empirical heat transfer correlations from the literature have been used to assess surface cooling in various heat transfer regimes. Based on the above calculations, water and lactic acid generally appear to be superior to $\mathrm{C}_{3} \mathrm{~F}_{5} \mathrm{H}_{3} \mathrm{O}$, HFE7100, and $\mathrm{R} 338 \mathrm{mccq}$ in surface cooling applications. Water and lactic acid evaporate much slower than $\mathrm{C}_{3} \mathrm{~F}_{5} \mathrm{H}_{3} \mathrm{O}$, HFE7 100 , and $\mathrm{R} 338 \mathrm{mccq}$; therefore, the likelihood for water and lactic acid droplets to reach the surface is higher. For the convective boiling regime, the calculations show that water is better than lactic acid, $\mathrm{C}_{3} \mathrm{~F}_{5} \mathrm{H}_{3} \mathrm{O}$, HFE7100, and $\mathrm{R} 338 \mathrm{mccq}$. Lactic acid has the highest calculated critical heat flux as well as the highest heat flux in the film boiling regime. In order to validate the calculated ranking of surface cooling effectiveness of these agents, experiments should be performed in various heat transfer regimes under conditions commensurate with those in actual applications.

Surface cooling by liquid droplets is a very complicated heat transfer process because it depends on so many parameters which include the thermophysical properties (surface tension, density, viscosity, heat of vaporization, etc.) of the liquid, droplet size, droplet impact velocity, spray mass flux, and surface properties. Even for non-burning, smooth surfaces, calculations of surface heat fluxes from first principles are not possible without resorting to experimental observations. Empirical heat transfer correlations under conditions encountered in fires are lacking, and the quantification of surface cooling as a means to extinguish the burning fuel remains elusive, especially when the fuel is a liquid. 
In order to obtain a better understanding of droplet cooling of solid surfaces during fires, experiments performed under the conditions (droplet size, momentum, application rate, etc.) encountered in fire fighting are needed in the various heat transfer regimes. These types of experiments are still lacking in the literature. Surface cooling experiments involving liquid droplets and liquid surfaces are non-existent because the complexity of droplet-surface interaction makes the characterization of the heat transfer processes very difficult. A significant experimental effort in this area will be necessary to develop the knowledge and engineering correlations required for fire-fighting applications

\section{RECOMMENDATIONS FOR ADDITIONAL STUDY}

The current investigation has provided significant new insights into the behavior and desired characteristics of fire extinguishing agents which act purely by heat extraction. All three of the major components have indicated that such agents can have efficiencies in terms of volume or mass requirements which, while reduced from those of halon 1301, whose production have been banned., are sufficiently high to warrant further investigation as possible replacements. Recommendations are provided here for a limited research effort designed to provide additional understanding of thermal agent behavior and characteristics and to provide experimental results for one potential thermal agent, methoxy-nonafluorobutane, which appears promising and for which only limited experimental results are available. The survey of data bases indicated that lactic acid has physical properties which should make it a particularly effective fire extinguishing agent. Due to it corrosiveness, lactic acid alone is unlikely to be used for this purpose. However, it is possible that a useful agent could be made by mixing lactic acid with water. For this reason, the effectiveness of water/lactic acid mixtures for fire extinguishing will also be tested.

One of the gaps in knowledge for the current investigation was the lack of experimental measurements of extinguishment concentrations for gaseous thermal agents in methane/air diffusion flames. We propose to use an existing coflowing burner to measure extinguishing concentrations for $\mathrm{N}_{2}, \mathrm{Ar}, \mathrm{He}$, and $\mathrm{CO}_{2}$. If successful, this approach will provide an easily implemented, alternate approach for experimentally characterizing the effectiveness of gaseous fire-extinguishing agents.

All of the detailed chemical-kinetic modeling to date has used methane as the fuel. It is important to investigate the sensitivity of the findings to the fuel used. A limited series of calculations will be performed for a more complicated fuel such as ethylene or heptane, and the results will be compared to those using methane in order to identify any effects of fuel on extinguishing behavior.

An important finding of the kinetic modeling was that the location of heat extraction is not important to the effectiveness of a thermal agent as long the resulting heat deficit is convected into the flame zone. Much of the heat extraction associated with the release of liquid agents such water or methoxy-nonafluorobutane can be due to evaporation of the liquid at ambient and raised temperatures as the liquid droplets travel to and enter flame zones. Most laboratory methods for testing fire extinguishing efficiency use only gases, so the contribution of the heat of vaporization is not exploited. A unique counterflow diffusion flame facility at NIST is designed to investigate the effectiveness of liquid agents released into an ambient air coflow. During the next funding period it is proposed that this facility be used to compare the effectiveness of methoxynonafluorobutane when released either as a gas or as a liquid. It is anticipated that the mass flow of this agent required to cause extinction of the counterflow flame for a given strain rate will be lower for the liquid. This experiment represents an important test of our understanding of the effectiveness of thermal agents. The findings of this experiment also have practical limitations for specifying the amount of an agent required to extinguish a fire and for the design of systems designed to deliver liquid agents. 


\section{ACKNOWLEDGEMENTS}

This research is part of the Department of Defense's Next Generation Program Fire Suppression

Technology Program, funded in part by the DOD Strategic Environmental Research and Development Program under Contract W74RDV73243630.

\section{REFERENCES}

1. DIPPR Data Compilation of Pure Compound Properties Database, V9.02, NIST Standard Reference Data Program \#1 1, NIST, Gaithersburg MD (1995).

2. NIST Thermodynamic Properties of Refrigerants and Refrigerant Mixtures Database (REFPROP), V5.0, NIST Standard Reference Data Program \#23, NIST, Gaithersburg MD (1996), V6.0, (1998).

3. Heathfield, A. E., Anastasi, C., Pagsberg, P., and McCulloch, A., Atmosph. Envir. 32, 711-717 1998.

4. Grzyll, L. R., Back, D. D., Ramos, C., and Samad, N.A., Development of a Rapid Screening Technique for Second-Generation Halon Alternatives, SBIR Phase II Final Report, Contract Number DAAH01-93C-R150, (1996).

5. Minor, B., Compositions Including a Three Carbon Cyclic Fluoroether, U.S. Patent No. 5480572 (1996).

6. Minor, B., Compositions Including a Fluoroamine and a Second Component, U.S. Patent No. 5441659 (1995).

7. Minor, B., Chisolm, T. E. C., and Shealy, G. S., Azeotrope (Like) Compositions with Fluoromethyl Trifluoromethyl Ether and Dimethyl Ether, U.S. Patent No, 5607616 (1997).

8. Pitts, W. M., Nyden, M. R., Gann, R. G., Mallard, W. G. and Tsang, W., Construction of an Exploratory List of Chemicals to Initiate the Search for Halon Alternatives, NIST Technical Note 1279 (1990).

9. Sekiya, A. and Misaki, S., Chemtech 26, 44-48 (1996).

10. NIST Structures and Properties Database and Estimation Program, NIST Standard Reference Data Program \#25,Versoin 2.02, National Institute of Standards and Technology, Gaithersburg, MD (1994).

11. Fishtine, S. H., Ind. Eng. Chem. 55, 20-28 (1963).

12. Hawley, G. G., Condensed Chemical Dictionary, Eighth Ed., Van Nostrand Reinhold Company, New York (1971).

13. Chueh, C. F. and Swanson, A. C., Chem. Eng. Progress 69, 83-85 (1973); Can. J. Chem. Eng. 51, 596600 (1973).

14. Rihani, D. N. and Doraiswamy, L. K., Ind. Eng. Chem. Fund. 4, 17-21 (1965).

15. NIST Chemistry Webbook, http://webbook.nist.gov.

16. 3M Corporation; web site http://www.mmm.com/fluids/7100.html.

17. Salvi-Narkhede, M., Adcock, J. L., Gakh, A., and Van Hook, W. A., J. Chem. Thermodynamics 25, 643647 (1993).

18. Wang, B. H., Adcock, J. L., Mathur, S. B., and Van Hook, W. A., J. Chem. Thermodynamics 3, 699-710 (1991).

19. Matsuo, S., Tanaka, Y., Takada, N., Yamamoto, H., and Sekiya, A., J. Chem. Eng. Data 43, 473-476 (1998).

20. Defibaugh, D. R., Carillo-Nava, E., Hurly, J. J., Moldover, M. R., Schmidt, J. W., and Weber, L. A., J. Chem. Eng. Data 42, 488-496 (1997).

21. Aldrich Fluorinated Products Catalog, 1998-1999, Aldrich Chemical Company, Milwaukee, WI.

22. Defibaugh, D. R., Gillis, K. A., Moldover, M. R., Morrison, G., and Schmidt, J. W., Fluid Phase Equilibria 81, 285-305 (1992). 
23. Apollo Scientific, Derbyshire, UK; http://www.apolloscientific.co.uk/.

24. Peters, N., Prog. Energy Combust. Sci. 10, 319-339 (1984).

25. Peters, N, Twenty-First Symp. (Intl.) Combust., pp. 1231-1250, The Combustion Institute, Pittsburgh, (1986).

26. Tsuji, H., Prog. Energy Combust. Sci. 8, 93-119 (1982).

27. Dixon-Lewis, G., Twenty-Third Symp. (Intl.) Combust., pp. 305-324, The Combustion Institute, Pittsburgh (1990).

28. Potter, Jr., A. E., Heimel, S., and Butler, J. N., Eighth Symp. (Intl.) Combust., pp. 1027-1034, Williams and Wilkins, Baltimore (1962).

29. Friedman, R. and Levy, J. B., Combust. Flame 7, 195-201 (1963).

30. Ibiricu, M. M. and Gaydon, A. G., Combust. Flame 19, 5 1-62 (1964).

31. Dodding, R. A., Simmons, R. F., and Stephens, A., Combust. Flame 15, 313-315 (1970).

32. Milne, T. A., Green, C. L., and Benson, D. K., Combust. Flame 15, 255-263 (1970).

33. Papas, P., Fleming, J. W., and Sheinson, R. S., Twenty-Sixth Symp. (Intl.) Combust., pp. 1405-1411, The Combustion Institute, Pittsburgh (1996).

34. Hahn, W. A. and Wendt, J. O. L., Eighteenth Symp. (Intl.) Combust., pp. 121-131, The Combustion Institute, Pittsburgh (1981).

35. Dixon-Lewis, G., David, T., Gaskell, P. H., Fukutani, S., Jinno, H., Miller, J. A., Kee, R. J., Smooke, M. D., Peters, N., Effelsberg, E., Warnatz, J., and Behrendt, F., Twentieth Symp. (Intl.) Combust., pp. 18931904, The Combustion Institute, Pittsburgh (1984).

36. Smooke, M. D., Puri, I. K., and Seshadri, K., Twenty-First Symp. (Intl.) Combust., pp. 1783-1792, The Combustion Institute, Pittsburgh, (1986).

37. Dixon-Lewis, G., David, T., and Gaskell, P. H., Archivum Combustionis 6, 3 - 21 (1986).

38. Puri, I. K., Seshadri, K., Smooke, M. D., and Keyes, D. E., Combust. Sci. Tech. 56, 1-22 (1987).

39. Chelliah, H. K., Law, C. K., Ueda, T., Smooke, M. D., and Williams, F. A., Twenty-Third Symp. (Intl.) Combust., pp. 503-511, The Combustion Institute, Pittsburgh (1990).

40. Law, C. K., Twenty-Second Symp. (Intl.) Combustion, pp. 1381-1402, The Combustion Institute, Pittsburgh (1988)

41. Tsuji, H. and Yamaoka, I. Twelfth Symp. (Intl.) Combust., pp. 997-1005, The Combustion Institute, Pittsburgh (1969).

42. Tsuji, H. and Yamaoka, I., Thirteenth Symp. (Intl.) Combust., pp. 723-731, The Combustion Institute, Pittsburgh (1971).

43. Kcc, R. J., Miller, J. A., Evans, G. H., and Dixon-Lewis, G., Twenty-Second Symp. (Intl.) Combust., pp. 1479-1494, The Combustion Institute, Pittsburgh (1988).

44. Seshadri, K. and Williams, F. A., Int. J. Heat Mass Transfer 21, 251-253 (1978).

45. Fisher, E. M., Williams, B. A., and Fleming, J. W., "Determination of the Strain in Counterflow Diffusion Flames From Flow Conditions," 1997 Fall Technical Meeting of the Eastern States Section of the Combustion Institute, pp. 191-194, Hartford, CT (Oct. 27-29, 1997).

46. Maruta, K., Yoshida, M., Guo, H., Ju, Y., and Niioka, T., Combust. Flame 112, 181-187 (1998).

47. Chan, S. H., Yin, J. Q., and Shi, B. J., Combust. Flame 112, 445-456 (1998).

48. Gore, J. P., Lim, J., Takeno, T., and Zhu, X. L., Paper AJTE99-6311, Proceedings of the $5^{\text {th }}$ ASME/JSME Joint Thermal Engineering Conference, San Diego, CA (March 15-19, 1999).

49. Westbrook, C. K., Combust. Science Tech. 23, 191-202 (1980).

50. Westbrook, C. K., Nineteenth Symp. (Intl.) Combust., pp. 127-141, The Combustion Institute, Pittsburgh (1982).

51. Westbrook, C. K., Combust. Science Tech. 34, 201-225 (1983).

52. Noto, T., Babushok, V., Hamins, A., and Tsang, W., Combust. Flame 112, 147-160 (1998). 
53. Linteris, G. T., Burgess, Jr., D. R., Babushok, V., Zachaariah, M., Tsang, W., and Westmoreland, P., Combust. Flame 113, 164-180 (1998).

54. Saso, Y., Zhu, D. L., Wang, H., Law, C. K., and Saito, N., Combust. Flame 114, 457-468 (1998)

55. Rumminger, M. D., Reinelt, D., Babushok, V., and Linteris, G. T., Combust. Flame 116, 207-219 (1999),

56. Hamins, A., Trees, D., Seshadri, K., and Chelliah, H. K., Combust. Flame 99, 231-239 (1994).

57. Tanoff, M. A., Dobbins, R. R., Smooke, M. D., Burgess, Jr., D. R., Zachariah, M. R., and Tsang, W., " $\mathrm{C}_{1}$ and $\mathrm{C}_{2}$ Fluorinated Hydrocarbon Effects on the Extinction Characteristics of Methane Vs. Air Counterflow Diffusion Flames," pp. 116-126, Halon Options Technical Working Conference, Albuquerque, NM (May 6-8, 1997).

58. Lentati, A. M. and Chelliah, H. K., Combust. Flame 115, 158-179 (1998).

59. Lentati, A. M. and Chelliah, H. K., Twenty-Seventh Symp. (Intl.) Combust., pp. 2839-2846, The Combustion Institute, Pittsburgh (1998).

60. Tuovinen, H., The Computer Modelling of the Combustion and Extinction of Methane-Air Premixed Flame, By Thermally Stable Gase, SP Report 1989:54, Swedish National Testing Institution, Borås, Sweden (1989).

61. Lutz, A. E., Kee, R. J., Grcar, J. F., and Rupley, F. M., OPPDIF: A Fortran Program for Computing Opposed-Flow Diffusion Flames, SAND96-8243, Sandia National Laboratories, Livermore, CA (1996).

62. Kee, R. J., Rupley, F. M., Meeks, E., and Miller, J. A., CHEMKIN-III: A FORTRAN Chemical Kinetics Package for the Analysis of Gas-Phase Chemical and Plasma Kinetics, SAND96-8216, Sandia National Laboratories, Livermore, CA (1996).

63. Frenklach, M., Wang, H., Yu, C.-L., Goldenberg, M., Bowman, C. T., Hanson, R. K., Davidson, D. F., Chang, E. J., Smith, G. P., Golden, D. M., Gardiner, W. C., and Lissianski, V., GRI-MECH 1.2, $\mathrm{http} / / / \mathrm{www} . \mathrm{me}$.berkeley.edu/gri_mech/

64. Fendell, F. E., J. Fluid Mech. 21, 28 1-303 (1965).

65. Liñán, A., Acta Astronautica 1, 1007-1039 (1974).

66. Giovangigli, V. and Smooke, M. D., Combust. Science Tech. 53, 23-49 (1987).

67. Nishioka, M. and Law, C. K., Combust. Flame 104, 328-342 (1996).

68. Norton, T. S., Smyth, K. C., Miller, J. H., and Smooke, M. D., Combust. Science Technol. 90, 1-34 (1993).

69. Puri, I. K. and Seshadri, K., Combust. Flame 65, 137-150 (1986).

70. Du, J. and Axelbaum, R. L., Twenty-Sixth Symp. (Intl.) Combust., pp. 1137-1142, The Combustion Institute, Pittsburgh (1996).

71. Simmons, R. F. and Wolfhard, H. G., Combust. Flame 1, 155-161 (1957).

72. Ishizuka, S. and Tsuji, H., Eighteenth Symp. (Intl.) Combust., pp. 695-703, The Combustion Institute, Pittsburgh (1981).

73. Sheinson, R. S., Penner-Hahn, J. E., and Indritz, D., Fire Safety J. 15, 437-450 (1989).

74. Roberts, A. F. and Quince, B. W., Combust. Flame 20, 245-251 (1973).

75. Babb, M., Gollahalli, S. R., and Sliepcevich, C. M., J. Propulsion Power 15, 260-265 (1999).

76. Hamins, A., Trees, D., Seshadri, K., and Chelliah, H. K, Combust. Flame 99, 221-230 (1994).

77. Hamins, A., Gmurczyk, G., Grosshandler, W., Rehwoldt, R. G., Vazquez, I., Cleary, T., Presser, C., and Seshadri, K., "4. Flame Suppression Effectiveness," in Evaluation of Alternative In-Flight Fire Suppressants for Full-Scale Testing in Simulated Aircraft Engine Nacelles and Dry Bays (Grosshandler, W. L., Gann, R. G., and Pitts, W. M., Eds.), NIST SP 861, pp. 345-465, National Institute of Standards and Technology, Gaithersburg, MD (April, 1994).

78. Moore, T. A., Weitz, C. A., and Tapscott, R. E., "An Update of NMERI Cup-Burner Test Results," pp. 551-564, Halon Options Technical Working Conference, Albuquerque, NM (May 7-9, 1996). 
79. Coward, H. F. and Hartwell, F. J., J. Chem. Soc., 1522-1532 (1926).

80. Liñán, A. and Williams, F. A., Fundamental Aspects of Combustion, Oxford University Press, New York (1993).

81. Gordon, A. S., Smith, S. R., and McNesby, J. R., Seventh Symp. (Intl.) Combust., pp. 317-324, Butterworths, London (1959).

82. Tapscott, R. E., Personal Communication, February 26, 1999, NMERI In-House Testing, June 2, 1997.

83. Flynn, R. M. and Thomas, S. D., Fire Extinguishing Process and Composition, U. S. Patent 5,718,293, February 17, 1998.

84. Downic, B., Polymeropoulos, C., and Gogos, G., Fire Safety J. 24, 359-381 (1995).

85. Engel, O. G., J. Res. NBS 54, 281-298 (1955).

86. Chandra, S. and Avedisian, C. T., Proc. R. Soc. Lond. A432, 13-41 (1991).

87. Chandra, S. and Avedisian, C. T., Int. J. Heat Mass Transfer 35, 2377-2388 (1992).

88. Mundo, C., Sommerfeld, M., and Tropea, C., Int. J. Multiphase Flow 21, 151-173 (1995).

89. Yarin, A. L. and Weiss, D. A., J. Fluid Mech. 283, 141-173 (1995).

90. Bernardin, J. D. and Mudawar, I., Int. J. Heat Mass Transfer 39, 2023-2037 (1996).

91. Bernardin, J. D., Stebbins, C. J., and Mudawar, I., Int. J. Heat Mass Transfer 40, 73-88 (1997).

92. Bernardin, J. D., Stebbins, C. J., and Mudawar, I., Int. J. Heat Mass Transfer 40, 247-267 (1997).

93. Bernardin, J. D. and Mudawar, I., Int. J. Heat Mass Transfer 40, 2579-2593 (1997).

94. Mudawar, I. and Valentine, W. S., J. Heat Treating 7, 107-121 (1989).

95. Klinzing, W. P., Rozzi, J. C., and Mudawar, I., J. Heat Treating 9, 91-103 (1992).

96. Mudawar, I. and Deiters, T. A., Int. J. Heat Mass Transfer 37, 347-362 (1994).

97. Hall, D. D. and Mudawar, I., Int. J. Heat Mass Transfer 38, 1201-1216 (1995).

98. Estes, K. A. and Mudawar, I., Int. J. Heat Mass Transfer 38, 2985-2996 (1995).

99. Mudawar, I. and Estes, K. A., ASME J. Heat Transfer, 118, 672-679 (1996).

100. Rein, M., Fluid Dynamic Research 12, 61-93 (1993).

101. Henry, R. E. and Fauske, H. K., ASME J. Heat Transfer 101, 280-287 (1979).

102. Spalding, D. B., Some Fundamentals of Combustion, Butterworths Scientific Publications, London (1955).

103. Kanury, A. M., Introduction to Combustion Phenomena, Gordon \& Breach, New York (1975).

104. Chin, J. S. and Lefebvre, A. H., AIAA J. 21, 1437-1443 (1983).

105. Rcid, R. C., Prausnitz, J. M., and Poling, B. E., The Properties of Gases \& Liquids, $4^{\text {th }}$ ed., McGrawHill, New York (1987).

106. Lefebvre, A. H., Atomization and Sprays, Taylor \& Francis, Washington (1989).

107. Qiao, Y. M., and Chandra, S., ASME J. Heat Transfer 120, 92-98 (1998).

108. Deb, S. and Yao, S.-C., Int. J. Heat Mass Transfer 32, 2099-21 12 (1989). 


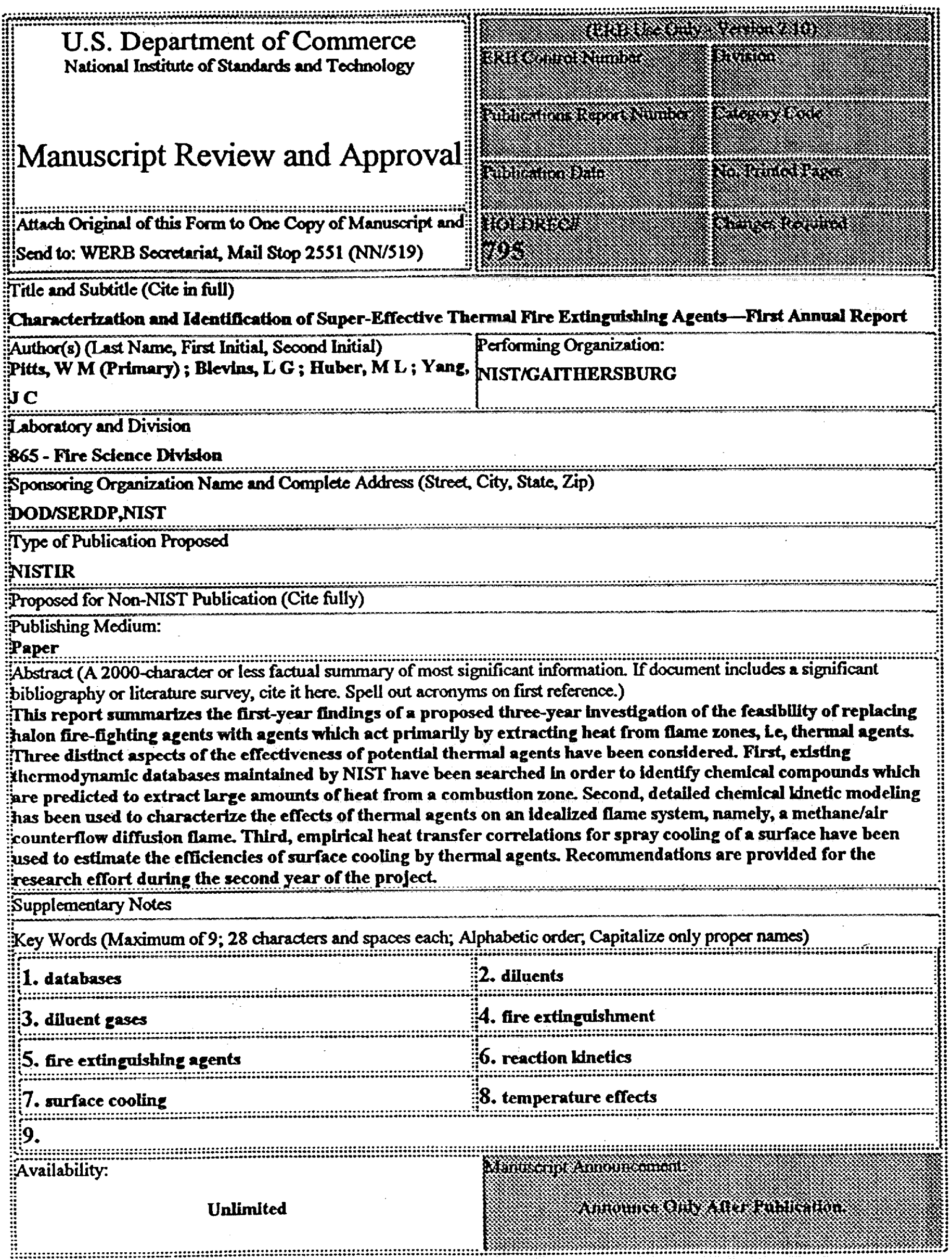

